Available to DOE and DOE Contractors from Office of Scientific and Technical Information P.O. Box 62, Oak Ridge, TN 37831

Prices available from (615) 576-8401

Available to the public from

National Technical Information Service

U.S. Department of Commerce

5285 Port Royal Road, Springfield, VA 22161

Prepared for the U.S. Department of Energy under Contract No. DE-AC03-76SF00098

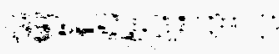




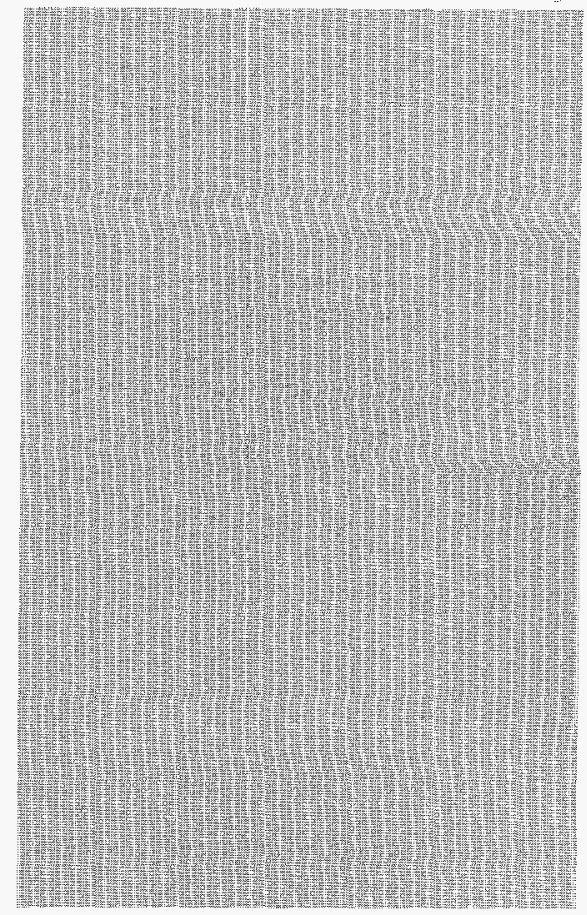

\title{
Energy Analysis Program 1994 Annual Report
}

\author{
Mark D. Levine, Program Head
}

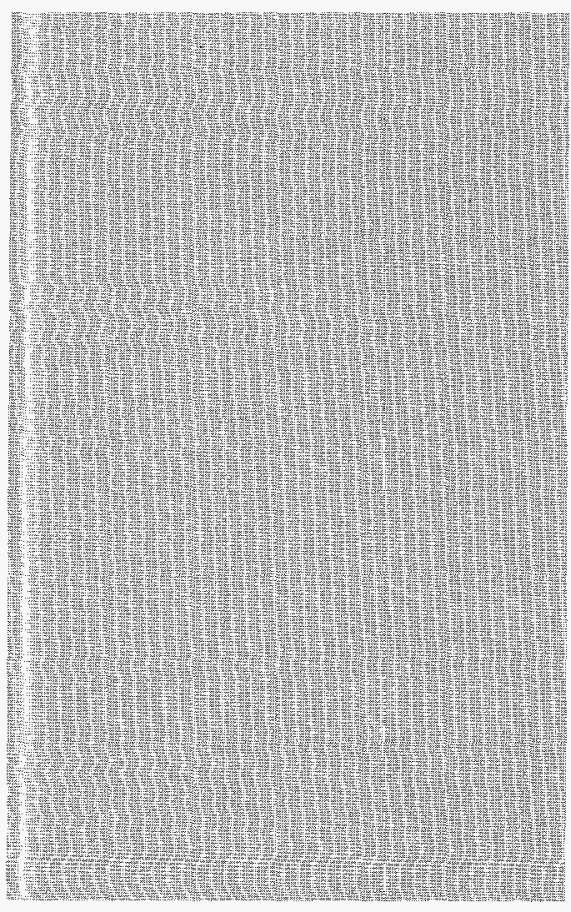

Energy \& Environment Division Lawrence Berkeley Laboratory University of California Berkeley, California 94720

(510) $486-5001$

Report No. LBL-36990 


\section{DISCLAIMER}

Portions of this document may be illegible in electronic image products. Images are produced from the best available original document. 



\section{Contents}

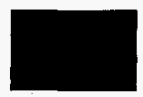

Building Energy Analysis

Office Technology Energy Use and Savings Potential ...

Commissioning of Energy Efficiency Measures: Costs and Benefits for 16 Buildings

DEEP: The Database on Energy Efficiency Programs

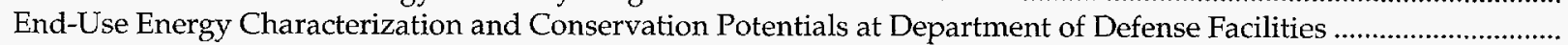

A New Approach to Estimate Commercial Sector End-Use Load Shapes and Energy Use Intensities .........................

Energy Management Control Systems for Remote-Monitoring and Whole-Building Control

Monitoring the Effectiveness of Cooling Retrofits in Sacramento Public Housing Projects

Alternatives to Compressive Cooling in the California Transition Climate Zones

Commercial Heating and Cooling Loads Component Analysis

Building Energy Compilations

Energy Performance of 21 Superinsulated Houses.

Energy-Efficient Government Purchasing as a Market-Pull Strategy.

Urban Energy and Environmental Issues

The Potential for Reducing Urban Air Temperatures Through Vegetative Cooling ...................................................

Materials for Cool Roofs

Cool Building and Paving Materials Workshops

Ozone Air Quality Implications of Large-Scale Albedo and Vegetation Modifications ...

Space-Varying $\mathrm{NO}_{x} /$ ROG Control Ratios for Maximizing Ozone Air Quality Improvements in the South Coast Air Basin .

\section{Energy Efficiency Standards}

Analysis of Federal Appliance Efficiency Standards...

Engineering Analyses of Appliance Efficiency Improvements

Assessing the Impacts of Appliance Standards on Manufacturers

Natural Gas Utility Effects of Federal Residential Appliance Efficiency Standards

Utility Planning and Policy

The Cost and Performance of Utility Commercial Lighting Programs

Impact of Power Purchases from Nonutilities on the Utility Cost of Capital...

Transmission Interface Constraints...

Review of Performance-Based Ratemaking for U.S. Gas Distribution Companies .

DSM Shareholder Incentives: Current Designs and Economic Theory .....

Risk Allocation in DSM Bidding Programs

End-Use Efficiency Policies for a Restructured Electricity Sector

Energy Efficiency, Economics, and Policy Issues

The Effect of Efficiency Standards on Water Use and Water Heating Energy Use in the U.S.:

A Detailed End-Use Treatment

Collaboration with Pacific Northwest Labs on ROADMAP .

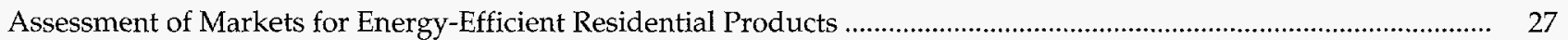

Commercial Data and Forecasting......

The AUTO Model

Analysis of Revenue-Neutral Feebates as a Policy Tool for Increasing

Auto Fuel Economy

Pay-As-You-Drive Auto Insurance as a Means of Reducing Greenhouse Gas Emissions ............................................

Research to Improve the Modeling of In-Use Vehicle Emissions

Analysis of the Performance of Markets for Energy Efficiency

International Energy and Environmental Issues.

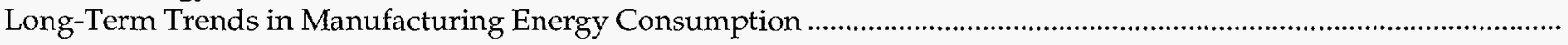

Land Use, Urban Design, and Urban Travel

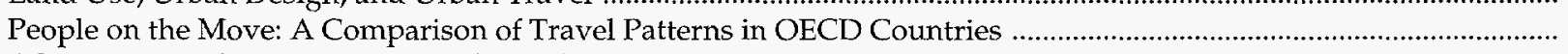

$\mathrm{CO}_{2}$ Emissions from Passenger and Freight Transportation: A Historical Decomposition

of Trends from 1973 to 1992 
Energy Use and $\mathrm{CO}_{2}$ Emissions from Transportation in Japan

The Residential Space Heating Problem in Eastern Europe

Comparison of Service Sector Electricity Use in OECD Countries

Energy Use in Finland: An International Perspective

Building Standards for Mexico

Electricity End Use in Mexico: International Comparisons for Three Industries.

The Role of Cogeneration in China's Energy System

The Building Materials Industry in China: An Overview

Energy Efficiency of Cement Plants in China: Results of Case Studies Involving Site Visits

Energy Efficiency and Decision-Making in the Chinese Cement Industry

Recent Trends in China's Energy Supply and Demand

Macroeconomic Implications of $\mathrm{CO}_{2}$ Mitigation

Carbon Flows and Costs of Mitigation Options in the Forest Sector: Studies for Eight Developing Countries

An Assessment of Energy Efficiency in Buildings and Industry: A Study for the World Energy Council..... International Comparisons of Energy Efficiency Workshop

Mitigation Options for Human Settlements: A Report for the Intergovernmental Panel on Climate Change

Conducting Greenhouse Gas Mitigation Assessment in Developing Countries 


\section{Introduction}

工

ast year at this time, the then new

Administration had achieved the passage of the Energy Policy Act and had released its Climate Change Action Plan. Both documents provided a strong impetus for energy-efficiency programs and policies. Federal energyefficiency programs expanded in response to both Congressional and Administration initiatives.

The major events in the outside world look very different as this Annual Report is being prepared. The new Congress is decidedly unenthusiastic about energy-efficiency policies to reduce the growth of greenhouse gas emissions. The emphasis on federally-funded activities designed to impact markets in order to increase energy efficiency in the near term is not likely to continue. Even the support for longer term energy-efficiency research and development is uncertain, although this support will be stronger than for programs that effect change in the near term.

At the same time, profound changes are taking place within the U.S. electric utility industry. The proposal to permit retail competition in California, put forward in April 1994 by the Public Utility Commission in that state, captured the attention of the entire industry in the days, weeks, and months that followed. Major moves are underway to shake out unproductive or expensive capital from an overcapitalized industry, particularly in the face of low-cost power from natural gas-fired combustion turbines. Among the potential casualties of this transformation appears to be some largescale demand-side management (DSM) programs as well as utility research and development.

These new circumstances will undoubtedly provide interesting challenges to the Energy Analysis Program, both in its efforts to maintain continuity in its long-term research programs and to respond to exciting new research opportunities.

Some of the major achievements of the past year include:

- The initiation of training in greenhouse mitigation measures for 37 developing countries through the U.S. Country Studies Program. The Energy Analysis Program is responsible for overall organization of this training effort. The leaders within our Program are Jayant Sathaye and Steve Wiel.

- The completion of an in-depth study of the economics of commercial lighting DSM programs, showing typical costs of less than 4 cents per kilowatt-hour saved (in which all costs, including those borne by customers, are counted). This study, led by Joe Eto and Ed Vine, is expected to play an important role in the national debate over the cost effectiveness of DSM programs. It is, at this time, the most complete assessment of such costs and savings across a large group of utilities.

- Initiation of a DOE-sponsored interagency program to shift government procurement practices toward energy-efficient and renewable energy products. Because the federal government is the largest single purchaser in the world of many energyrelated products, this program has the potential for substantial nearterm payoffs as well as providing an incentive for manufacturers to introduce more energy-efficient products in the future. Jeff Harris, working out of our Washington, D.C., office, is the leader of this effort.

- Beginning a multi-year project for the U.S. Environmental Protection Agency (EPA) to assess markets for efficient technologies in the residential sector. This project marks the beginning of a transition in our analytic techniques from a focus solely on technology data to one that combines technology and market data in equal measure with design programs and policies that promote efficiency. Jon Koomey and Rich Brown are the leaders of this effort.

- Continuation of an extremely active role in international energy analyses. This includes the leadership of a World Energy Conference study of energy efficiency and advanced technology in the industrial and buildings sectors (Mark Levine, Nathan Martin, and Lynn Price); leadership in preparing one of the four policy chapters for the Intergovernmental Panel on Climate Change, Working Group II (Mark Levine, chapter on human settlements, with emphasis on energy efficiency in buildings); in-depth stud- ies on the structure of energy demand in Poland and Estonia (Lee Schipper); energy and housing in Eastern Europe (Steve Meyers and Lee Schipper); and a series of studies on energy and carbon dioxide emissions associated with transportation in industrialized countries (Lee Schipper). Among his other activities, Jayant Sathaye edited special issues of two journals and contributed articles to each: Energy Policy, on mitigation methods for climate change, and Energy-The International Journal, on household fuels in Asia.

- Analysis of costs and benefits of energy-efficiency improvements in a host of appliances. The analysis for refrigerators and freezers served as the technical basis for the consensus standards proposed by industry and the environmental community. The leaders of this effort are Isaac Turiel and Jim McMahon. The group also completed a valuable analysis of advanced technologies for energy efficiency in residential appliances and lighting products.

- Quantitative analysis of the benefits of commissioning commercial buildings. Mary Ann Piette demonstrated that a package of commissioning actions typically increased the savings from efficiency measures by $20 \%$.

- Development of a labeling procedure for identifying "cool" roofing materials. This project (led by Hashem Akbari) will allow builders to identify roofing materials that will reduce air conditioning loads and minimize urban heat islands.

- Quantitative assessment of feebates (revenue-neutral fees and rebates) to promote increased auto fuel economy. This major policy analysis suggested that improvements in fuel economy of cars on the order of 15 to $20 \%$ above baseline over the next fifteen to twenty years is possible with feebates of relatively small magnitude.

We are in the process of defining some new directions for the Program. We have added expertise in applied microeconomics and anticipate being able to participate in a whole new group of policy studies based on econometric analyses. We have added two staff 
members who are experienced in urban air quality modeling and we are anticipating initiating new policy analyses in this area. We expect to begin soon a major effort to commercialize energyefficient, ozone-free refrigerators in China, with funding support from EPA, the Global Environmental Facility, and the Montreal Protocol. Finally, we have organized a small group to promote new work on technology and policy studies of transportation. We are striving to create new activities in each of these areas of research.

Finally, the Energy and Environment Division's D.C. Project Office completed its first full year of operation in 1994. The D.C. Project Office-managed by the Program's Steve Wiel and Jeff Harriswas established not only to provide more frequent interactions with our funding clients (primarily DOE, EPA, and USAID), sister laboratories, and non-governmental organization allies in general, but also to provide more customized coordination for selected projects. The D.C. Office has greatly enhanced our effectiveness in working with the federal government and other institutions in Washington. We are initiating a major expansion of the Office in 1995.

\section{Program Staff}

Mark D. Levine, Program Head

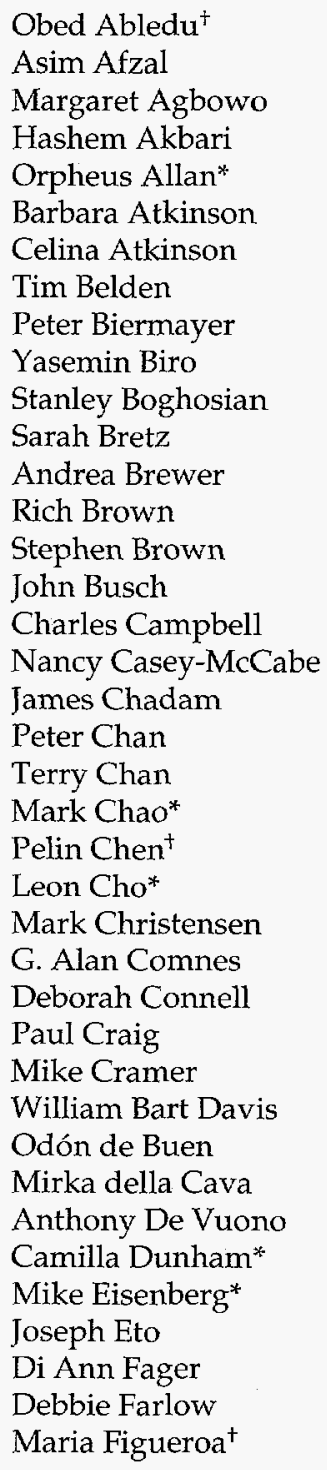

Obed Abledu ${ }^{\dagger}$

Asim Afzal

Margaret Agbowo

Barbara Atkinson

Celina Atkinson

Tim Belden

Peter Biermayer

Yasemin Biro

Stanley Boghosian

Sarah Bretz

rewer

Rich Brown

Stephen Brown

John Busch

Charles Campbel

James Chadam

Peter Chan

Terry Chan

Mark Christensen

G. Alan Comnes

Deborah Connel

Paul Craig

Mike Cramer

William Bart Davis

Odón de Buen

Mirka della Cava

Anthony De Vuono

Camilla Dunham*

Mike Eisenberg*

Joseph Eto

Debbie Farlow

Maria Figueroa ${ }^{\dagger}$
Anthony Fisher
Beth Fishman
Ellen Franconi
Rafael Friedmann
Ted Gartner
Beth Goldberg
Charles Goldman
William Golove ${ }^{t}$
Roger Gorham ${ }^{+}$
Robert Gramlich
Peter Grasty
Steve Greenberg
Bjorn Grindeu ${ }^{\dagger}$
Daly Guiterrez
Sajid Hakim*
William Hanemann
James Hanford
Jeffrey Harris
Dorothy Harvey
Kristin Heinemeier
Ellen Hodges
Moira Howard
Richard Howarth
Yu J. Huang
Katy Janda
Judith Jennings
Frank Johnson
Patricia Juergens
Edward Kahn‡
Anton Kast
Andrea Ketoff
Marta Khrushch ${ }^{\dagger}$
Nancy Kiang
Suzie Kito
Johanna Kollar
Steven Konopacki
Jonathan Koomey
Florentin Krause
Dan Kurn

Marie-Alice L'Heureux

Ronnen Levinson

Jiang Lin

Barbara Litt

Xiaomin Liu

James Logan

James Lutz

Susan Mahler

Willy Makundi

Chris Marnay

Nathan Martin

Eric Martinot

Pricilla McCoy

C. Bartlett McGuire

James McMahon ${ }^{\ddagger}$

Alan Meier ${ }^{\ddagger}$

Stephen Meyers

Mithra Moezzi

Patty Monahan

Nandita Mongia

Puran Mongia

Diana Morris

Louis Morton ${ }^{\dagger}$

Kara Nelson

Bruce Nordman

Richard Norgaard

Karen Olson

Shmuel Oren

Ken Orvis

Hugh Outhred $^{+}$

Chris Payne

Leena Peraelae ${ }^{t}$

Mary Ann Piette

Mel Pomerantz

Brian Pon

Lynn Price

Scott Prudham ${ }^{\dagger}$

Huimin Qin ${ }^{\dagger}$

Zhigang Qin*
John Randolph

Gregory Rosenquist

Marc Ross

Glenn Saika

Jurgen Salay

Alan Sanstad

Jayant Sathaye ${ }^{\ddagger}$

Lee Schipper $\ddagger$

Lynn Scholl

Agah O. Sezgen

Claudia Sheinbaum ${ }^{\dagger}$

Leslie Shown

Irina Shukman

Jonathan Sinton

Richard Sonnenblick

Lene Sorensen ${ }^{t}$

Ruth Steiner

Steven Stoft

Haider Taha

Mike Ting

Kenneth Train

Isaac Turiel

Robert Twiss

Fridtjof Unander ${ }^{\dagger}$

Pravin Varaiya

Edward Vine

Diana Vorsatz

Elaine Watt

Tom Wenzel

Stephen Wiel

Lorraine Williams

Nancy Wishner

Winifred Wood

Xi Xiaolin

Fu Qiang Yang

Chung-Seok Yoo ${ }^{\dagger}$

Justin Zeitz*

Hui Zhang

Shuyu Zhangt

*Student Assistant 


\section{Building Energy Analysis}

\section{Office Technology Energy Use and Savings Potential}

M.A. Piette, M. Cramer, J.H. Eto, J.G. Koomey

Office information technologies, which use an increasing amount of energy in commercial buildings each year, are often considered the fastest growing electric end use. LBL recently completed an energy-use analysis of office equipment in New York State, looking at the energysavings potential of energy-efficient equipment as well. We developed a model that separately tracks equipment densities and energy-use characteristics for eight categories of office equipment: mainframe computers, mini-computers, personal computers (PCs), monitors, printers, copiers, fax machines, and cash registers. The model specifies power requirements and hours of use for three modes of average operation for each device: active, standby, and suspend. The energy-use intensity of each device is expressed as a function of the average device density (number of units/ $\mathrm{kft}^{2}$ ), the hours of operation in each mode, and the average power requirements in each mode. Increases in device densities through 2010 are based on market sales forecasts and commercial floor space projections. The output from the model is an estimate of the total energy use (in GWh) for each device by building type.

Three scenarios were examined: 1 ) the business-as-usual scenario, 2) another, which employed an increased use of power-managed devices, such as those promoted under the Energy Star Computers Program sponsored by the U.S. EPA, and 3) a scenario with products more efficient than the standard Energy Star products. The Energy Star Computers Program currently includes PCs, monitors, and printers and is being expanded to copiers and fax machines. We conducted a series of sensitivity analyses to explore uncertainties in model inputs. The Figure shows the total commercial sector energy use for the three scenarios. The total is shown with and without mainframe and mini-computers, which are projected to decrease in all three scenarios.

The business-as-usual baseline forecast confirms that office equipment energy use has been rising over the past decade and will continue to do so for the next decade and beyond. Office equipment currently consumes about $2900 \mathrm{GWh} /$ year in the State of New York, comprising $7 \%$ of commercial sector electricity use. Under this baseline scenario, the total commercial sector load in New York would increase to $3300 \mathrm{GWh} /$ year by the year 2000 and doubleagain before 2010. Widespread use of power-management technologies could reduce this load growth by about $30 \%$ by the year 2000, while use of more advanced energy-efficient technology could reduce total energy use by office equipment to $1800 \mathrm{GWh} /$ year -or less than current consumption-in 2010.

The average $\mathrm{PC}$ and monitor together consume about $400 \mathrm{kWh} /$ year. This amounts to $18 \mathrm{BkWh} /$ year for the $45 \mathrm{mil}-$ lion PCs in the U.S. The Energy Star Computers Program has succeeded in promoting the incorporation of powermanagement features in about half of the desktop and deskside PCs sold today. If every computer in the U.S. used powermanagement devices, energy use per machine would drop to about $150 \mathrm{kWh} /$ year, leading to energy savings valued at about $\$ 1$ billion/year. Unfortunately, not all Energy Star PCs and monitors perform as expected. Early findings from the field suggest that a large fraction, and perhaps most, of such PCs and monitors do not achieve the expected energy savings. Power-management features are often incompatible with local area networks or software, enabled incorrectly, disabled by user preference, or defeated because of user patterns or differences in PC and monitor powermanagement systems.

EPA is working with manufacturers to resolve these problems. Beginning in October 1995, Energy Star equipment will be shipped with more user-friendly features already enabled and fewer incompatibility problems. LBL is currently tracking field performance data from power-managed office equipment.

\section{Reference}

Piette MA, Cramer M, Eto JH, Koomey JG. Office Technology Energy Use and Savings Potential in New York. Lawrence Berkeley Laboratory Report No. LBL-36534, 1994.

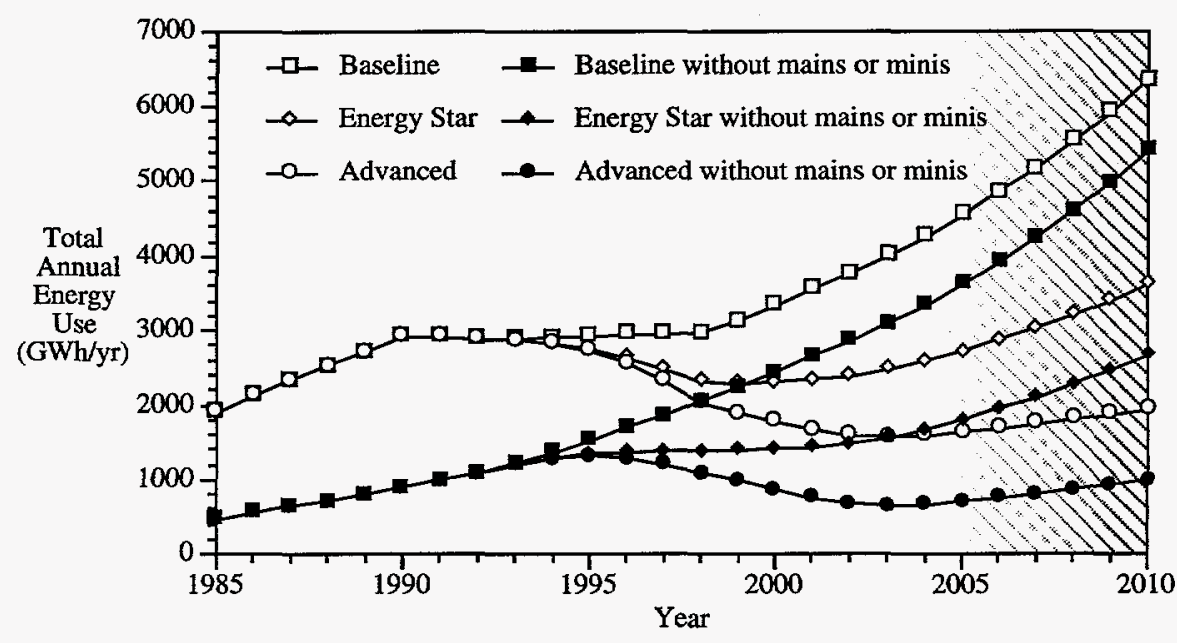

Figure. Total yearly energy use by scenario in New York State. Total commercial sector energy use is shown for three scenarios: Baseline, Energy Star, and Advanced EnergyEfficiency. The total is shown with and without mainframe and mini-computers because they do not change among the scenarios. 


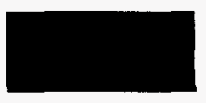

\title{
Commissioning of Energy Efficiency Measures: Costs and Benefits for 16 Buildings
}

\author{
M.A. Piette, B. Nordman, S. Greenberg
}

Building systems and energy-efficiency measures (EEMs) often do not perform as well in practice as in design. Building commissioning, which involves tests to bring a system from static installation to full working order, is a beneficial intervention to verify that the building is operating as intended. Utilities, building owners, government agencies, and others concerned with building performance are interested in the value of commissioning.

We examined the costs and benefits of utility-funded commissioning of EEMs in 16 new commercial buildings in the Pacific Northwest. The costs to commission the EEMs involved a trained commissioning agent developing and executing functional tests and following up to ensure that important deficiences were corrected and documented. The benefits of commissioning were the energy savings from correcting deficiences. Nonenergy benefits of deficiency corrections were tracked according to four primary categories of improvements: control, operations and maintenance, indoor-environmental quality, and equipment life. These benefits may be more important than energy-saving benefits, but are difficult to quantify in monetary terms
The EEMs that were commissioned involved dynamic interactions with controls, such as heating or cooling systems. Static EEMs, such as wall insulation, were not commissioned. In total, 46 EEMs were commissioned among the 16 buildings. Energy-savings estimates were developed for 35 deficiency corrections. Overall, approximately half of the energy savings from commissioning came from correcting deficiences that were related to the energy-saving characteristics of the EEMs. The other half of the savings were from correcting deficiences that would have been present whether or not the EEM was installed. This suggests the need to commission all important energyconsuming systems, not just the EEMs.

Commissioning was found to be costeffective for most of the buildings. The simple payback time for commissioning as a stand-alone activity is derived by comparing the cost of commissioning to the energy-costs savings from deficiency corrections. The median payback time was seven years, with five buildings having payback times of less than two years (see Figure). This estimate is based on low energy prices in the Pacific Northwest, with electricity at $4 \$ / \mathrm{kWh}$. Under national average energy prices, the median payback time for commissioning would be reduced to 3.5 years.

\section{Reference}

Piette MA, Nordman B, Greenberg S. Commissioning of Energy-Efficiency Measures: Costs and Benefits for 16 Buildings. Prepared for the Bonneville Power Administration. Lawrence Berkeley Laboratory Report LBL-36448, 1994.

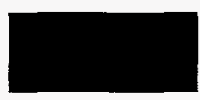

DEEP: The Database on Energy Efficiency Programs
To address concerns regarding the cost-effectiveness of demand-side management (DSM) activities, the U.S. Department of Energy's (DOE) Integrated Resource Planning Programinitiated the Database on Energy Efficiency Programs (DEEP) project at LBL. The goal of the DEEP project is to provide information that systematically compares measured DSM program performance and costs. By providing this information, we try to identify successful DSM practices and thereby contribute to the successful maturation of the DSM industry.

In this project we collect information on DSM programs that are sponsored by electric and gas utilities as well as other organizations such as government agencies. The information includes program descriptions and key summary data on program costs, energy and de- mand savings, participation rates, costeffectiveness, and evaluation methodologies. We obtain this information from process and impact evaluation reports that have been prepared by the utilities as well as from direct contact with staff at utilities and state and regional energy organizations.

In addition to collecting DSM data, we also periodically conduct specialized analyses and publish reports on the performance and measured savings of selected DSM programs. In the past year, we published our first DEEP report on a comparative analysis of 20 commercial lighting DSM programs from utilities across the United States. We will continue to assess the performance of utility DSM programs in the coming year by analyzing new residential construction programs and the largest 1992 commer- cial sector multi-measure rebate programs.

A similar project was initiated in May 1994 at the international level. The International Energy Agency (IEA) DSM Program is an international collaboration with 14 IEA member-countries working to clarify and promote opportunities for DSM. The Program has five Tasks (organized in annexes), the first of which establishes an international database on DSM. The International Database on Energy Efficiency Programs (INDEEP) project will make available information on international electric and gas utility DSM programs as well as those carried out by others (e.g., government agencies and energy service companies). Initially, the database will consist of programs implemented by participating IEA countries (Austria, Denmark, Netherlands, 
Spain, Sweden, and the United States), the European Commission, and Korea.

The first year's work is a pilot project to explore the feasibility and nature of an international database on DSM programs. In this project, participants have assessed the transferability of DSM program results, the usefulness of existing data-collection instruments and databases on DSM programs, and the level of interest among potential users for an international database on DSM programs. Participants have reviewed existing DSM program databases and reports, conducted case studies on three to five DSM programs in each participant's country, entered program information into the data-collection instruments, and identified and contacted potential users of an international DSM database. In 1995, we will conduct a workshop on the project and prepare a report on the pilot project.

Working with the Evaluation and Monitoring Topic Committee of the Association of Demand-Side Management Professionals, we helped identify and clarify the issues surrounding DSM program-evaluation standards and produced a report on DSM program-evaluation standards and guidelines. We also surveyed Committee members in order to compile a bibliography of key evaluation and monitoring references and produced a report on useful references for those involved in program evaluation. We also managed research in two other areas: assessment of training needs and requirements for evaluators working in the DSM field and identification of issues affecting evaluation in a competitive environment.

\section{References}

Eto JH, Vine EL, Shown L, Sonnenblick RS, Payne C. The Cost and Performance of Utility Commercial Lighting Programs. Lawrence Berkeley Laboratory Report No. LBL-34967, 1994.

Vine EL, Eto JH, Shown L, Sonnenblick, RS, Payne, C. Evaluation of commercial lighting programs: A DEEP report. In: Proceedings of the ACEEE 1994 Summer Study on Energy Efficiency in Buildings, August 28-September 3,1994. Vol. 4. Washington, DC: American Council for an Energy-Efficient Economy, 1994, pp. 4.231.

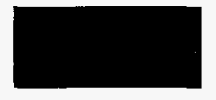

\section{End-Use Energy Characterization and Conservation Potentials at Department of Defense Facilities}

\section{H. Akbari, S. Konopacki}

The objectives of this project are 1) to develop an energy database by building type and end use for U.S. Department of Defense (DoD) facilities; 2) to enhance the DoD Energy Office's ability to track energy use by end use; and 3) to establish a vehiclefor transferringouranalyticalmethodologies for end-use energy analysis to the U.S. Corps of Engineer's Construction Engineering Research Laboratory. The methodology was tested initially at one DoD installation, Fort Hood, Texas. We anticipate that the methodology and much of the database developed for Fort Hood can be easily transferred to other installations.

We apply an integrated method for the estimation of end-useenergy consumption and load shapes that relies explicitly on measured whole-installation or substation short-interval energy use to reconcile preliminary engineering estimates. The method consists of two steps. First, using various, available on-site survey data, we develop preliminary building prototypes for the installation and simulate the prototypical buildings using the DOE-2 building energy analysis computer program to obtain hourly energy consumption data by end use. Second, we reconcile initial estimated end-useloads to hourly metered loads for the entire installation or substation using the End-use Disaggregation Algorithm (EDA), developed at LBL, to obtain adjusted, reconciled end-use load profiles for all building types.
The building types at Fort Hood cover a wide spectrum of commercial and residential buildings. The commercial buildings include administration buildings, warehouses, vehicle maintenance shops, a hospital, grocery stores, retail stores, car washes, churches, and restaurants. The residential buildings include single-family detached houses and single-story twoand four-plex units. Barracks, which serve both residential and administrative purposes, are also modeled. Computer simulations provide a consistent method for estimating space-conditioning energy use that takes into account the interaction between building operation, building thermal properties, and the climate. Lighting, equipment, and other end uses are schedule-driven and can be determined without simulations. The DOE-2 program is used

to perform the simulations of heating, ventilating, and air-conditioning energy use.

We will reconcile the initial simulated hourly end-use data against short-interval data collected for sixteen feeders at Fort Hood. The Figure shows the hourly electricity consumption data for the entire Fort Hood installation. The reconciled hourly electricity consumption data for all major building types and end uses will enable us to accurately estimate conservation potentials at Fort Hood and other DoD installations and to design effective programs to achieve the potentials.

\section{Reference}

Akbari H. Validation of an algorithm to disaggregate whole-building hourly electrical load into end uses. EnergyThe International Journal 1994 (in press).

Figure. Daily average electricity use at the Fort Hood installation. Note that, during hot summer days, about $50 \%$ of daily electricity use is used for air conditioning; air conditioning contributes to over $60 \%$ of hourly peak loads.

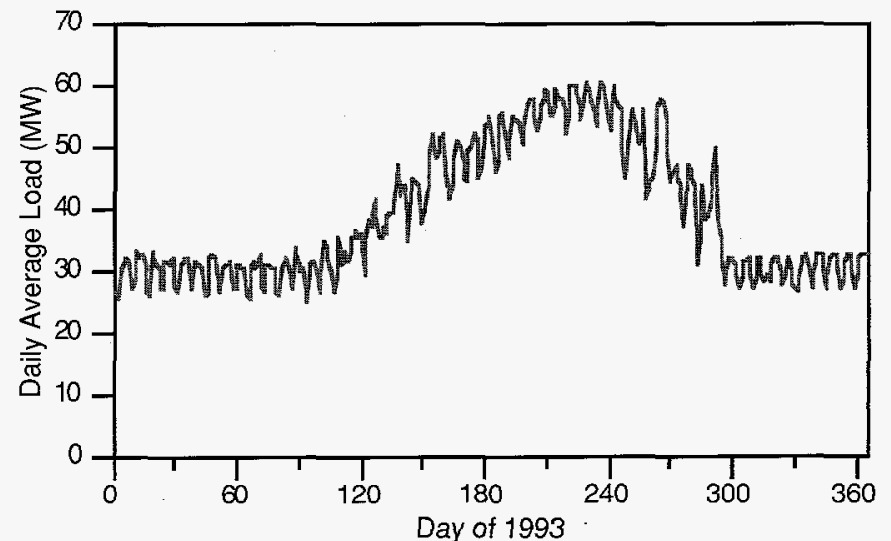




\section{A New Approach to Estimate Commercial Sector End-Use Load Shapes and Energy Use Intensities}

\section{H. Akbari, J. Eto, S. Konopacki}

We used the end-use load-shapeestimation technique developed at LBL to estimate the annual energy use intensities (EUIs) and hourly end-use load shapes (LSs) of commercial buildings in Pacific Gas and Electric Company's (PG\&E) service territory. The results were used as updated inputs for the peak demand forecasting models used by PG\&E and the California Energy Commission (CEC). We estimated EUIs for 11 building types, 10 end uses, 3 fuel types, 2 building vintages, and as many as 5 climate regions.

The core data for the project were 1) detailed on-site surveys for approximately 800 buildings, 2) mail surveys for 6000 buildings, 3) load research data for more than 1000 utility accounts, and 4) hourly weather data for five climate regions. Our integrated methodology consisted of two parts. The first was the reconciliation (using LBL's End-use Disaggregation Algorithm (EDA)) of initial end-use LS estimates with measured whole-building load data to produce in- termediate EUIs and LSs. The second part required adjusting the EUIs for direct incorporation into the forecasting models.

These adjustments included: 1) development of year 1986 EUIs for end uses (electric heating, and all non-electric end uses) not estimated through the application of $\mathrm{EDA}$; 2) re-specification of all 1986 EUIs to a 1975 base year through application of the short-run price elasticity of demand and historic energy prices; 3) removal of fuel-saturation effects for all reconciled electric end uses, except indoor and outdoor lighting and other miscellaneous uses for which, by definition, the saturation is $100 \%$; 4 ) incorporation of previous LBL work to further disaggregate the electric miscellaneous EUIs into distinct categories for office equipment and miscellaneous; 5) for the space-conditioning end uses, explicit accounting of the effects of the first generation of mandatory minimum building energy efficiency standards; and 6) for the space-conditioning end-use specifi- cation used by the CEC model, a separate accounting for the impacts of equipment energy efficiency and for the additional variations in energy use for the five climate regions represented by the two regions for which explicit reconciliations were performed. The Table provides an example of the electric EUIs formatted for the forecasting model of PG\&E. Similar data for all fuels (electricity, natural gas, and others) have been prepared for both PG\&E and CEC's forecasting models.

\section{References}

Akbari H, Eto JH, Konopacki S, Afzal A, Heinemeier K, Rainer LI. Integrated Estimation of Commercial Sector EndUse Load Shapes and Energy Use Intensities in the PGEE Service Area, Lawrence Berkeley Laboratory Report No. LBL-34263, 1993.

Akbari $H$. Validation of an algorithm to disaggregate whole-building hourly electrical load into end uses. EnergyThe International Journal 1994 (in press).

Table. PGEE 1975 base year electric EUIs for coastal and inland climate zones ( $\left.k B t u / f t^{2} y r\right)$.

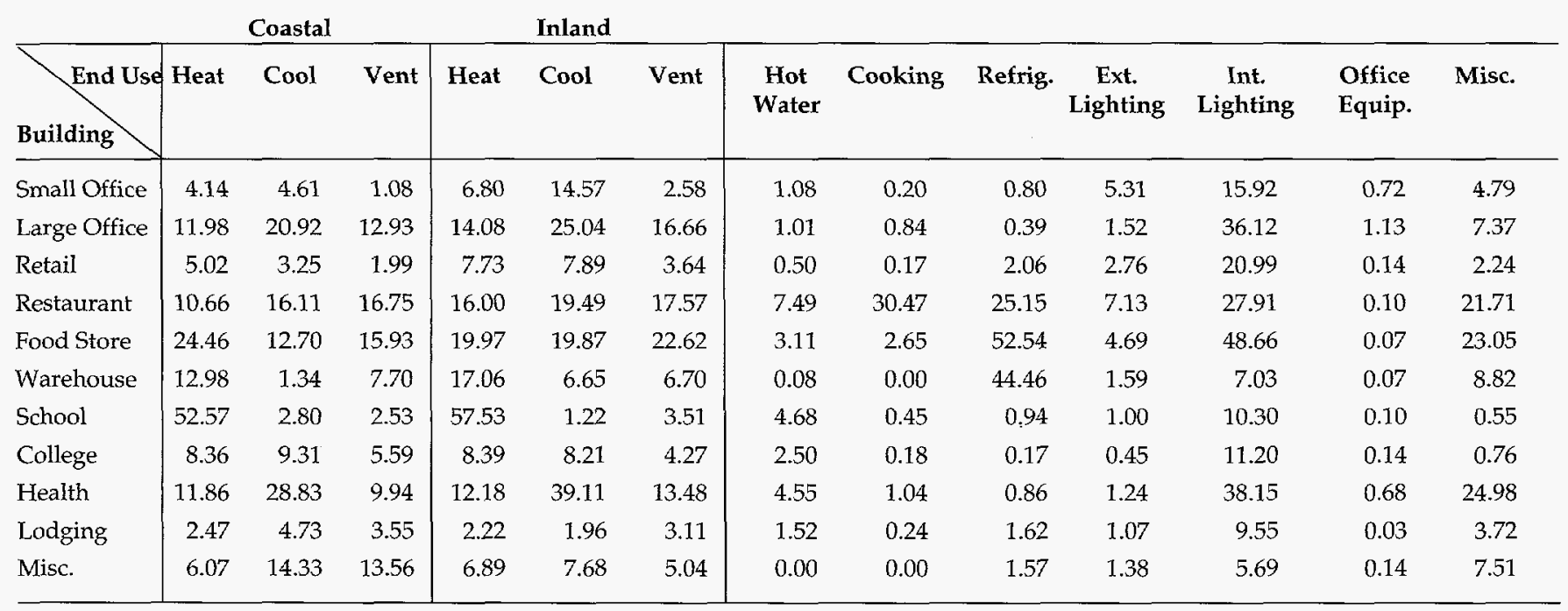




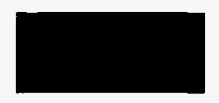

\section{Energy Management Control Systems for Remote-Monitoring and Whole-Building Control}

\section{K. Heinemeier, H. Akbari}

Monitoring building energy performance is important in building commissioning, operation, and maintenance, and in such utility efforts as demand-side management impact evaluation, forecasting, and conservation measure technology assessment. However, monitoring can be quite expensive. The use of existing energy management and control systems (EMCSs) may be a cost-effective alternative. EMCS-based monitoring has the following advantages: lower costs, since the equipment has already been purchased and installed; an increased amount of available data; and enhanced on-site processing capabilities. On the other hand, the adequacy of using EMCSs as a substitute for more conventional dedicated monitoring equipment has not been conclusively established, so researchers are frequently reluctant to use them or take advantage of their benefits.

The objectives of this project were 1) to confirm the effectiveness of EMCS monitoring; 2) to determine how closely EMCS monitoring substitutes for dedi- cated monitoring in terms of accessibility, storage, availability of the necessary data, and data accuracy; 3) to develop and demonstrate methods for improving the effectiveness of EMCS monitoring taking fullest advantage of its benefits; 4$)$ to assess the relative effectiveness of EMCS monitoring in three likely scenarios - with no review of the data, after somedata review for reasonableness, and after more thorough instrumented datavalidation procedures; and 5) to determine why any deficiencies exist and how they could be addressed during EMCS specification, installation, commissioning, and maintenance.

The objectives of the project were achieved by investigating one case-study site where we collected data from both the EMCS (a Barrington 4000) and a dedicated datalogger (a Synergistics C180). To verify the data collected from the EMCS and datalogger, we installed a temporary datalogger. The Figure shows chiller electricity consumption data collected from these three sources. On a daily basis, the differences between the EMCS, the dedicated datalogger, and the temporary datalogger were only about $2 \%$. Although the data are equivalent, the processes of collecting data from the EMCS and the dataloggers were somewhat different. We developed methods of review and processing and investigated the effectiveness of EMCS monitoring. The results of the case study have been combined with our previous studies of the EMCS and monitoring industries to assess the current suitability of EMCSs for monitoring, its likely future suitability, and the possible means of influencing this future suitability.

\section{Reference}

Heinemeier KE. The Use of Energy Management and Control Systems to Monitor the Energy Performance of Commercial Buildings. Ph.D.Thesis, Department of Architecture, University of California, Berkeley. Lawrence Berkeley Laboratory Report No. LBL-36119, 1994.

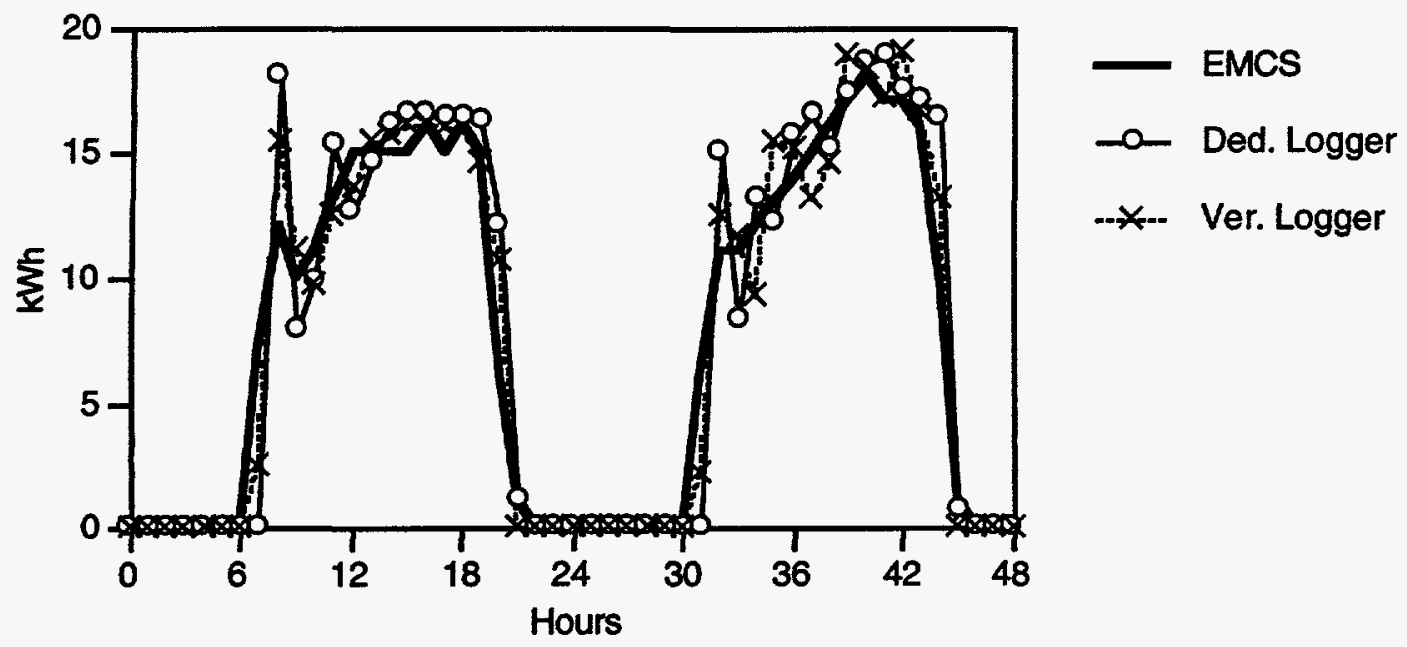

Figure. Chiller energy consumption data collected by an existing EMCS, a dedicated datalogger, and verification datalogger at a case-study site, showing that the data collected are essentially equivalent. 


\section{Monitoring the Effectiveness of Cooling Retrofits in Sacramento Public Housing Projects}

\section{Y.J. Huang , J. L. Warner}

As part of the DOE-HUD Initiative, we are collaborating with the Sacramento Housing and Redevelopment Agency (SHRA) and the Sacramento Municipal Utility District (SMUD) to evaluate the energy performance and comfort benefits of cooling retrofits in public housing. Starting in 1992, SHRA embarked on a retrofit of 1950-vintage public housing projects and single-family houses through its lead-abatement and housing-retrofit program. Among the retrofit measures selected wereseveral aimed at improving summer indoor comfort while minimizing cooling energy use-including ground-source heat pumps, evaporative coolers, high-performance windows, and light-colored roofs. In addition to monitoring the pre- and post-retrofit indoor conditions and building electricity consumption, SMUD is supporting these energy retrofits through rebates. LBL's Energy Analysis Program is responsible for the experimental design of the monitoring plan, for analyzing the measured data to assess the effectiveness of these retrofits, calibrating LBL's computer models, and using the measured data, combined with the calibrated computer models, to determine the applicability of these cooling measures to buildings and climates elsewhere in California.

By the fall of 1994, SHRA had installed ground-source heat pumps in a computer training center and a child care center of a 61-building public housing development. SHRA is now in the process of retrofitting the dwelling units with energy-efficient windows and new roofs covered with white elastomeric paint. At the same time, SHRA is also installing two-stage evaporative coolers in eleven scattered single-family houses. SMUD instrumented the buildings and began data-gathering in the fall; the data-gathering will resume in the spring of 1995. The monitored data are being sent via modem to LBL, where they will be analyzed and compared to DOE- 2 buildingenergy-analysis computer simulations of the same buildings. In the case of the ground-source heat pumps, the measured data will be used to validate and calibrate an untested computer model. To investigate potential neighborhood-cooling effects from the white roofs, we have also been monitoring outside temperatures at the housing development.
Due to the limited amount of monitored data gathered in 1994, the work to date has been preliminary, and the final evaluation and statewide assessment will not be completed until after the second monitoring season is completed in the summer of 1995. The final goal of the project is to determine the conservation potentials of the cooling retrofits for resi-

dential and light-commercial buildings in the state of California.

\section{Reference}

Huang YJ, Warner JL. Monitoring Cooling Retrofits Measures in Sacramento Public Housing: Monitoring and Analysis Plan, Report to the U.S. Department of Energy, 1994.

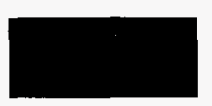

\section{Alternatives to Compressive Cooling in the California Transition Climate Zones}

\section{Y.J. Huang}

This multi-year project aims to demonstrate that homes can be built in the California Transition Climate Zones that do not require air conditioning to maintain comfortable indoor summer temperatures. The term "transition climate zones" refers to the areas 15 to 50 miles inland, where much of California's new housing construction is now occurring. Presently, these houses are being built with air conditioning, whose use is producing disadvantageous electricity-use profiles with low load factors and sporadic spikes coinciding with utility district peaks on hot summer afternoons. The alternative cooling strategies being investigated in this project include minimizing solar heat gain, using building mass or ground as a heat sink, mechanical or natural ventilation, evaporative cooling, and "smart" control systems to integrate these strategies

The project team includes three researchers from LBL and four from California universities. The research activities in the first project year (1993-94) included a preliminary assessment of climate conditions and alternative cooling strategies in the Transition Climate Zones (Huang, LBL) and an improved simulation of residential heating, ventilating, and air-conditioning systems (Winkelmann, LBL) and natural ventilation (Feustel, LBL); field monitoring of ventilation and thermal mass effects in test structures (Givoni, UCLA); laboratory studies of human comfort criteria (Arens, UCB); and a sociological study of public attitudes towards air conditioning and alternative cooling technologies (Hackett, UCD). Technical reports documenting research results from the first year are available from the individual researchers.

The Figure shows the effectiveness of ventilation in reducing the number of overheated hours, from nearly 2000 to less than 350 , in a typical house in Riverside, CA. It also shows how the addition of five simple, alternative cooling strategies (added insulation, low-E windows, light surface colors, partially exposed floor slab, and window overhangs) can further reduce the number of overheated hours from 330 in the base case Title-24 building to less than 30 hours, or less than $0.5 \%$ of the year.

During the second project year (199495), we will apply these techniques and translate this information into buildable house plans through a series of design workshops with the research team and invited local builders and architects. Along with the workshops, we will continue efforts to improve the modeling of residential evaporative coolers, to analyze phase-change wallboards, to provide design assistance to local builders, and to monitor the effects of surface color, thermal mass, and evaporative cooling in test structures.

\section{References}

Arens E, Bauman F, et al. Comfort and Health Considerations: Air Movement and Humidity Constraints. Center for Environmental Design Research, Berkeley, CA: University of California, 1994.

Buhl WF, Winkelmann FC. Enhanced Residential System Model for DOE-2.IE. Final Report to the California Institute for Energy Efficiency, Lawrence Berkeley Laboratory, 1994. 


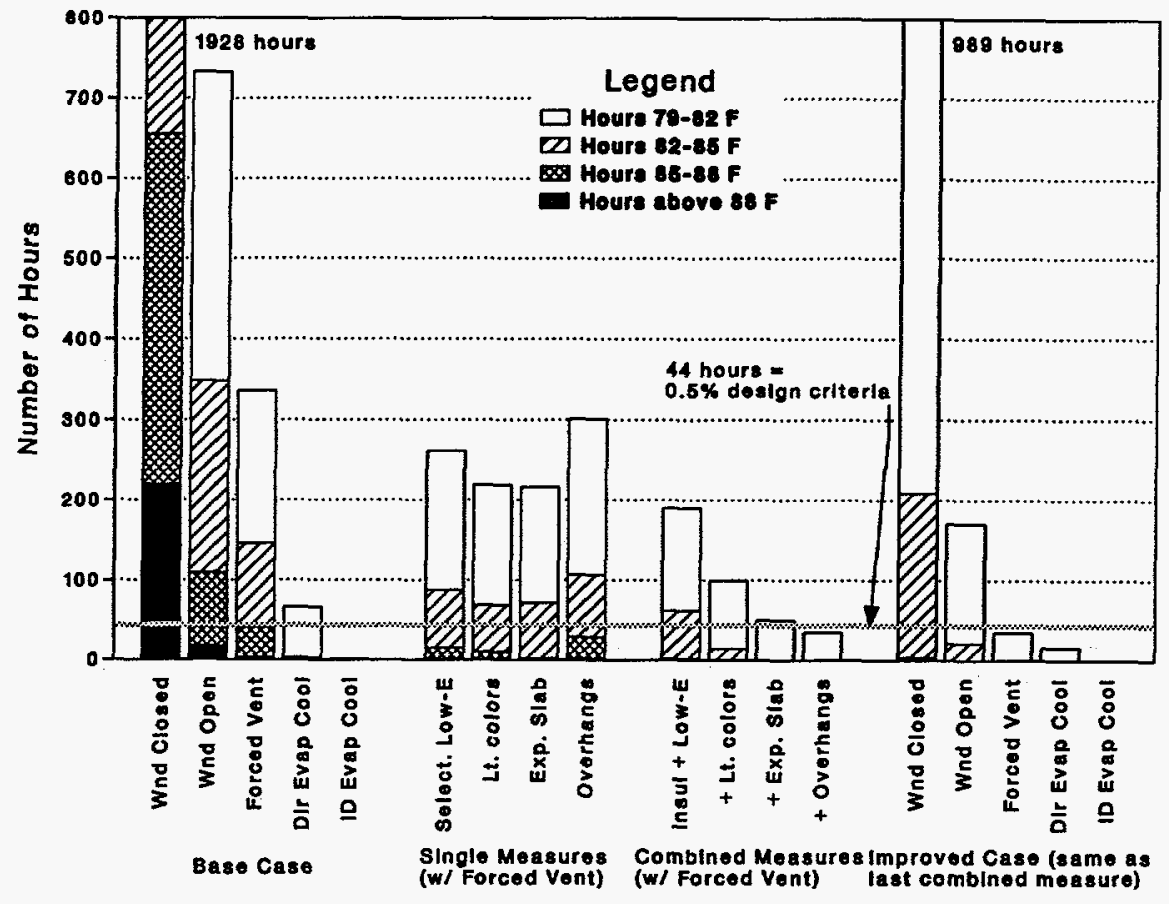

Figure. Number of hours above $78^{\circ} \mathrm{F}$ for various alternative cooling measures in a prototypical one-story house in Riverside, CA.
Feustel HE, Warner JW, Triedler B. Ventilative Cooling and Control Strategies: Air Flow Modeling and Smart Controls. Final Report to the California Institute for Energy Efficiency, Lawrence Berkeley Laboratory, 1994.

Givoni, B. Effectiveness of mass and night ventilation in lowering indoor daytime temperatures. In: Proceedings of the Conference on Passive and Low Energy Architecture, July 4-8, 1994. Sede Boger, Israel: Institute for Desert Research of the Ben-Gurion University, 1994 (in press).

Lutzenhiser L, Hackett B, Hall D, Hungerford D. Alternative Cooling Technologies for California: Social Barriers, Opportunities and Design Issues. Berkeley, CA: University of California, Universitywide Energy Research Group. UER-289, 1994.

Huang YJ, Zhang H. Analysis of Climatic Conditions and Preliminary Assessment of Alternative Cooling Strategies for Houses in California Transition Climate Zones. Lawrence Berkeley Laboratory Report No. LBL-36177, 1994.

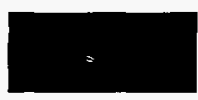

\section{Commercial Heating and Cooling Loads Component Analysis}

\author{
Y.J. Huang, E.M. Franconi
}

According to the U.S. DOE's 1989 Commercial Building Energy Consumption Survey (CBECS), commercial buildings consume 5.8 quadrillion Btus per year of site energy, about $10 \%$ of the total net energy consumption nationwide. As a major research sponsor, the Office of Building Energy Research at U.S. DOE is interested.in evaluating at a national level the potential impacts of different conservation technologies on commercial building energy consumption. This study represents an initial step toward this assessment by quantifying the approximate contribution of major building components, i.e., roofs, walls, foundations, infiltration, windows (solar and conduction), ventilation air, equipment, lighting, to the total heating and cooling loads of the U.S. commercial stock. These results can then be used to assess the energy-conserving potentials of new technologies.

The analysis builds upon two previous LBL studies. The first defined 481 prototypical commercial buildings covering three vintage/equipment combinations for 13 building types in 13 U.S. locations. In the second study, we updated the prototypes and developed a database characterizing U.S. commercial building heating/cooling energy use for the COMMEND forecasting computer model. In the current project, we used the DOE-2 building energy analysis computer program to simulate these prototypical buildings in five representative U.S. locations, and developed a technique for extracting from DOE-2 the contributions of various components of a building to its total loads. These component loads are then multiplied by the building population and disaggregated by building type, vintage, and region based on the 1989 CBECS. The survey is designed to produce a national picture of the energy-use characteristics of the commercial building sector.

Since DOE-2 calculates component loads in the Loads module, extracting the true component loads required adding functions to the DOE-2 program to adjust for zone temperature, to identify whether the zone is in the heating or cooling mode, and to account for thermal lag effects. The results are presented as pie charts showing the component loads for a building or building sector. The Figure shows a representative pie chart for a fast-food restaurant in Washington, D.C. The components' contribution to the amount of heating or cooling required is shown by the pie slices. The unattached portions of the pie charts are the building's heating and cooling loads.

In addition to calculating building component loads, we are also studying the variations in the efficiency of the heating, ventilating, and air-conditioning systems, which in turn vary depending on the air-handling system and control strategy. The effect for different distribution efficiencies on the building load is shown on the chart as concentric pie slices of the building's heating or cooling load. 


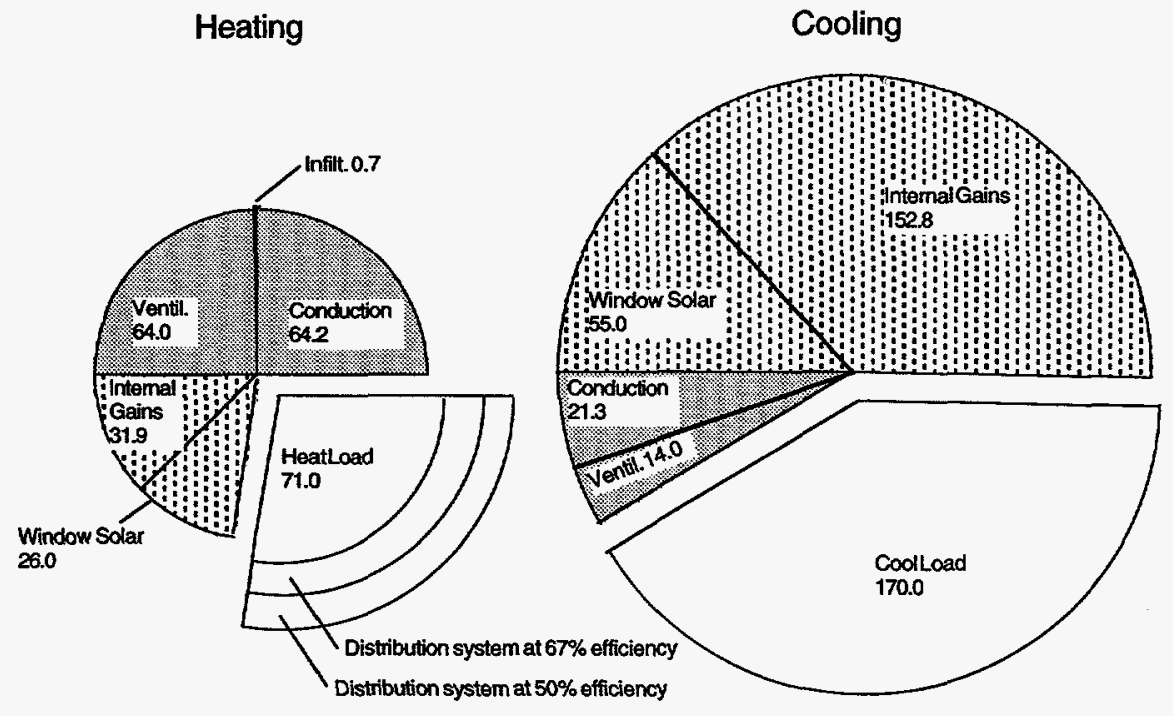

Figure. Component loads of a fast-food restaurant in Washington, D.C. (MBtus).

\section{References}

Sezgen AO, Franconi EM, Greenberg SE, KoomeyJG, AkbariH. Technology Data Characterizing Space Conditioning in Office Buildings: Application to End-Use Forecasting with COMMEND 4.0. Lawrence Berkeley Laboratory Report No. LBL-34123, 1994.

Huang YJ, Akbari H, Rainer L, Ritschard RL. 481 Prototypical Commercial Buildings for 20 Urban Market Areas (Technical documentation of building loads database developed for the GRI Cogeneration Market Assessment Project). Lawrence Berkeley Laboratory Report No. LBL29798, 1990.

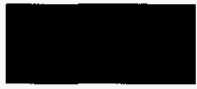

\section{Building Energy Compilations}

\author{
A.K. Meier
}

Staff in the Building Energy Analysis Group participate in numerous studies to collect and compile field measurements of building energy use. Together, these compilations are called Building Energy-use Compilation and Analysis (BECA).

The actual energy use of buildings and equipment, and the savings from energy efficiency measures, are essential elements of forecasting and policy development. Such information will confirm (or refute) the efficacy of new, efficient designs, the savings from retrofits, and the cost-effectiveness. In the last eight years, we have compiled data on the monitored performance of new commercial office buildings, thermal storage systems, multifamily retrofits, singlefamily retrofits, refrigerators, and office equipment. Since we do not monitor buildings, we depend on data contributions from other building researchers.

A recent study compared the actual electricity use of refrigerators to the energy use predicted by laboratory tests (as shown on the yellow "Energy Guide" labels). The compilation demonstrated that, although there are large individual variations in energy use among refrigerators, the label reasonably and accurately predicts the average energy use of a large number of units (see Figure). In a related project, the strong temperature dependence of refrigerator energy use was demonstrated.

New, low-energy homes are the current focus of compilation activity and are discussed in the article "Energy Perfor- mance of 21 Superinsulated Houses." In addition, data are being collected on the "miscellaneous" residential uses of electricity. Nationally, the miscellaneous uses represent about $20 \%$ of residential

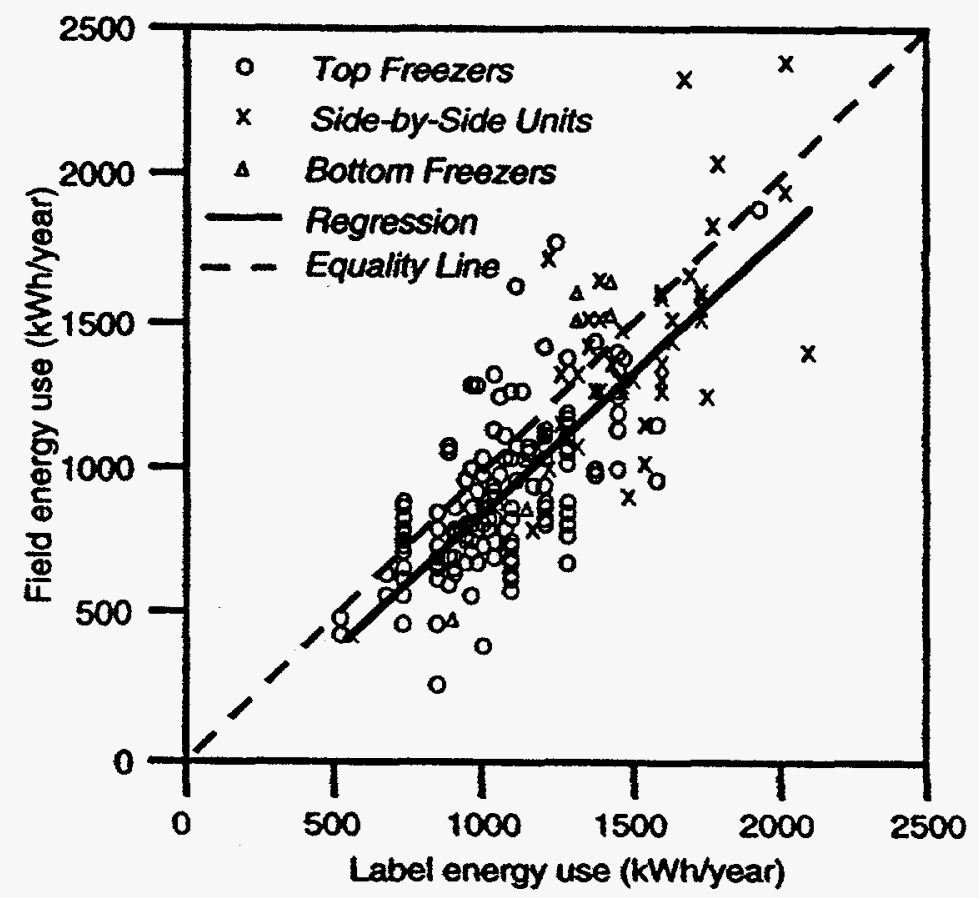

Figure. A comparison of labeled and field annual electricity use of refrigerators. Each symbol represents one refrigerator. The dashed line indicates equal consumption in label and field, while the solid line represents a regression fit. 
consumption but a single "miscellaneous" appliance-such as a water bed or a swimming pool-is often the largest end use in a home. Trends in residential electricity use suggest that the miscellaneous end use will become an increasingly important component of electricity demand. This compilation will help utilities forecast electricity demand and consumers find new ways of using electric- ity more efficiently. Finally, we are investigating similar trends in office equipment in commercial buildings.

Future compilations will include monitored savings from commercial building heating, ventilating, and air conditioning retrofits, residential water heating retrofits, and documentation of exemplary low-energy commercial buildings.

\section{References}

Meier AK. Refrigerator energy use in the laboratory and the field. Energy and Buildings 1995 (in press).

Meier AK, Megowan A, Litt B, Pon B. The New York State Residential Refrigerator Electrical Energy Monitoring Project. Lawrence Berkeley Laboratory Report No. LBL- 33708, 1993.

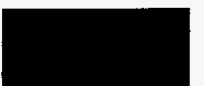

\section{Energy Performance of 21 Superinsulated Houses}

\author{
B. Litt, A.K. Meier
}

During the early 1990s Bigelow Homes, a well-known production builder of superinsulated houses in the U.S., constructed approximately 100 townhouses per year in the Chicago area. Bigelow's successful marketing strategy included a guarantee that heating bills for the first three years would not exceed $\$ 200$ annually (for the medium and small-sized dwellings) and a prize for the household with the lowest bill. The houses have high levels of insulation, a combined gas furnace-hot water system with a novel air distribution system, and high-performance windows. In addition, the builder employed special construction techniques to minimize air infiltration. We evaluated the performance of 21 houses using occupant surveys and an analysis of utility bills. The results confirm that occupants are satisfied with their houses and receive heating bills that are often less than half of those in standard new homes in the area. Furthermore, the houses cost little more to build than standard construction.

Except for an occasional (optional) sunspace, the houses do not look at all unusual. The four housing types studied are single-family detached with and without passive solar, duplex, and townhouse. Passive solar houses have south-facing sunspaces or a majority of windows on the south side. No particular attention was paid to the orientation of the other houses. The duplexes are joined only at their garages. Living areas range from 930 to $3800 \mathrm{ft} 2$ (58 to $350 \mathrm{~m}^{2}$ ) including basements.

Bigelow houses used only $40 \%$ to $60 \%$ of the space-heating energy of a comparable gas-heated house (see Figure). The townhouses used less energy than the detached houses, both for space heating and for other uses. Electricity use varied widely and appeared to be no lower than normal. Energy efficiency was not a major concern in the choice of household appliances. Most houses have central air conditioning and many showed significant peaks in electricity use during the summer of 1993. If their total energy use is compared to that of other low-energy houses, the Bigelow houses are among the highest. To be truly "low-energy" the builder would need to address lighting and appliance use, hot water use, and space cooling.

There are three conclusions from this evaluation. First, the Bigelow houses consume about one-half of the spaceheating energy of a conventional new
Figure. Bigelow homes' total gas use. house. Second, the occupants do not feel that they have sacrificed amenities for lower energy consumption and, in fact, many report improved comfort compared to where they used to live. Finally, the concept of "low energy" must extend beyond low space-heating energy use to include such other normal services as water heating, refrigeration, and lighting.

\section{Reference}

Litt B, Meier A. What is a low-energy house? In: Proceedings of the ACEEE 1994 Summer Study on Energy Efficiency in Buildings, August 28-September 3, 1994. Vol. 9. Washington, DC: American Council for an Energy-Efficient Economy, 1994, pp. 9.213-9.220.

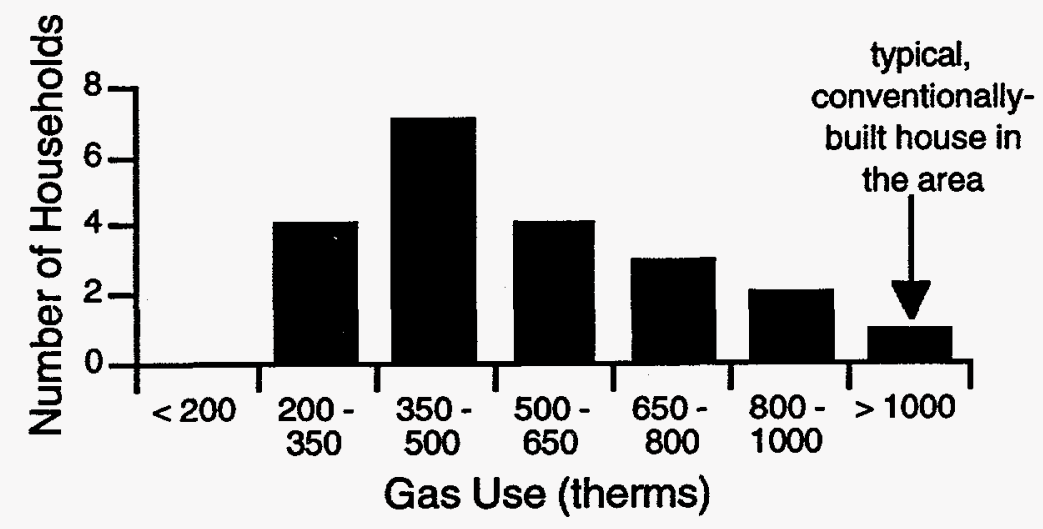




\section{Energy-Efficient Government Purchasing as a Market-Pull Strategy}

\author{
J. Harris* , N. Casey-McCabe*, F. Johnson*
}

The U.S. federal government is the largest single purchaser in the world of many energy-related products. Federal buying power-along with that of state and local agencies-represents a largely untapped resource to increase the energy efficiency of consumer products and commercial equipment. We are helping the U.S. DOE Federal Energy Management Program (FEMP) to develop and lead a government-wide initiative aimed at capturing this opportunity for market transformation.

The U.S. government spends over $\$ 70$ billion a year to purchase supplies and equipment, of which an estimated \$10-20 billion are energy-related products (see Figure). In the aggregate, state and local government buying power is roughly three to four times greater than the entire federal market. By purchasing energy-efficient products based on life-cycle costs, not just first-costs, government agencies save both energy and money.

Including energy efficiency as a criterion in government purchasing also represents a market-pull strategy affecting the entire commercial market. First, there are opportunities to aggregate the purchasing power of the public sector. By coordinating energy-efficiency criteria among federal agencies, across levels of government, and with utility demand-side management programs, we can help shift the mix of products manufactured and sold. All consumers will then benefit from higher efficiencies and from lower costs due to manufacturing volumeand competition. Second, public sector purchasing can help create entry markets for new technologies not yet commercially available. By adapting the "developmental procurement" methods commonly used in weapons procurement, civilian agencies would offer to purchase advanced products-better than any now available-provided that these products meet performance and cost specifications.

Throughout the federal government, both policy and procedural reforms are needed to help redirect purchase decisions toward today's best energy-efficient practice and to open up the federal market as a point of entry for tomorrow's more advanced technologies. Federal initiatives to increase the purchase of energy-efficient products are authorized under the 1992

* Energy and Environment Division Washington, D.C. Project Office. FY 1993.
Energy Policy Act, recent Policy Letters from the Office of Management and Budget, and Executive Orders on federal energy management and environmentallypreferred products. The most recent Executive Order, signed in March 1994, directs federal agencies to purchase "bestpractice" energy-efficient products (i.e., those in the upper $25 \%$ of the market, or at least $10 \%$ more efficient than current federal standards).

To implement the Executive Order, DOE is co-sponsoring an interagency "Procurement Challenge". This program encourages all agencies to change their direct purchases from commercial sources, acquisition through the supply agencies (Defense Logistics Agency and General Services Administration), or "indirect" purchases made as part of larger construction and service contracts. Agencies participatown buying patterns, whether through

ing in the Challenge make a voluntary commitment to lead the way toward energy-efficient purchasing, either through "best-practice" buying or by committing to purchase new, advanced technologies.

Our role is to assist DOE with program coordination and technical support in analyzing government purchasing patterns, the efficiency characteristics of currently available products, and opportunities for introducing new, advanced products. Our analyses draw upon related studies for the federal applianceand equipment standards, as well as LBL's technical expertise in areas such as lighting, building components (windows, duct systems, high-albedoroof coatings), and equipment and controls. We also help coordinate the federal effort on energy-efficient procurement with activities by a State Procurement Collaborative and utility and industry partners, among others.
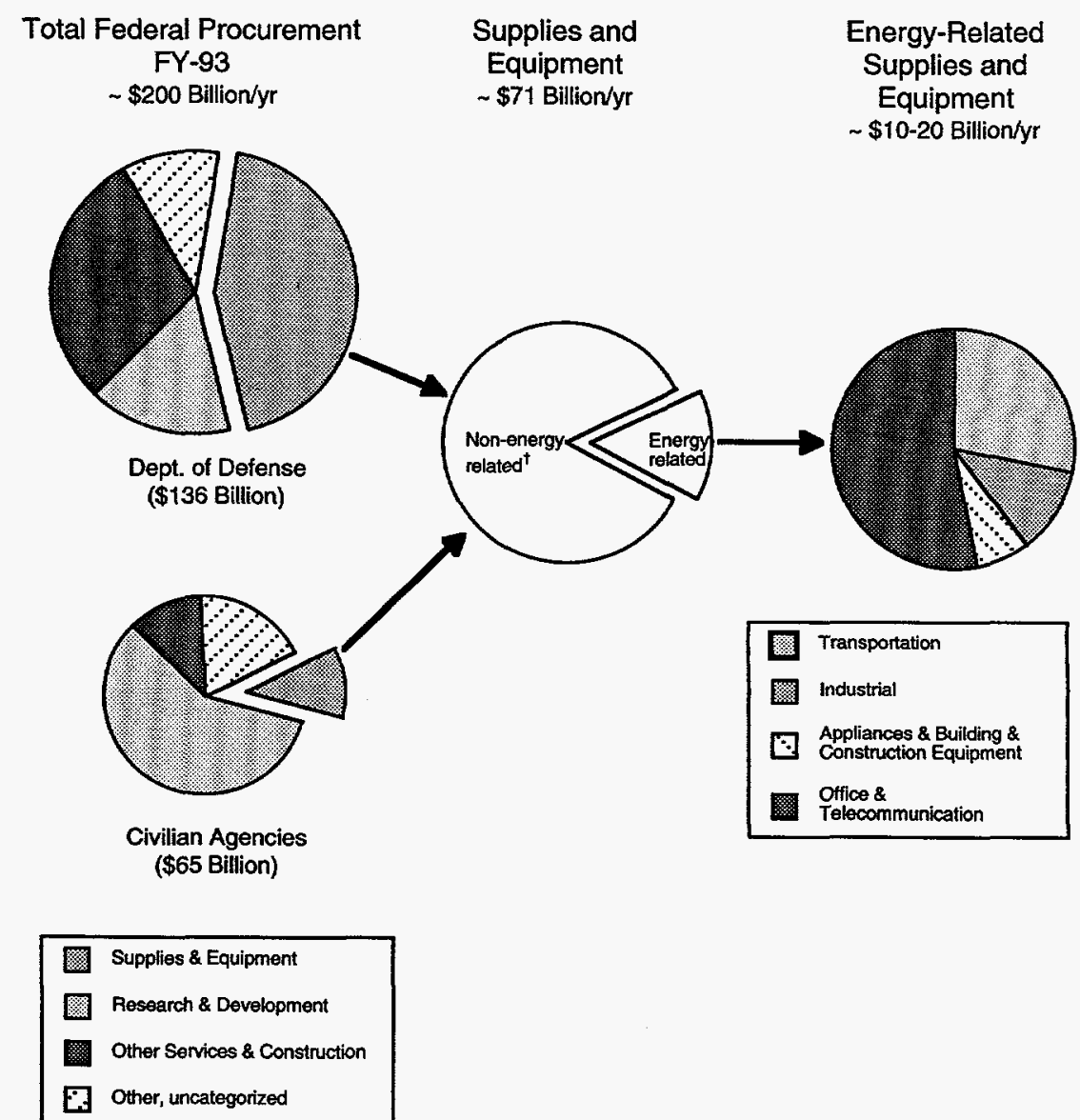

Figure. Energy-related supplies and equipment purchases by the federal government in

${ }^{+}$Non-energy-related includes defense-related equipment such as aircraft and ships. 


\title{
Urban Energy and Environmental Issues
}

\section{The Potential for Reducing Urban Air Temperatures Through Vegetative Cooling}

\author{
D.M. Kurn, S.E. Bretz, H. Akbari
}

Urban air temperatures can be lowered by reducing the amount of solar energy converted to sensible heat. One way to accomplish this is by increasing urban vegetation, which reduces sensible heat gain through both shading and evapotranspiration. This process can create an "oasis" of lower air temperatures throughout a region.

We investigated the potential for cooling the Los Angeles Basin through vegetation. We analyzed meteorological data gathered at 23 weather stations operated by Southern California Edison (SCE) to detect existing "oases" in the Basin. We also made traverse measurements in the Whittier Narrows Recreation Area, located in Los Angeles County south of Rosemead, to detect signs of temperature depression and increased absolute humidity brought about by evapotranspiration.

We examined data from four stations, separated from each another by $15-$ 25 miles $(24-40 \mathrm{~km})$. The data were strongly affected by the stations' distance from the Pacific Ocean. That, in addition to other effects produced by the city's scale, made the network inadequate for detecting urban oases. An examination of moisture sources, however, concluded that 1) advection and evapotranspiration are significant contributors to humidity in Los Angeles and that 2) a vegetated surface can be as effective as a high-albedo surface in reducing the sensible heat gain of the urban air. Our preliminary analysis indicates that near-surface air temperatures over vegetated areas appear to be $1-2^{\circ} \mathrm{C}$ lower than background air temperatures. We estimate that vegetation may lower urban temperatures in the boundary layer by $1^{\circ} \mathrm{C}$, while the establishment of vegetative canopies, i.e., trees, may lower temperatures by an additional $2{ }^{\circ} \mathrm{C}$ under the canopy. An increase in vegetation in residential neigh- borhoods may reduce peak loads by 0.9 GW and total energy consumption by 0.5 $\mathrm{BkWh}$ /year, saving $\$ 50$ million annually. The Table provides a summary of neighborhood cooling effects of vegetation and the resulting electricity savings.

Our traverse measurements detected a strong temperature depression without an accompanying rise in specific humidity, suggesting that the effects of vegetation are far more localized on temperature than they are on specific humidity. Thus, vegetation oases may be best revealed by analyzing humidity measurements. However, such a conclusion should first be verified with similar higher resolution humidity measurements. Supplementing the SCE weather station network with stations operated by the National Weather Service or the South Coast Air Quality Management District may provide sufficient resolution for the detection and analysis of existing urban vegetation oases. However, considerable effort would be required to calibrate the various stations so that slight differences in temperature and larger differences in specific humidity could be assigned to evapotranspiration. Once vegetation oases are located, temporary weather stations placed in the area can aid us in making traverse measurements and controlled comparisons. Future traverse measurements could be improved by performing the measurements more frequently and over a longer time period (for example all day and night) and duringdifferent types of days (cloudy, windy, and so on). This effort may be combined with building-energy monitoring and simulation to determine the impact of the vegetation oasis on energy use.

\section{Reference}

Kurn DM, Bretz SE, Huang B, Akbari $\mathrm{H}$. The Potential for Reducing Urban Air Temperatures and Energy Consumption Through Vegetative Cooling. Lawrence Berkeley Laboratory Report No. LBL35320, 1994.

Table. Potential vegetative cooling, peak load reductions, annual energy savings, and annual monetary savings in the Los Angeles Basin.

\begin{tabular}{llll}
\hline & Boundary layer & Canopy layer & Total \\
\hline Physical effects & $1^{\circ} \mathrm{C}$ cooling & $\begin{array}{l}2^{\circ} \mathrm{C} \text { cooling, } \\
\text { reduced wind } \\
\text { speed, shading }\end{array}$ & \\
Peak load reduction & $0.6 \mathrm{GW}$ & $0.3 \mathrm{GW}$ & $0.9 \mathrm{GW}$ \\
Annual energy savings & $0.3 \mathrm{BkWh} /$ year & $0.2 \mathrm{BkWh} /$ year & $0.5 \mathrm{BkWh} /$ year \\
Monetary savings & $\$ 30$ million & $\$ 20$ million & $\$ 50$ million
\end{tabular}




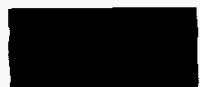

\section{Materials for Cool Roofs}

\author{
P. Berdahl, S. Bretz, H. Akbari, A. Rosenfeld
}

Although it is well known that white and other solar-reflective materials can keep roofs cooler and reduce air-conditioning costs, information on the solar reflectance (albedo) of building materials is often unavailable. In this project we are gathering this information by measuring solar reflectances and analyzing how a given reflectance results from the use of particular materials, including the effects of morphology and purity. This information can then be used to identify methods for increasing solar reflectance. To transfer the available information into the commercial arena, we are holding workshops and other discussions with industrial suppliers and promoting standards and labeling programs for reflective roofing materials.

Solar reflectance is calculated from measurements using an ultraviolet-visible, near-infrared spectrometer equipped with an integrating sphere. The spectrometer measures the monochromatic reflectance over theimportant spectral range of wavelengths from 0.3 to 2.5 micrometers. Figure 1 shows the results for a green asphalt roofing shingle and two green alternative materials; also shown is a standard solar spectrum (thin line). The overall solar reflectance is determined by averaging the monochromatic reflectance using the solar spectrum as a weighting function. Note that the coating with $\mathrm{Cr}_{2} \mathrm{O}_{3}$ pigment over black has about the same visible reflectance as the green asphalt shingle, but has a much higher reflectance in the nearinfrared portion of the solar spectrum. This example demonstrates that, in principle, increasing the solar reflectance without changing the visible appearance of materials is possible. When a white $\mathrm{TiO}_{2}$ pigment is added to the coating, the visible reflectance is increased, resulting in a lighter green color (top curve) with even higher solar reflectance.

Figure 2 illustrates the importance of solar reflectivity on roof temperature. These measurements, made on a clear day with surfaces facing the noontime sun, showed temperature differences as large as $48^{\circ} \mathrm{C}$ $\left(86^{\circ} \mathrm{F}\right)$ relative to that of the ambient air. At the same time, a surface with a good coating of white paint was only $10^{\circ} \mathrm{C}\left(18^{\circ} \mathrm{F}\right)$ above air temperature. Solar reflectivity is not the only important parameter in determining roof temperatures; the infrared

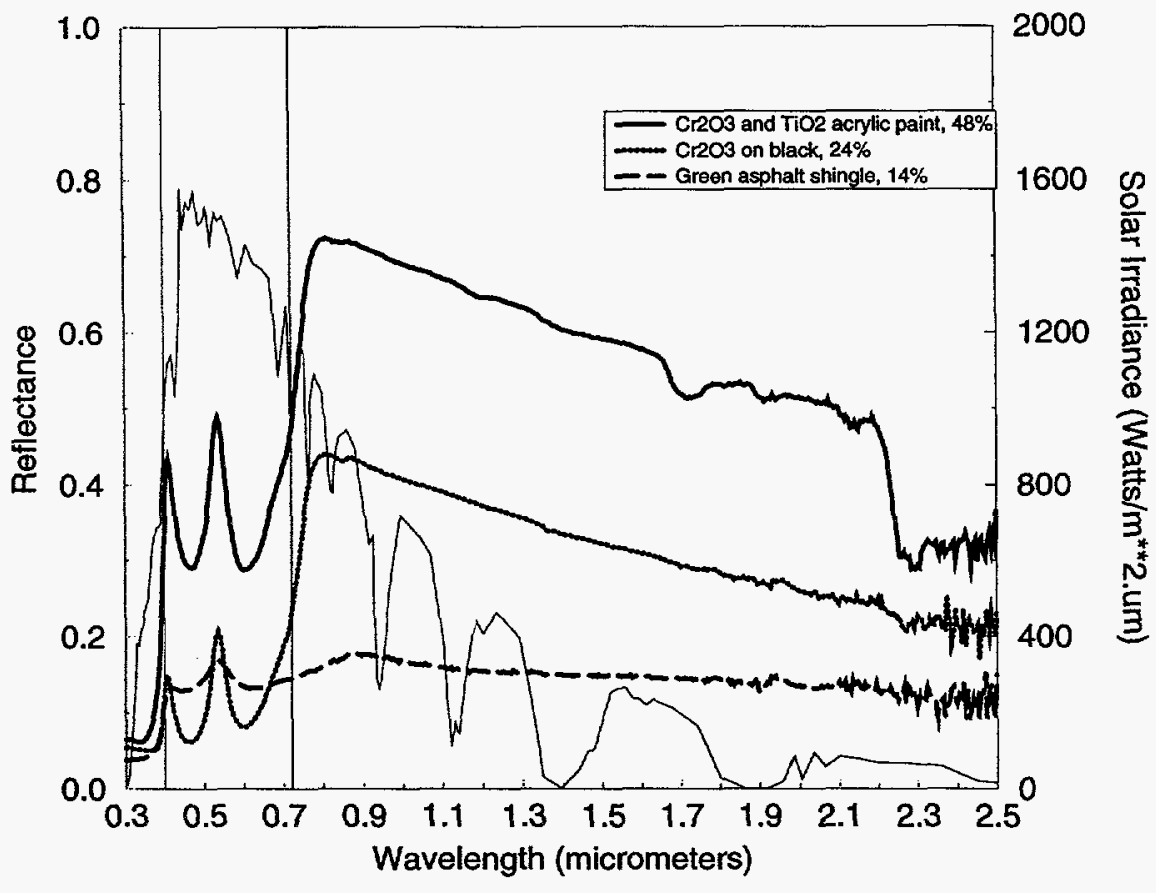

Figure 1. Spectral reflectance as a function of wavelength for three green samples, a light green $\mathrm{Cr}_{2} \mathrm{O}_{3}+\mathrm{TiO}_{2}$ pigmented coating, a darker green $\mathrm{Cr}_{2} \mathrm{O}_{3}$ coating, and a green asphalt shingle. The spectrally averaged solar reflectance of each of these samples is computed to be $48 \%, 30 \%$, and $14 \%$, respectively. The thin curve shows the standard solar spectrum used for computing the average solar reflectance (right scale).

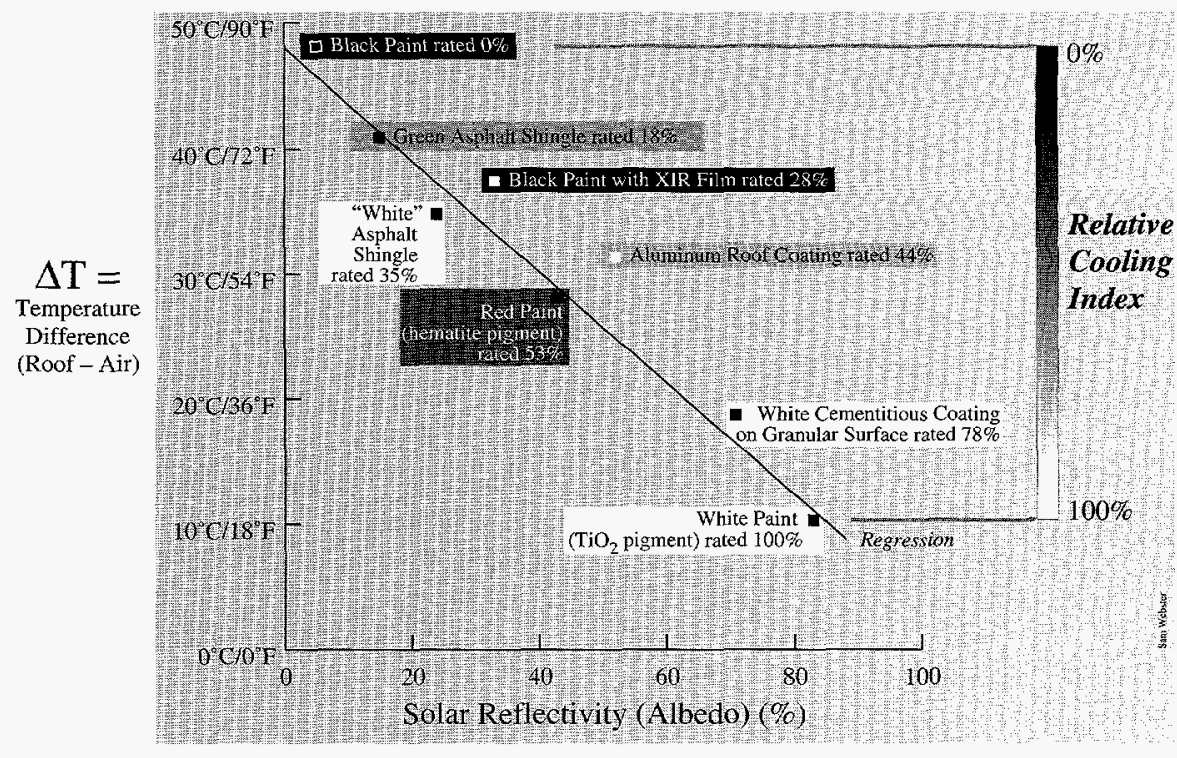

Figure 2. Measured temperature rise (roof minus air) of oarious materials in the midday sun. The black paint with a visibly transparent, infrared reflective film (XIR) is a novel material which appears black but which nevertheless is cooler in the sun. The aluminum roof coating is similar to materials sold for solar heat control, but which is inferior in this regard to white paint. 
emissivity and convection coefficient are important as well. The two samples represented by white squares in Figure 2 were determined to have a reduced infrared emissivity compared to most materials and are consequently observed to be significantly hotter than other samples with comparable solar reflectance. Convection heat loss has a role comparable to that of infrared emission in limiting the temperature rise in sunlight. The most noticeable effect of convection on a plot such as Figure 2 is that measurements made on a different day yield a similar correlation between temperature rise and solar reflectivity, but with a different slope. The convection coefficient is sensitive to the local wind speed and to the relative orientation of the surface and the wind.

Based on these observations, we can propose a "relative cooling index," which rates a given material relative to standard black and white paints (see the right scale of Figure 2). The numerical value of the index can be obtained by comparative temperature measurements in sunlight. Another, more convenient method for deriving the cooling index may be made by measuring solar reflectance and infrared emittance with laboratory instrumentation and using a standard convection coefficient to calculate the expected temperature rise in the sunlight.

\section{Reference}

Berdahl P, Bretz S. Technical issues for the development of cool materials. In: Proceedings of the Workshop on Cool Building Materials. Lawrence Berkeley Laboratory Report No. LBL-35514, 1994.

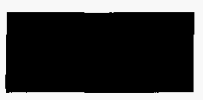

\section{Cool Building and Paving Materials Workshops} H. Akbari

Option 9, the Cool Communities Project, of the national Climate Change Action Plan (CCAP) calls for mobilizing community and corporate resources to plant trees and lighten the surfaces of buildings to reduce cooling energy use in buildings. The Cool Communities Project estimates savings of more than 100 billion kilowatt-hours of energy per year, corresponding to an annual $27 \mathrm{mil}-$ lion tons of avoided carbon emissions by the year 2015. The Table summarizes the energy-saving potentials of the Cool Communities Project.

To pursue the CCAP's objectives, we collaborated with the Building and Fire Research Laboratory of the National Institute of Standards and Technology to hold two conferences: one exploring the need for a national plan to assess the technical feasibility and commercial potential of high-albedo ("cool") building materials; and the second, outlining a course of action for developing the plan. The meetings took place in February and July 1994 in Gaithersburg, Maryland.

The proceedings of the first conference, the Workshop on Cool Building Materials, includes the minutes of the conference and copies of presentation materials distributed by the conference participants. The second conference led to the preparation of a ten-year national plan for developing and commercializing technologies for cool building and pavement materials. The proposed $\$ 30$ million plan identifies program goals and benefits, as well as program tasks and issues related to costs, program participants, and program management. The plan proposes support from the U.S.DOE as well as the construction industry. The program has identified ten tasks in two areas: decision-support systems and performance data, and the evaluation of cool construction materials. This national plan is being distributed for general comments. dollar figures in 1990 dollars.

${ }^{\dagger} \mathrm{MtC}=$ million metric tons of carbon.

\section{References}

Akbari H, Fishman B, and Frohnsdorff $\mathrm{G}$, eds. Proceedings of the Workshop on Cool Building Materials. Lawrence Berkeley Laboratory Report LBL35514, 1994.

Akbari H, ed. Cool Construction Materials: A Proposed National Plan for Development and Commercialization of Cool Building and Pavement Materials Technology. Washington, DC:U.S. Department of Energy, 1994 (in press).

Table. Base case air-conditioning (A/C) use and savings potential from a combination of cool surfaces and shade tree programs. The estimated impact of cool surfaces is about onehalf to two-thirds of the total savings. The Table does not address benefits or penalties in heating energy use resulting from planting shade trees and using high-albedo roofs. All

\begin{tabular}{llllll}
\hline & 1995 & 2000 & 2005 & 2010 & 2015 \\
\hline Base Case A/C Use & & & & & \\
$\quad$ Electricity (BkWh) & 441 & 464 & 488 & 512 & 539 \\
Cost (utility + customer) & $\$ 42 \mathrm{~B}$ & $\$ 44 \mathrm{~B}$ & $\$ 46 \mathrm{~B}$ & $\$ 49 \mathrm{~B}$ & $\$ 51 \mathrm{~B}$ \\
$\mathrm{CO}_{2}(\mathrm{MtC})^{\dagger}$ & 110 & 116 & 122 & 128 & 135 \\
Annual Savings & & & & & \\
$\quad$ Fraction of base case & $0 \%$ & $5 \%$ & $10 \%$ & $15 \%$ & $20 \%^{\ddagger}$ \\
$\quad$ Electricity (BkWh) & 0 & 23 & 49 & 77 & 108 \\
Cost (utility + customer) & $\$ 0 \mathrm{~B}$ & $\$ 2.2 \mathrm{~B}$ & $\$ 4.6 \mathrm{~B}$ & $\$ 7.3 \mathrm{~B}$ & $\$ 10 \mathrm{~B}$ \\
$\mathrm{CO}_{2}(\mathrm{MtC})^{+}$ & 0 & 6 & 12 & 19 & 27 \\
\hline
\end{tabular}

$\ddagger$ Potential savings in 20 years when re-surfacing and trees have matured. 


\section{Ozone Air Quality Implications of Large-Scale Albedo and Vegetation Modifications}

\section{H. Taha, A. Meier, S. Douglas, * A. Winert}

While the energy savings from highalbedo materials and increased urban vegetation havebeen demonstrated and documented at the building scale, their impacts on the regional meteorology and air quality have yet to be analyzed. This modeling study aims at quantifying the positive and negative implications of these two strategies on the ozone air quality in the South Coast Air Basin (SoCAB) and analyzing the net benefits from each case.

Implementation of high-albedo materials and increased urban vegetation may lower ambient temperatures, thereby decreasing the demand for cooling in warm and hot climates. Lowered air temperatures would also decrease the photochemical reaction rates, biogenic emissions from existing vegetation, and evaporativelosses from mobile and stationary sources, while the reduced demand for cooling would result in reduced emissions from power plants. All of these effects would result in less photochemicalsmog formation. However, lower air temperatures can also mean reduced atmospheric mixing heights, which may translate into higher apparent concentrations of ozone and its precursors. Also, the introduction of certain tree species may actually increase local emission of biogenichydrocarbons-major precursors to ozone formation.

The interactions among these various elements are complex and need to be resolved through the use of sophisticated modeling tools. In this study, three-dimensional, mesoscale, Eulerian meteorological and photochemical models were used to simulate the regional meteorology and ozone air quality implications of increased albedo and urban vegetation. The Colorado State University Mesoscale Model (CSUMM) and the Urban Airshed Model (UAM) were used to simulate the SoCAB's meteorology and air quality, respectively.

The simulations indicate that exposure to harmful levels of ozone on a very smoggy day in August can be reduced by $5 \%$ with respect to the California and na- tional standards by increasing albedo or vegetation in the SoCAB. With respect to the California Stage I health alert, the exposure can be reduced by $80 \%$. During a more typical (less severe) episode than the one examined in this study, the potential improvements in air quality could belarger. The simulations also show that if trees are introduced into the SoCAB, improvements in air quality can be achieved only if the trees are of low- or non-emitting species.

Results from this modeling project were considered by the South Coast Air Quality Management District and served as a basis for the inclusion of high-albedo materials and urban vegetation in the 1994 Air Quality Management Plan released by the District earlier this year.

\section{Reference}

Taha HG ef al. Analysis of Energy Efficiency and Air Quality in the South Coast Air Basin:Phase-IIDocument. LawrenceBerkeleyLaboratory ReportNo.LBL-35728, 1994.

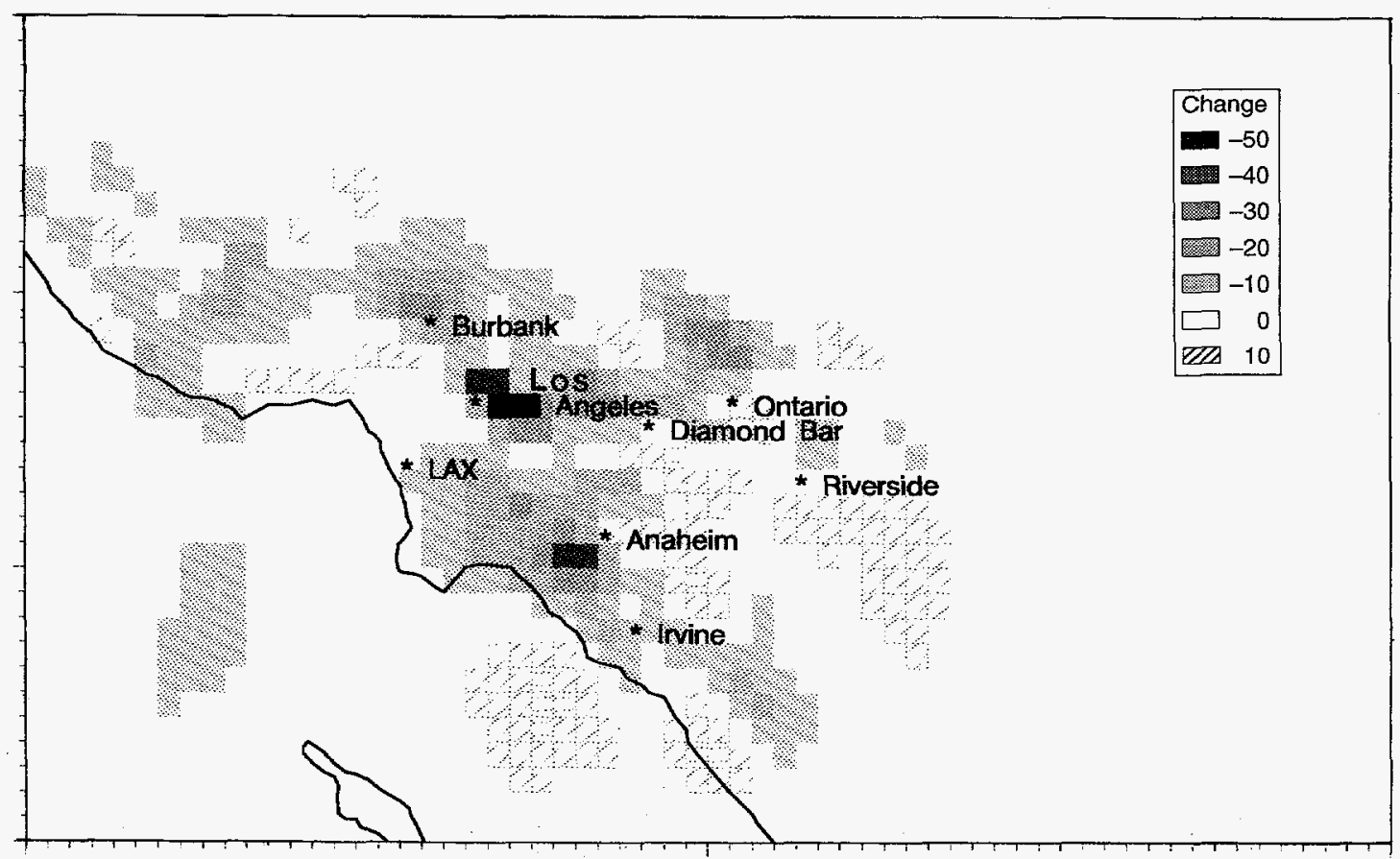

Figure. Deviation in ozone concentrations (in parts per billion (ppb)) from the base case for a case in which both albedo and vegetation were increased by moderate amount in the SoCAB. Results shown are for $3 P_{M}$ on a smoggy day in August. Shades of grey represent areas with decreased ozone concentrations whereas the hatching represents areas where ozone actually increased. The net effect is a reduction in ozone in the SoCAB.

\footnotetext{
* Systems Applications International, Inc., San Rafael, CA.

${ }^{+}$Environmental Science and Engineering Program, University of California at Los Angeles.
} 


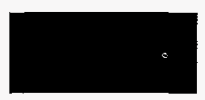

\section{Space-Varying $\mathrm{NO}_{x} /$ ROG Control Ratios for Maximizing Ozone Air Quality Improvements in the South Coast Air Basin}

\section{H. Taha, T. Wenzel, M.D. Levine}

It is generally thought that reducing the emissions of ozone precursors, i.e., oxides of nitrogen and reactive organic gases $\left(\mathrm{NO}_{x}\right.$ and $\mathrm{ROG}$, respectively), would reduce ozone concentrations and improve air quality in major air basins. However, the impacts of emission-control measures on ozone air quality are not straightforward. Implementing the current strategies of uniform reductions in emissions of $\mathrm{NO}_{x}$ or ROG may actually result in locally increasing or decreasing ozone concentrations depending on meteorology and the level and mix of existing emissions - each of which varies from one area to another in the air basin. We need to improve our understanding of ozone formation as it relates to locationspecific conditions within air basins.

In this study, we use three-dimensional mesoscale meteorological (CSUMM) $^{*}$ and photochemical (UAM) ${ }^{\dagger}$ models to study the South Coast Air Ba$\sin (\mathrm{SoCAB})$ of California. We use these models to test alternative emission-control scenarios and assess various policy approaches to improving the air quality in the Basin. An approach of interest has been to investigate the use of space-varying $\mathrm{NO}_{\mathrm{x}} / \mathrm{ROG}$ control ratios instead of uniform reductions in $\mathrm{NO}_{x}$ and $R O G$ as is often proposed in current regulations. The production of ozone in any one subbasin depends on the ratio of ROG to $\mathrm{NO}_{\mathrm{x}}$. Since each sub-basin has different mixes of precursors, it may require a different ROG/NO control to prevent ozone formation from peaking. By varying this ratio to the characteristics of each subbasin, maximal improvements in air quality can be achieved.

For this analysis, we divided the SoCAB into three smaller air basinsWest Basin, San Bernardino, and River- side-and for each sub-basin a different $\mathrm{NO}_{\mathrm{x}} / \mathrm{ROG}$ reduction ratio is used.

Our simulations of an episode during August 26-28, 1987, indicate that a regulation based on space-varying $\mathrm{NO}_{x} /$ ROG ratios would require only modest control levels to achieve significant results, i.e., comparable to those achieved by large $\mathrm{NO}_{\mathrm{x}}$ control. For example, a control level of $30 \%$ to $50 \%$ may be sufficient to produce improvements in air quality that would otherwise require a 90\% (or greater) uniform reduction in $\mathrm{NO}_{x}$ emissions. Furthermore, there are no localized increases in ozone.

These findings are preliminary but encouraging and we plan to continue our modeling work to assess the effectiveness and feasibility of space-varying emission control strategies. Other major air basins will also be simulated.

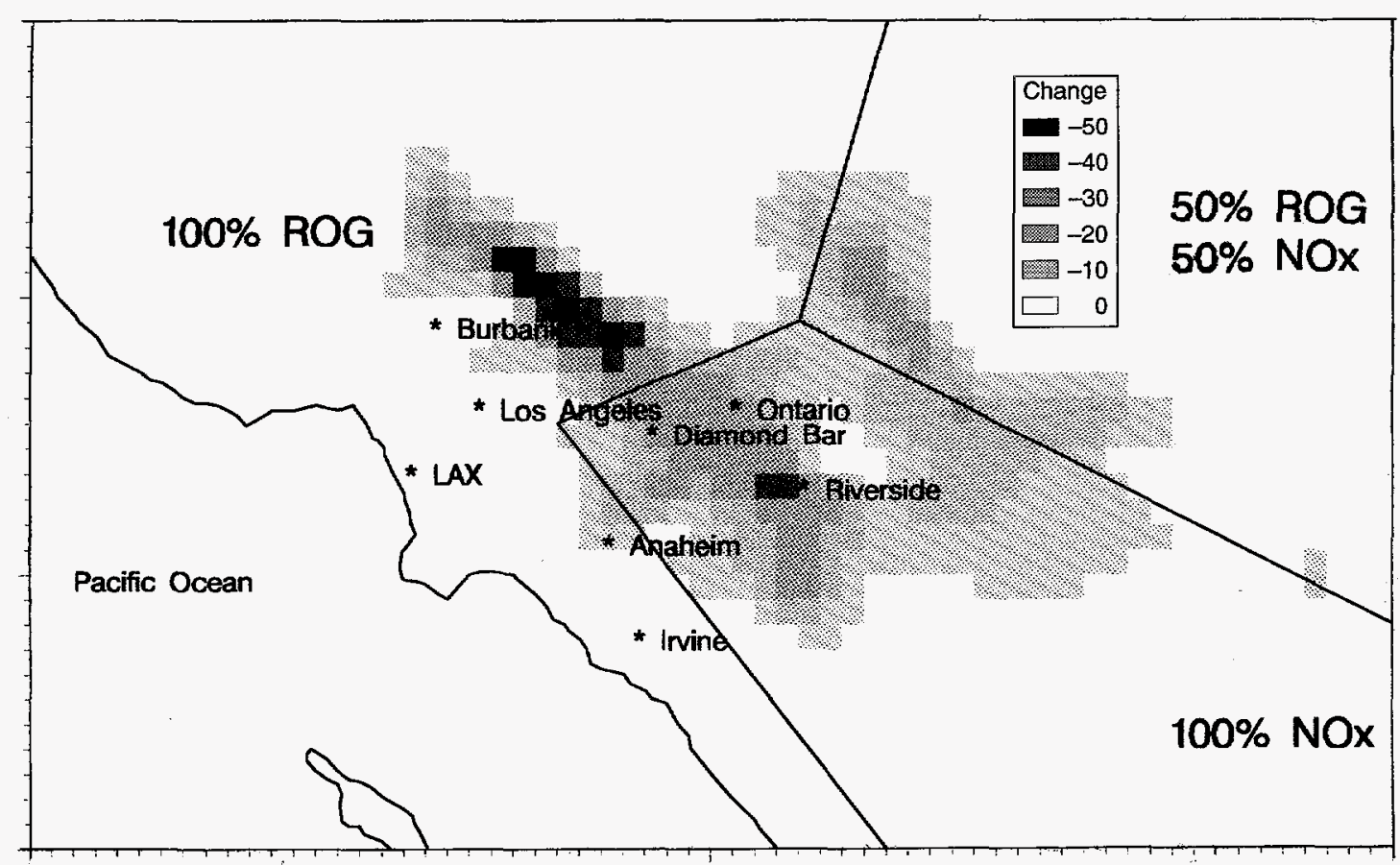

Figure. Ozone concentration differences (in parts per billion ( $p p b$ )) for a space-varying $N O_{x} / R O G$ control measure with respect to a base case at 3 P.M. on August 27, 1987. The control level is $30 \%$ and the resulting largest decrease in ozone concentrations is on the order of $50 \mathrm{ppb}$. The straight lines delineate sub-basin boundaries and the percentages within each show how the $30 \%$ control level is to be partitioned between $\mathrm{NO}_{x}$ and ROG. Unlike uniform control on emissions (as required in current regulations), space-varying control," like the one shown in this Figure, results in no increases in ozone.

\footnotetext{
* Colorado State University Meteorological Model.

† Urban Airshed Model.
} 


\title{
Appliance Energy Efficiency Standards
}

\author{
Analysis of Federal Appliance Efficiency Standards \\ J.E. McMahon, B. Atkinson, S. Boghosian, P. Chan, T. Chan, J.G. Koomey, M.E. Lecar, M.D. Levine, J. Lutz, \\ G. Rosenquist, A.O. Sezgen, S. Stoft, I. Turiel
}

The Energy Policy and Conservation Act (P.L. 94-163), as amended by the National Energy Conservation Policy Act (P.L. 95-619) and by the National Appliance Energy Conservation Act of 1987 (P.L. 100-12) and by the National Appliance Energy Conservation Amendments of 1988 (P.L. 100-357), provides energyconservation standards for 12 types of consumer products and authorizes the Secretary of Energy to prescribe amended or new energy standards for 13 types of products. ${ }^{*}$ The Energy Policy Act of 1992 (P.L. 102-486) adds five products: (14) general-service fluorescent lamps and incandescent reflector lamps, (15) shower heads, (16) faucets, (17) water closets, and (18) urinals, for which test procedures and labels will be developed. This Act sets standard levels for lamps, motors, commercial heating and cooling equipment, and commercial water heaters, and includes a schedule for possible amendments to the standards.

Initiated in 1979, LBL's assessment of the standards is designed to evaluate their economic impacts according to the legislated criteria (see Figure).

The economic impact analysis is performed in five major areas:

- Engineering Analysis, which establishes the technical feasibility and product attributes including costs of design options to improve appliance efficiency.

- Consumer Analysis at two levels: national aggregate impacts (forecasts) and impacts on individuals (life-cycle cost analysis). The national aggregate impacts include forecasts of appliance

* Products covered: (1) refrigerators, refrigerator-freezers, and freezers, (2) room air conditioners, (3) central air conditioners and heat pumps, (4) water heaters, (5) furnaces, (6) dishwashers, (7) clothes washers, (8) clothes dryers, (9) direct heating equipment, (10) kitchen ranges and ovens, (11) pool heaters, (12) television sets, and (13) fluorescent-lamp ballasts. sales, efficiencies, energy use, and consumer expenditures. The individual impacts are analyzed by life-cycle cost, payback periods, and cost of conserved energy, which evaluate the savings in operating expenses relative to increases in purchase price.

- Manufacturer Analysis, which provides an estimate of manufacturers' response to the proposed standards. Their response is quantified by changes in severalmeasures of financial performance.

- Utility Analysis, which measures the impacts of the altered energy-consumption patterns on electric utilities.

- Environmental Analysis, which estimates changes in emissions of carbon dioxide, sulfur oxides, and nitrogen oxides resulting from reduced energy consumption in the home and at the power plant.

This year, based on our analysis, DOE proposed possible updated standards for eight products: room air conditioners, water heaters, mobile home furnaces, direct heating equipment, kitchen ranges and ovens, pool heaters, televisions, and fluorescent light ballasts. Data collection and analysis continued for possible updated standards for refrigerators and freezers, central air conditioners, and heat pumps and furnaces.

In the next year, we will continue the analysis of possible energy efficiency standards for theeleven products listed above, and for dishwashers, clothes washers, and dryers.

The Energy Policy Act of 1992 expands the appliance efficiency program at DOE to include lamps, motors, commercial heating and cooling, and commercial water heating. We will perform analyses of possible standards for highintensity dischargelamps, the four plumbing products, and small electric motors, as well as look at rating and information programs for luminnaires and for office equipment.

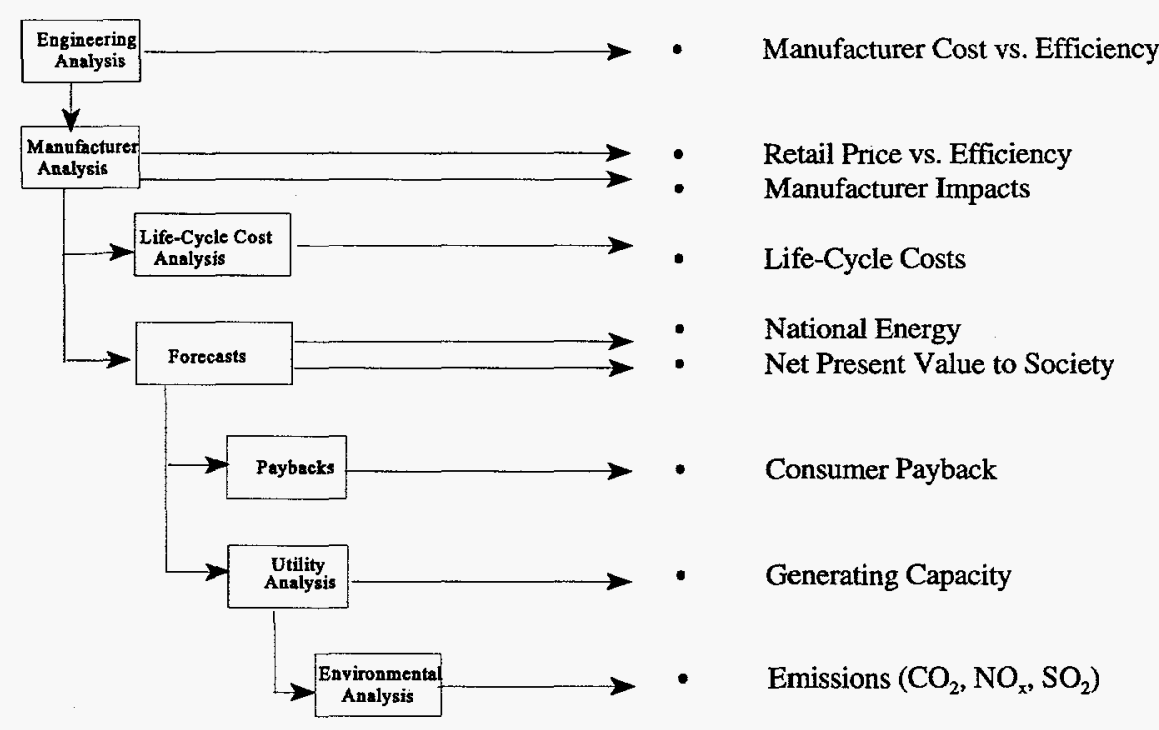

Figure. Analytic framework for the appliance standards analysis. 


\section{References}

U.S. Department of Energy, Assistant Secretary for Energy Efficiency and Renewable Energy, Office of Codes and Standards. Technical Support Document: Energy Conservation Standards for Consumer Products: Refrigerators, Refrigerator-Freezers, and Freezers. Washington, D.C.: U.S. Department of Energy Technical Support Document, 1994 (in press).
JE McMahon, $X$ Xiaolin, Uncertainty analysis of life-cycle cost: residential electric heat pump water heaters. In: Proceedings of the ACEEE 1994 Summer Study on Energy Efficiency in Buildings, , August 28-September 3, 1994. Vol. 8. Washington, D.C.: American Council for an Energy-Efficient Economy, 1994. pp. 8.131-8.139.

U.S. Department of Energy, Assistant
Secretary, Conservation and Renewable Energy, Building Equipment Division. Energy Conservation Standards for Consumer Products: Water Heaters, Direct Heating Equipment, Mobile Home Furnaces, Pool Heaters, Ranges and Ovens, Room Air Conditioners, Televisions, and Fluorescent Light Ballasts. U.S. Department of Energy Technical Support Document, 1993.

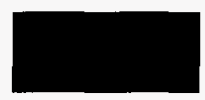

\section{Engineering Analyses of Appliance Efficiency Improvements}

I. Turiel, B. Atkinson, C. Atkinson, P. Biermayer, S. Boghosian, T. DeVuono, C. Dunham, S. Hakim, J. Logan,

\section{J. Lutz, G. Rosenquist}

The economic impacts of appliance efficiency standards depend largely on the relation between cost and energy consumption of a consumer product. Our engineering analysis seeks to identify this cost-consumption relationship for selected appliances.

In 1994 we completed engineering analyses for refrigerators, freezers, central air conditioners, and heat pumps. This work involved extensive meetings with industry and government task force working groups.

We responded to comments on the advance notice of proposed rulemaking for these products and also completed a technical support (supports a proposed rule) document (TSD) for refrigerators and freezers. As a result of these analyses, modified refrigerator and freezer standards should take effect in 1998. We have also responded to comments and are revising our TSDs for the following eight products: room air conditioners, water heaters, mobile home furnaces, direct heating equipment, kitchen ranges and ovens, pool heaters, televisions, and fluorescent-light ballasts.

New analyses of dishwashers, clothes washers, and clothes dryers have been initiated. Additionally, analyses of small motors, plumbing products, lighting products, and office equipment are all in progress. Finally, a report on advanced appliances was completed and served as input for a Report to Congress that satisfies a portion of the 1992 Energy Policy Act. This report analyzes energy savings that may be derived from promoting the use of appliances that are more efficient than required by existing energy efficiency standards.

The engineering analysis consists of the following steps: select appliance classes; select baseline units for each class; select design options for each class; and determine the maximum technologically feasible design, the efficiency improvement, and the cost for each option for each class. Data are obtained through contacts with trade organizations and manufacturers, from suppliers of purchased parts and materials, and from computer simulations.

In 1995 we plan to write the techni$\mathrm{cal} /$ support documentation for the engineering analysis of central heating and central air conditioning/heat pumps. We will respond to comments on a notice of proposed rulemaking on the those prod- ucts. We will also revise our report on the analysis of eight products (water heaters, pool heaters, direct heating equipment, mobile homeheaters, fluorescent ballasts, room air conditioners, ranges/ovens, and televisions). Work will continue on small motors, plumbing products, lighting products, and office equipment.

\section{Reference}

I. Turiel, et al., Evaluation of Advanced Technologies for Residential Appliances and Residential and Commercial Lighting. Lawrence Berkeley Laboratory Report No. LBL-35982, 1994.

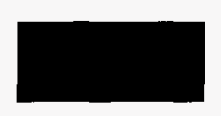

\section{Assessing the Impacts of Appliance Standards on Manufacturers}

\author{
T. Chan, S. Stoft
}

The Manufacturer Analysis assesses the impact of appliance standards on the profitability and competitiveness of the various appliance-manufacturing industries affected by mandatory energy efficiency standards. The primary tool used for this evaluation is the Manufacturer ImpactModel (LBL-MIM). LBL-MIMuses engineering cost and efficiency estimates as well as collected economic and financial data as inputs. Outputs include price, rate of profit, shipments, revenues, net income, and the standard errors of these estimates. LBL-MIM also provides estimates of retail prices used by the Residential Energy Model (LBL-REM) and the life-cycle cost analysis.

This year we integrated an industrysupplied model entitled the Government Regulatory Impact Model (GRIM) into the LBL-MIM. As a result, this enhanced model is now referred to as the LBLManufacturer Analysis Model (LBLMAM). This revised model allows the manufacturer impact analysis to include an analysis of the effects of standards using a cash-flow analysis (e.g., using industry net present value as another impact variable) without sacrificing any of the functionality in the LBL-MIM.

We used the LBL-MAM to perform an analysis of the impact of standards on refrigerators, refrigerator-freezers, and freezers. The results are contained in a technical support document to be published by the U.S. Department of Energy.

Data collection and preliminary analyses for the analysis of central air conditioners, boilers, and furnaces were also begun. We havesubmitted question- 
naires to firms, trade associations, and consultants in the industries.

In 1995, we expect to complete an analysis of comments submitted in response to the notice of participatory rulemaking for water heaters, pool heaters, direct heating equipment, room air conditioners, mobile home furnaces, kitchen ranges and ovens (including microwave ovens), television sets, and fluorescent lamp ballasts. We also expect to analyze comments on the refrigerator, refrigerator-freezer, and freezer technical support documents and to complete a manufacturer impact analysis of central air conditioners, furnaces, and boilers. A re-analysis of water heaters, pool heaters, direct heating equipment, room air conditioners, mobile home furnaces, kitchen ranges and ovens (including microwave ovens), television sets, and fluorescent lamp ballasts will also be done, and we will begin the analysis of clothes washers, clothes dryers, and dishwashers.

\section{Reference}

U.S. Department of Energy, Assistant Secretary for Energy Efficiency and Renewable Energy, Office of Codes and Standards. Technical Support Document: Energy Conseroation Standards for Consumer Products: Refrigerators, Refrigerator-Freezers, and Freezers. Washington, D.C.: U.S. Department of Energy Technical Support Document, 1994 (in press).

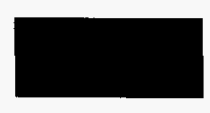

\title{
Natural Gas Utility Effects of Federal Residential Appliance Efficiency Standards
}

\author{
C. Marnay, M.L. Barcella, * A. Kast
}

We conduct analyses of several effects that imposed residential appliance energy efficiency standards, including one for the natural gas industry, could have on the nation.

The supplying, long-distance transmission, and distribution of natural gas have traditionally been performed by separate companies. Furthermore, the structure of the gas industry has changed considerably over the last decade, resulting in a structure wherein the first two steps are competitive, while the third remains regulated. Therefore, estimating the effect of a loss in residential natural gas demand on the industry must be done at two levels, the deregulated upstream gas market, which establishes the wholesale or "city gate" gas price, and the local distribution company (LDC) sector in which regulated retail rates prevail. We developed the approach shown in the Figure to address the two levels. The input to this process is an LBL Residential Energy Model (LBL-REM) estimate of the natural gas demand reduction. The North American Regional Gas Model (NARG) ${ }^{\dagger}$ estimates the price drop in the city gate price caused by the standard. The Regionally Estimated LDC Cost Model (RELCM) estimates the downstream price effect. Because of the heavy burden of fixed cost recovery, a decline in sales can be expected to result in higher LDC costs, which are passed through in higher customer rates.

In preliminary tests of possible efficiency standards for residential natural gas appliances, the LDC effect tends to dominate and residential rates are predicted to rise slightly, although standards will still reduce customer bills because of lower usage.

\section{Reference}

U.S. Department of Energy, Assistant Secretary for Energy Efficiency and
Renewable Energy, Office of Codes and Standards. Technical Support Document: Energy Efficiency Standards for Consumer Products: Refrigerators, Refrigerator-Freezers, and Freezers. Washington, D.C.: U.S. Department of Energy, 1994 (in press).

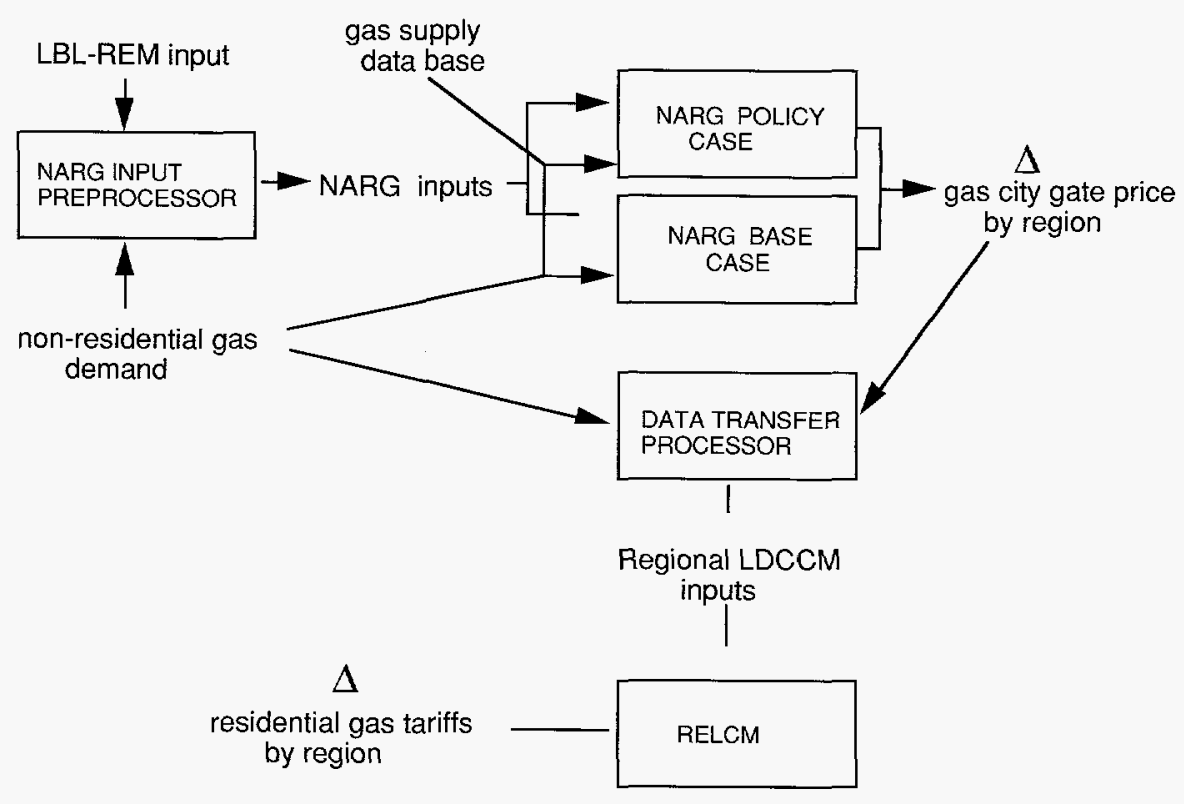

Figure. Two-level data flow.

\footnotetext{
* Consulting Economist, Washington, D.C.

${ }^{+}$NARG is a proprietary product of Decision Focus Inc., Mountain View, CA.
} 


\section{Utility Planning and Policy}

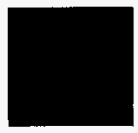

\section{The Cost and Performance of Utility Commercial Lighting Programs}

\section{J. Eto, E. Vine, L. Shown, R. Sonnenblick, C. Payne}

In recent years, utility activities aimed at designing, implementing, and evaluating demand-side management (DSM) programs have increased significantly. Unprecedented growth in DSM spending has led some to express concern that the results of DSM may be disappointing relative to the expenditures. To address these concerns, we conducted a study of the total cost and measured performance of 20 utility commercial lighting programs. These programs, undertaken by utilities primarily for the purpose of acquiring a cost-effective resource, were often the largest single DSM program offered by the sponsoring utilities.

We collected and systematically analyzed information on program costs, energy and demand savings, participation rates, cost effectiveness, and evaluation methodologies. Our primary sources of information were process-and-impact evaluation reports prepared by the utilities (typically in response to regulatory filing requirements), verified and supplemented through extensive discussions with utility staff.

Our analysis was based on the total cost (including customer contributions) and measured performance of the 20 DSM programs; all calculations of program costs and energy savings were based on post-program evaluations conducted by the utilities. Careful analysis of the 20 programs proved to be a timeconsuming and difficult process due to differences in utility reporting of DSM program data and evaluation methods used to measure savings. We are working with regulators to ensure greater consistency in terminology and reporting protocols for future DSM programs.

We found that each of the 20 programs was a cost-effective energy investment from a total resource cost perspective. That is, the cost of the programs was less than the projected supply costs the programs allowed the utilities to avoid. The cost of energy saved by the

Notes to Figure: by about $3 \%$. programs ranged from a low of $1.2 \phi /$ $\mathrm{kWh}$ to a high of $7.6 \mathrm{c} / \mathrm{kWh}$ (see Figure). Weighted by energy savings, the average cost of energy saved by the programs was $3.9 \mathrm{c} / \mathrm{kWh}$. We found that some of the differences in costs were explained by differences in program size and utility avoided costs.

Decisions regarding future investment in DSM activities should be based on a clear and systematic comparison of program impacts. The goal of our continuing work in this area is to improve DSM programs by identifying best practices through such comparisons.

\section{Reference}

Eto J, Vine E, Shown L, Sonnenblick R, Payne C. The Cost and Performance of Utility Commercial Lighting Programs. Lawrence Berkeley Laboratory Report No. LBL-34967, 1994.

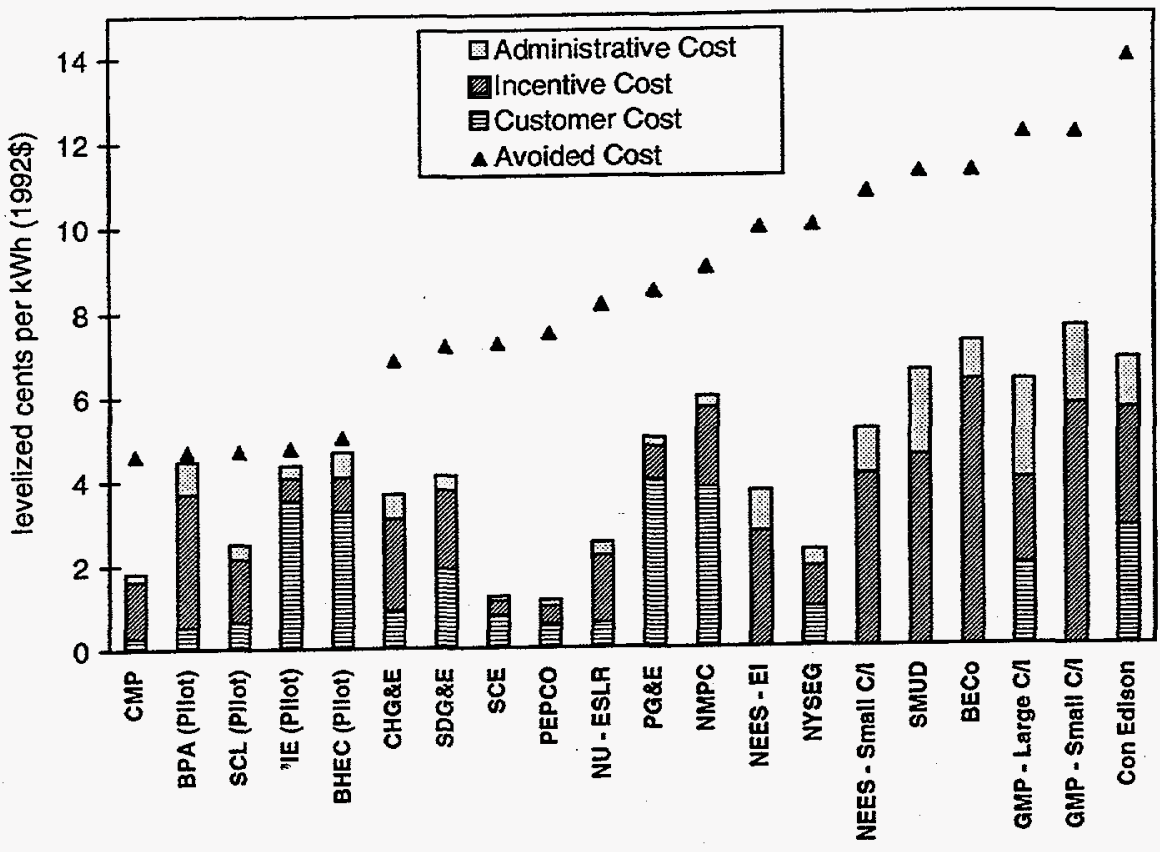

Figure. Total resource cost of commercial lighting energy savings.

1. Levelized total resource costs and avoided costs are calculated at a $5 \%$ real discount rate.

2. Utility avoided costs are calculated by LBL from utility cost test ratio estimates and utility estimates of program levelized costs.

3. Evaluation costs are not included in utility costs; based on the programs that do report these costs, we estimate that evaluation costs increase the utility component of total resource costs

4. Free riders' costs and savings are included in the calculation of levelized total resource costs.

5. We rely on utility post-program estimates of savings based on measured consumption data, and make no judgment on the accuracy of utility evaluation methods. For utilities who do not base post-program savings estimates on measured consumption data, we adjust their tracking database estimates of savings by an adjustment factor. 


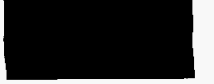

\title{
Impact of Power Purchases from Nonutilities on the Utility Cost of Capital
}

\author{
E. Kahn, S. Stoft, T. Belden
}

The 1992 U.S. Energy Policy Act reflects a debate initiated by bond rating agencies concerning the financial impact of long-term power purchase contracts between nonutility generators(NUGs) and utilities. The bond rating agencies assert that these contracts are the equivalent of debt to the utilities and therefore raise the cost of capital to the purchaser. Nonutility generators claim that these contracts reduce risk to the utilities.

The basis for the concern lies in the capacity payments associated with the NUG contracts. These payments must be made if energy from the project is available, whether it is taken or not. This obligation is perceived to be a contingent liability to the utility. Representatives of NUG developers argue that utilities that purchase power from NUGs reduce their risk by transferring certain of the burdens associated with power plant construction to private parties and by imposing the availability risk on NUGs. It is argued that these factors should improve the credit of a utility that purchases power from NUGs.

We approach these questions from the perspective of the equity markets. If NUG contracts really are equivalent to debt, then they raise the risk to the firm and this should be observable in the equity market.

\section{Conceptual Model}

The effect of NUG contracts is hypothesized to be an effective change in the debt-equity ratio, D/Eq. NUG contracts have capacity payments that are thought to be equivalent to debt payments. We call this NUG "equivalent debt" Dn. To account for the effect of utility construction projects, we must include one more variable, which we refer to as Cor CWIP. Since we expect the impact of the CWIP variable to be proportional to its magnitude but inversely proportional to the equity base that its impact is spread over, we enter it in our stochastic equation as C/Eq. This brings us to our base stochastic model:

$$
r_{e}=b_{0}+b_{1} \frac{D}{E q}+b_{2} \frac{D n}{E q}+b_{3} \frac{C}{E q}+\varepsilon
$$

Note that equity, Eq, acts as a normalization divisor for all three variables, which reduces heteroscadaticity in the error term. The coefficients $b_{i}$ are estimated statistically and $\varepsilon$ is the error term. In all cases, we use the Capital Asset Pricing Model (CAPM) for the dependent variable $r_{e^{\prime}}$ which is the cost of equity capital.

\section{Estimation Issues}

There are numerous data issues associated with estimating our model. The two most important involve different specifications of the equivalent debt, Dn, which we call NUG, and variations on the sample over which we estimate the basic model. We employ three different estimates of the NUG variable, identified as 1, 2, and 3. We run our basic sample of utilities with and without two particular data points that represent potential problems. We refer to these samples as $\mathrm{N}$ and $\mathrm{S}$. All together there are six combinations of NUG variableand sample selection. These definethe cases reported in the Table of results.

\section{Statistical Results}

Regression results are listed in the Table. For each variable, the estimated coefficient is given, with thet statisticlisted in parenthesis below it. On theoretical grounds, we expect that the Debt/Equity variable should be positive and significant, and this is the case.

With respect to our central question, the results are unambiguous. The CWIP variable has a positive and significant coefficient. There is no significance to the NUG coefficient. This result suggests that utility construction does increase risk and raise the utility cost of equity capital.

The coefficients in the Table have a straightforward interpretation. The average $r_{e}$ consists of three components: (1) the intercept term has a value of approximately 0.08 , (2) the Debt/Equity coefficient of approximately 0.01 adds a return requirement of about 0.0088 for the average value of the Debt/Equity variable of about 0.88 , and (3) the CWIP co-efficient of about 0.05

Table. Regression results of various versions of the model.

\begin{tabular}{lcccccc}
\hline & $\mathrm{S} 1$ & $\mathrm{~N} 1$ & $\mathrm{~S} 2$ & $\mathrm{~N} 2$ & $\mathrm{~S} 3$ & $\mathrm{~N} 3$ \\
\hline Intercept & 0.0776 & 0.0812 & 0.0791 & 0.0816 & 0.0777 & 0.0817 \\
& $(15.18)$ & $(13.70)$ & $(14.51)$ & $(13.72)$ & $(15.27)$ & $(13.85)$ \\
Debt/Equity & 0.0095 & 0.0099 & 0.0097 & 0.0099 & 0.0095 & 0.0099 \\
& $(2.08)$ & $(2.13)$ & $(2.13)$ & $(2.13)$ & $(2.07)$ & $(2.16)$ \\
NUG & -0.0034 & -0.0012 & 0.0414 & 0.0223 & -0.0108 & -0.0123 \\
& $(-0.47)$ & $(-0.16)$ & $(0.67)$ & $(0.33)$ & $(-0.59)$ & $(-0.53)$ \\
CWIP & 0.0636 & 0.0476 & 0.0522 & 0.0438 & 0.0631 & 0.0470 \\
& $(4.19)$ & $(2.34)$ & $(2.88)$ & $(2.18)$ & $(4.42)$ & $(2.52)$ \\
Adjusted $\mathrm{R}^{2}$ & 0.45 & 0.26 & 0.46 & 0.27 & 0.45 & 0.27 \\
\hline
\end{tabular}

adds a return requirement of about 0.015 for an average value of the CWIP variable of 0.29 . The result is an average cost of equity capital of about 0.1038 , which is approximately the average value of $r_{e}$ in our sample. For a utility with CWIP that is one standard deviation above the average, the cost of capital increases by 0.005 .

\section{Conclusions}

Our principal finding is that we cannot detect any evidence to support the debt-equivalence hypothesis. At least as far as the cost of equity capital is concerned, we find more evidence to support the notion that utility construction raises the cost of capital than that NUG purchases do. This finding tends to support arguments made by NUGs on this issue. This conclusion is supported by reasonably strong statistical results. Our results tell us nothing about the source of the risk associated with CWIP. It is entirely possible that it lies with the regulator, rather than with the firm.

These conclusions must be tempered by a frank assessment of the data quality upon which the statistical analysis rests. TheNUG data in particular are quite weak. We have relied on the best publicly available compilations, but they are highly imperfect. We expect this situation to improve over time. It would be interesting to revisit these questions when the quality of the data is better.

\section{Reference}

Kahn E, Stoft S, Belden T. The Impact of Power Purchases from Nonutilities on the Utility Cost of Capital. Lawrence Berkeley Laboratory Report No. LBL-34741, 1994. 


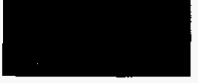

\section{Transmission Interface Constraints}

\author{
R. Baldick*, E. Kahn
}

When a high-voltage network is subject to a constraint that limits the amount of power that can be moved from one region to another, there is said to be an interface limit. We model this problem heuristically. Such models are quite valuable under current industry conditions because they delineate technical opportunities and choices in situations where there may be conflicting views among competing parties and regulatory authorities. We organize and enumerate the choices, clarify the practical conditions that dictate the optimum in particular cases, and help motivate the final choices made by planners.

Transmission line loadability is constrained by both voltage and steady-state stability criteria. While thermal limits are relevant for short lines, voltage constraints determine loadability for intermediate lines up to 200 miles in length and stability limits determine loadability for long lines. We focus on the range of lengths for which the voltage constraint is limiting.

We formulate the problem of serving increased local load without violating an interface constraint. The planning solution is an appropriate trade-off among local generation, transmission upgrades or extensions, and specialized reactive support equipment. The local generation alternative has been recognized as a generic means of relieving a voltage-limited transmission constraint, but there does not appear to bea general treatment of the conditions under which it is economical. Part of the complexity of the trade-off is the bundled nature of generation service provided at the load center. This service includes not only real power, but also voltage support in the form of reactive power.

Most of the literatureaddressing specialized reactivesupport equipment treats the generation and transmission alternatives as fixed. We view the choices of generation transmission and reactive support jointly. We model a three-node system and derive optimal construction plans for joint generation, transmission, and reactivecompensation. Network-sensitivity parameters are calculated for the model system under specified reliability criteria. The sensitivity of optimal choice to economic factors is illustrated.
One interpretation of our general result is that it provides a "network externality" correction to the traditional planning criteria and procedures based primarily on comparison of generation costs. The key insight offered by our model is that when cost differences between local and remote generation are relatively small, there are substantial advantages to building generation at local nodes.

\section{Reference}

Baldick R, Kahn E. The Transmission Interface Constraint Problem. Lawrence Laboratory Berkeley Report No. LBL34772, 1993.

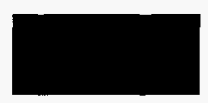

\section{Review of Performance-Based Ratemaking for U.S. Gas Distribution Companies}

\section{G.A. Comnes}

Performance-based ratemaking (PBR) is an innovative form of regulation being considered by U.S. energy utilities and their regulators as a substitute for traditional, cost-of-service/rate-of-return (COS/ROR) regulation. PBR, also known. as incentive regulation, strengthens financial incentives to improve rates, costs, or other aspects of performance. Although incentive ratemaking is widely used to regulate telecommunications utilities, only a handful of energy utilities have pursued it. In this project, we reviewed nine proposals for PBR made by "early adopting" gas local distribution companies (LDCs). Using the plans filed by these early adopters as an empirical basis, we analyzed pivotal issues faced by utilities that embark on PBR.

$\mathrm{PBR}$ is most often considered a regulatory alternative when a utility faces competition and restructuring in one or more of its business segments. Such emerging competition is becoming a criti- cal issue to gas and electric utilities. The most common strategy employed by PBR mechanisms is to weaken the link between a utility's regulated prices and its costs. This decoupling is accomplished either by decreasing the frequency of rate cases or by employing external measures of cost for the purposes of setting rates. PBR mechanisms are developed with the recognition of the information asymmetry between the regulator and the regulated utility. That is, PBR places an emphasis on ratemaking methods that improve performance without resorting to micromanagement.

The nine plans we reviewed included many different types of incentive mechanisms. However, we believe it is useful to characterize the mechanisms according to the utility services coveredtransportation/distribution, procurement, or both-and by the PBR's scope within those service categories-broad or narrowly targeted (see Table).

Table. Typology of performance-based ratemaking for gas utilities.

\begin{tabular}{lll}
\hline & \multicolumn{2}{c}{ Scope } \\
\cline { 2 - 3 } Utility Service Category & \multicolumn{1}{c}{ Broad } & \multicolumn{1}{c}{ Targeted } \\
\hline $\begin{array}{l}\text { On-system Transportation, } \\
\text { Distribution, and Storage } \\
\text { (Base Rates) }\end{array}$ & - Rate Freeze/Index/Cap & $\begin{array}{c}\text { - Specific Base-Rate } \\
\text { Cost Incentive } \\
\text { Targeted Throughput } \\
\text { Incentives }\end{array}$ \\
$\begin{array}{l}\text { Procurement (Gas Supply } \\
\text { Rates) }\end{array}$ & $\begin{array}{l}\text { - Unit Cost Indices/ } \\
\text { Comprehensive }\end{array}$ & $\begin{array}{l}\text { Targeted Procurement } \\
\text { Cost Incentives }\end{array}$ \\
(all of the above) & - Unit Cost Index & - DSM Performance \\
& - Rate Comparison & Incentives \\
\hline
\end{tabular}

- Service Quality Indices

(can be Broad or Targeted) 
Narrowly targeted mechanisms have the advantage of being easier to design, but raise concerns that, by targeting a specific area of costs or performance, they divert utility management attention from other important goals and only lead to an increase in total costs. Broad mechanisms have the virtue of tying financial performance to more fundamental goals such as total rates, costs, or bills, but suffer from complexity and increased risk. This work focused on broad mechanisms because of their theoretical superiority and complexity.

We identified three ways in which PBR can provide benefits:

- Economic Resource Efficiency. Our research indicates that the categories the LDCs can best control include labor-related operating and maintenance and plant expenditures. For PBRs to be effective, they should focus on these cost categories. Of the nine plans reviewed, five attempted to apply incentives to these cost categories. The Figure shows how the plans approached earnings-sharing mechanisms. Although earningssharing mechanisms decrease marginal incentives for improved performance, they provide a way of reducing earnings swings that can otherwise make a plan nonviable. Our research indicates that earnings-sharing mechanisms should contain wide dead bands wherein little or no sharing occurs. The earnings-sharing mechanisms adopted by Pacific Gas \& Electric (PG\&E) and San Diego Gas \&Electric (SDG\&E), shown in the Figure, best exemplify the design standard we recommend.

Another way to strengthen the incentives for improved resource efficiency is to decrease the frequency of rate reviews. Although it is not feasible or desirable to eliminate rate reviews completely, it appears that the frequency of rate cases was cut by more than one-half as a result of the adoption of PBR plans.

- Allocation Efficiency (pricing flexibility). Allocative efficiency is achieved when prices for services are set at marginal cost or as close to marginal cost as possible-subject to a revenuerequirement constraint. Regulators can improve allocative efficiency by giving LDCs pricing flexibility in conjunction with safeguards against excessive profits. Three of the sample PBR proposals, those of Brooklyn Union Gas (BUG), New Jersey Natural Gas (NJNG), and Wisconsin Gas, included increased pricing flexibility in their proposals.

- Administrative and Regulatory Costs. PBR can in theory reduce the cost of regulation incurred by the utility, the regulator, and other intervenors. In our review, we found that the reduced frequency of rate cases was a potential source of administrative cost savings. Further, contentious "reasonableness" reviews are eliminated under the two broad procurement plans proposed by SDG\&E and SoCal Gas. However, the administrative cost savings are offset in part by an increase in plan monitoring and evaluation costs.

Although our findings are reasonably positive, PBR for energy utilities is not universally accepted as superior to COS/ROR regulation. Even its supporters would agree that there are several competing PBR mechanisms and that few have been adequately studied. It appears likely, however, that future proposals by utilities will be forthcoming and they should benefit from learning from the experience of early-adopting utilities.

\section{Reference}

Comnes GA. Review of Performance-Based Raternaking Plans for U.S. Gas Distribution Companies. Lawrence Berkeley Laboratory Report No. LBL-35680, 1994.

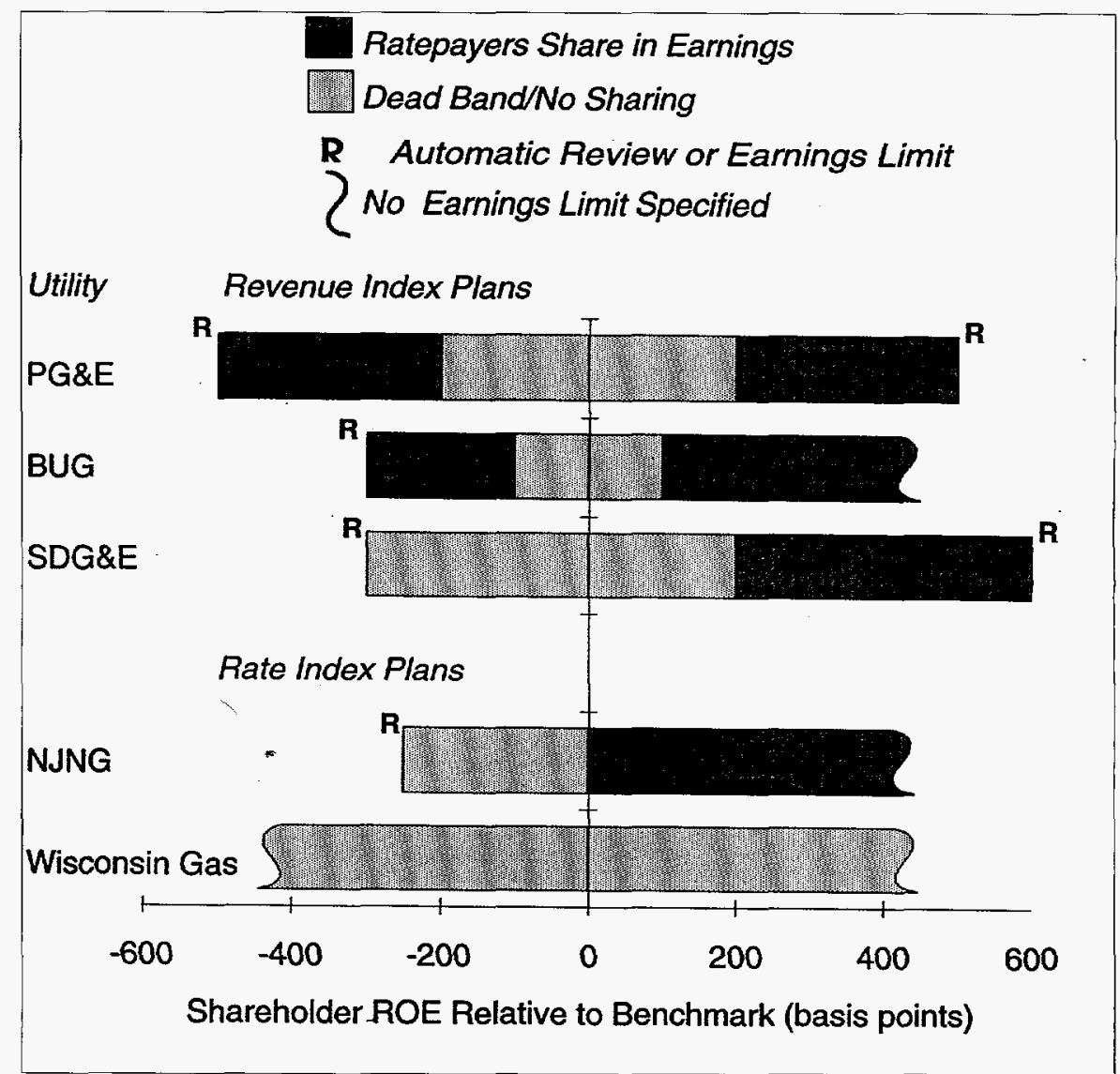

Figure. How PBRs incorporate earnings-sharing mechanisms. 


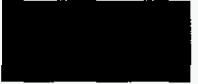

DSM Shareholder Incentives: Current Designs and Economic Theory

\author{
S. Stoft, J. Eto, S. Kito
}

By the end of 1993, demand-side management (DSM) shareholder incentive mechanisms had been approved for 53 U.S. electric and gas utilities in 20 states. With few exceptions, the incentive mechanisms had been developed case by case. We reviewed a number of these incentive designs by examining the performance of ten of the utilities. We then analyzed five design issues (see Figure): 1) the appropriate design or basis for DSMshareholder incentives (e.g., netbenefits vs. saved energy vs. monies spent) the quantity on the horizontal axis; 2) considerations for establishing incentive payments - the point on the vertical axis associated with a given level of performance; 3) the importance of the marginal incentive rate- the slope of the incentive payment curve; 4) the role of earnings, spending, and penalty caps to mitigate risks to both the utility and the regulator-represented by the tapering off of the incentive payment curve at very high and low levels of performance; and 5) the justification for separate incentive treatment of individual DSM programs-not shown in the Figure.

Our recommendations to improve the design of DSM shareholder incentives are summarized as follows:

- Use shared savings incentive mechanisms to maximize DSM net benefits;

- Use separate incentives for individual programs only in limited situations when net benefits are presumed positive but difficult to measure;

- Setexpected incentive payments based on covering a utility's "hidden costs," which consist of transitional management and risk-adjusted, opportunity costs;

- Use higher marginal incentive rates than are currently found in practice, but limit total incentive payments by adding a fixed charge;

- Mitigate earnings risks to utilities by lowering marginal incentive rate below some threshold of performance;

- Mitigate under-forecasting risks to regulators by lowering marginal incentive rate above some threshold of performance; and

- Apply DSM incentives in aggregate to DSM resource programs.

Examination of utility DSM shareholder incentives provides regulators with a unique opportunity to evaluate the effectiveness of a particular type of incen-

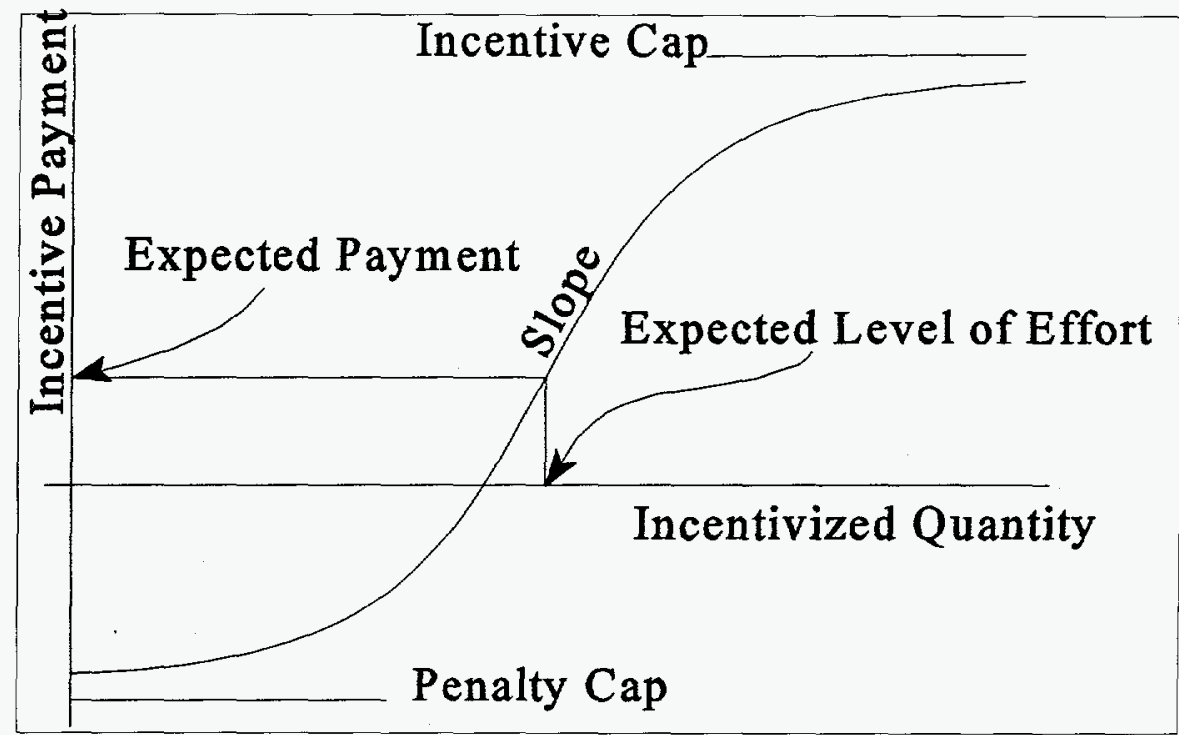

Figure. Structural elements of a DSM shareholder incentive mechanism. tive regulation designed to motivate utilities to achieve specific regulatory objectives. We observe that current mechanisms can probably be improved by harnessing their incentive powers more deliberately to ensure better alignment of regulatory objectives and utility financial self-interest. Better alignment reduces the likelihood of adversarial confrontations and eliminates the need for regulatory micro-management.

As regulators contemplate other applications of incentive regulation, the les-

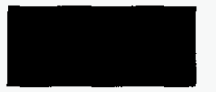

\section{Risk Allocation in DSM Bidding Programs}

C.A. Goldman, M.S. Kito

U.S. utilities continue to experiment with various approaches that allow developers of demand-sideresources to propose projects in competitive bidding solicitations, a phenomenon commonly referred to as "demand-side management (DSM) bidding." Since 1987, about 35 U.S. utilities have signed long-term contracts with developers of DSM resourcestypically energy service companies (ESCOs) - to provide a quantity of demand and energy savings at specified prices. DSM bidding programs account for only a small portion of the savings $(\sim 5 \%)$ currently achieved by utility DSM efforts nationally, but interest among regulators (and some utilities) in competitive procurement for DSM resources sons from DSM shareholder incentives are clear. Be explicit about the regulatory objective; then, when considering multiple objectives, look broadly at alternatives that have the potential to meet these objectives without compromising the incentive properties of the mechanisms.

\section{Reference}

Stoft S, Eto J, Kito S. DSM Shareholder Incentives: Current Designs and Economic Theory. Lawrence Berkeley Laboratory Report No. LBL-36580, 1994.

continues to increase. In 1994, we completed the first comprehensive study of eighteen DSM bidding programs.

One of the distinctive features of DSM bidding programs is their attempt to allocate the risks associated with DSM resources in an explicit fashion among ratepayers, DSM developers, and host customers through contracts signed between developers and utilities. In contrast, allocation of risks in more traditional utility DSM programs tends to be less well-defined, which often results in utility ratepayers implicitly bearing most of the risks. From the perspective of a utility and its ratepayers, the risks associated with DSM resources can be grouped into several broad categories: 
- Development Risk. This is a risk that the expected demand and energy savings will not materialize. For a DSM bidding program, the risk involves a DSM developer being unable to develop projectssuccessfully. Autility-runDSM program risks that sufficient numbers of customers will not agree to install DSM measures being promoted by the utility.

- Performance Risk. Risk that demand reductions and energy savings that result from completed installations do not persist over the expected economic lifetime of the measures.

- Demand Risk. Risk that the utility's forecasted need for new capacity may diminish over the economic lifetime of measures. In effect, the value of the energy savings decreases, which potentially jeopardizes the cost effectiveness of the DSM resource acquisition.

The Table compares the allocation of risks among various groups (ratepayers, utility shareholders, DSMdevelopers, and participating or host customers) in a prototypical utility rebate program and a DSM bidding program. In this stylized example, we assume that the utility is operating a large-scale DSM program that offers rebates to customers who purchase DSM measures. Program costs are expensed and the utility must achieve pre-specified performance goals in order to receive a financial incentive authorized by the regulator. Utility shareholders can also be penalized if the company fails to meet performance goals, which are typically specified in terms of minimum levels of market penetration, savings, or net benefits.

Who bears the risks associated with a traditional utility-run DSM program? Participating customers bear the development risks associated with installing the measures. Utility shareholders also bear some of the DSMdevelopment and performance risk, depending on how the shareholder incentive mechanism is structured. For example, utility shareholders are typically held accountable for achieving overall program market-penetration goals (because of the shareholder incentives). Ratepayers implicitly bear the bulk of the performance risk if savings do not persist over the economic lifetime of the measures because a significant portion of the cost of the measures (i.e., the rebate) is paid up front by ratepayers withoutstrong contractual guarantees that the estimated savings will be maintained. The utility also has some flexibility to manage demand risk. That is, if the program is no longer cost-effective for

Table. Risk allocation in utility rebate vs. DSM bidding program.

\section{Utility Rebate Program}

(with incentives

for utility shareholders)

DSM Bidding

Development Risk

- Proper installation/commissioning

- Market penetration risk (aggregate)

$\begin{array}{cl}\text { Participant } & \text { DSM developer } \\ \text { Shareholder/ratepayers } & \text { DSM developer }\end{array}$

Performance Risk

- Energy savings $\begin{array}{ccc}\text { - short-term } & \text { Ratepayers/shareholders } & \text { DSM developer } \\ \text { - long-term } & \text { Ratepayers } & \text { DSM developer }\end{array}$

Demand Risk Ratepayers Ratepayer

various reasons, then the utility can either cancel or alter the design of the program.

In a bidding program, DSM developers are responsible for proper installation and commissioning of DSM measures at individual facilities and for achieving in aggregate their contract demand-reduction goal. DSM developers also assume the risks associated with the near-term and long-term energy savings performance of installed measures. Ratepayers bear most of the demand risk in a bidding program because of the financial commitments involved in the long-term contract between the utility and DSM developer. Utilities use various contractual mechanisms to mitigate the development, performance, and demand risks to ratepayers of DSM resources. These risk-mitigation options include various types of security deposits, damageand penalty provisions, and "regulatory out" and "buy out" clauses. These provisions protect ratepayers quite well in situations in which projects fail to develop or energy savings deteriorate over the contract term. In particular, the "pay for performance" contracting methodsensurethat utilities and ratepayers only pay forverified energy savings.

Thus, from a policy perspective, DSM bidding programs are an important phenomenon because they are performancebased and because utilities typically pay only for energy savings that are verified over relatively long contract terms. This feature addresses some concerns raised by skeptics of traditional utility DSM programs who maintain that the actual societal costs are understated because of reliance on overly optimistic engineering savings estimates.

\section{Reference}

Goldman CA, Kito SM. Review of Utility Experiencewith DSM Bidding. Lawrence Berkeley Laboratory Report No. LBL35021, 1994.

\section{End-Use Efficiency Policies for a Restructured Electricity Sector}

\section{S. Wiel, J. Eto, C. Goldman}

Regulation and the structure of the electricity industry in the U.S. have been evolving along a distinctive path for about the last twenty years. The advent of independent power producers, efficient new combined-cycle natural gas-fired power plants, and low natural gas prices, all on the heels of an expensive three-decade experimentation with nuclear power that has left some utility companies with undesirably large assets on their books, are providing pressures for change. The re- sult is a large gap for many of these utilities between 1) the rates needed to recover the embedded costs of their power plants and long-term sales contracts that are no longer competitive and 2) the rates that would be charged if the electricity were generated solely with new technology in a competitive business environment. In the spring of 1994, these strong pressures triggered a dramatic acceleration in the regulatory and structural evolution of the electricity industry (see 
Figure). Today, there is keen interest among electricity regulators concerning such issues as special recovery of utility company stranded investments, regional transmission groups, performance-based ratemaking, and open retail competition.

As part of LBL's Integrated Resource Planning (IRP) Program, we have been monitoring the regulatory and structural changes that are taking place in the electricity industry, with an eye toward encouraging that change which most improves the overall economic efficiency of our society's electricity generation and consumption. Special attention is being paid to end-use efficiency, an often neglected factor in restructuring proposals, and to utility demand-side management (DSM) programs.

Since 1988, DSM has been enhanced in some states by changes in regulatory ratemaking to make DSM profitable for the utility company. Traditional regulation, practiced by all states until recently, establishes retail electricity rates in a way that economically discourages utilities from helping their customers use electricity more efficiently. Re-examining the rationale for, and where appropriate, promoting regulatory reform to make DSM profitable-whether within the existing

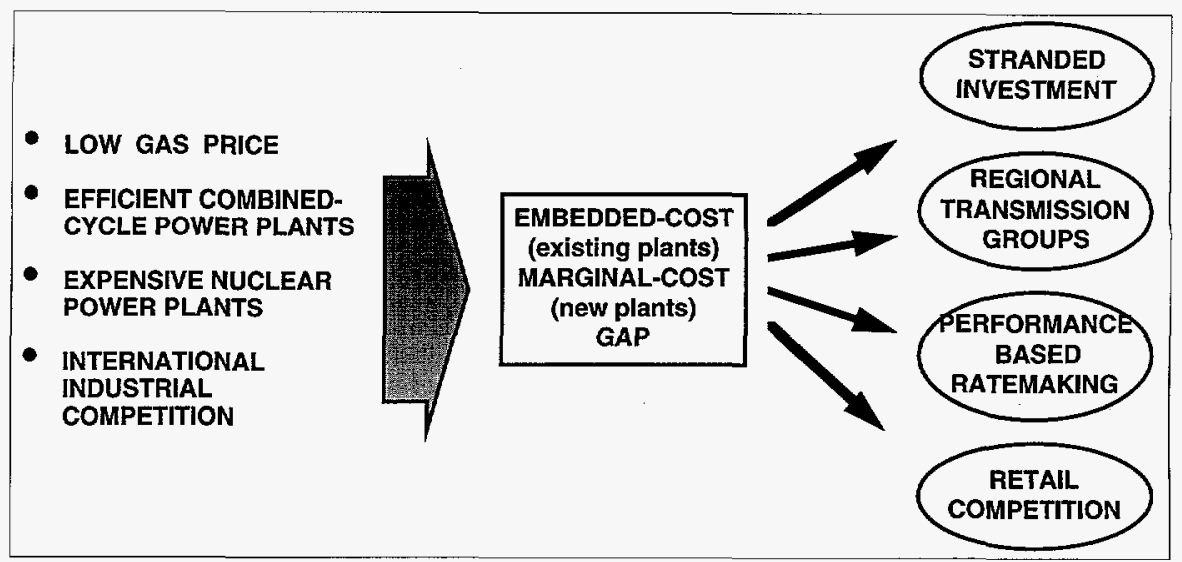

Figure. Winds of change in the U.S. power sector.

industry structure or in a restructured industry with open retail competitionare the key elements of our program.

Over the past two years, we have made written and oral presentations on this theme to the building energy efficiency community, the regulatory community, and the federal government. We have also made presentations to government agencies and other organizations in the European Union, Australia, Mexico, Japan, and the Philippines.

\section{Reference}

Wiel S. The impact of power sector restructuring on building energy efficiency: The role of IRP and DSM. In: Proceedings of the ACEEE 1994 Summer Study on Energy Efficiency in Buildings, August 28-September 3, 1994 . Vol. 6. Washington, DC: American Council for an Energy-Efficient Economy, 1994, pp. 6.251-6.261.

\section{Energy Efficiency, Economics, and Policy Issues}

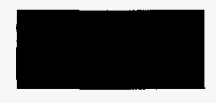

\section{The Effect of Efficiency Standards on Water Use and Water Heating Energy Use in the U.S.: A Detailed End-Use Treatment}

\author{
J.G. Koomey, C. Dunham, J.D. Lutz
}

Water heating is an important end use, accounting for roughly $16 \%$ of total primary energy consumption in the U.S. residential sector. Recently enacted efficiency standards on water heaters and equipment that uses hot water (e.g., dishwashers, clothes washers, showerheads, and faucets) will substantially affect the energy use of water heaters in the future. To assess current and future utility programs and government policies, regulators, resource planners, and forecasters need to understand the effects of these regulations.
Water heating is perhaps the most complicated of all residential energy end uses. Usage behavior varies greatly and depends on ownership of other appliances (e.g., clothes washers and dishwashers), characteristics of these appliances and other water-using equipment, water-inlet temperatures, hot water temperature set-points, and water-use temperatures.

Water heating has generally been analyzed in a haphazard manner, in large part because of its complexity. Measurements, with a few notable exceptions, have failed to capture the important data necessary for truly understanding how hot and cold water are used in U.S. homes. For example, researchers often report the number of gallons per day of hot water use per household, averaged over all households with different appliances. This number is only useful for determining total water-heating energy use and provides no guidance as to what impact different conservation measures might have. It is also of limited usefulness in assessing energy use for water heating in a particular household. The only way to 
assess such issues is to disaggregate total hot water use to reflect its various components.

We disaggregate total hot and cold water use (gallons per day) into their component parts: showers, baths, faucets (flow-dominated and volume-dominated), toilets, dishwashers, clothes washers, and other (landscaping, carwashing, and so on). We then use the end-use breakdown and data on equipment characteristics to assess the impacts of current efficiency standards on hot water use and water heater energy consumption. The Figure shows the results of these calculations for the year 2010.

The guiding philosophy behind this work is that explicit and well-chosen estimates about usage behavior for particular devices (e.g., the number of minutes each person showers per day) can be used to create a "bottom-up" estimate of total usage that is a reasonable portrayal of average water usage. Such detailed bottom-up estimates can be used to assess the effects of policies. In the case of water heating, creating such a disaggregated forecast is the only way to disentangle the effects of the various efficiency standards now affecting this end use.

Usage characteristics of particular
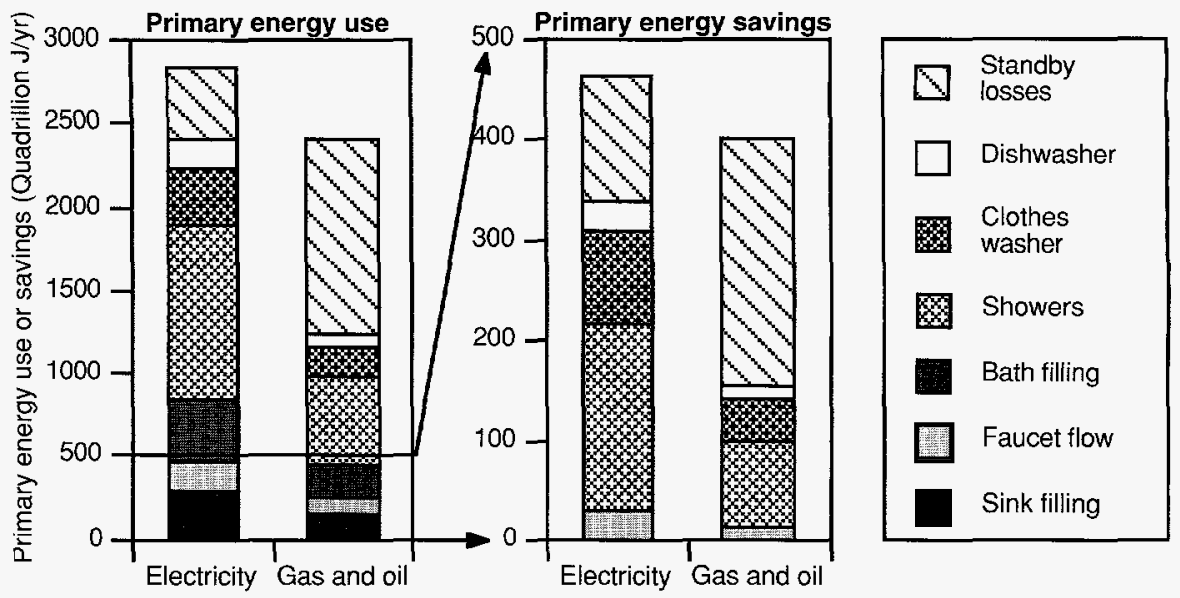

Figure. Projected reference case residential annual primary water heating energy use for the U.S. in 2010 and estimated annual savings in 2010 from flow control and water heater standards. Note: Primary energy for electricity calculated assuming 3.27 joules fuel per joule of electricity.

households may be quite different from the usage assumptions employed in these calculations. Nevertheless, we believe that our first-order estimates crudely represent average water-usage behavior in U.S. homes. We await more detailed data on water usage from the many studies now being conducted by U.S. utilities and others.

\section{Reference}

Koomey JG, Dunham C, Lutz JD. The Effect of Efficiency Standards on Water Use and Water Heating Energy Use in the U.S.: A Detailed End-use Treatment. Lawrence Berkeley Laboratory Report No. LBL-35475, 1994.

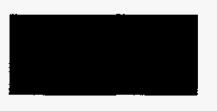

\section{Collaboration with}

\author{
J.G. Koomey, A. Nicholls*, D. Eike*, B. Kinzey*
}

One of the difficulties analysts face is making their data and results accessible to policy-makers. Too often, data that have been laboriously gathered languish in dense technical reports, never finding their way to the people who can best use the information. This collaboration between Pacific Northwest Laboratories (PNL) and LBL was initiated to overcome this problem.

ROADMAP is a software tool designed by PNL. The philosophy behind its creation is that modern database software and a skilled software designer can organize and compile existing data in a way that allows policy analysts who are not computer experts to easily extract relevant information. This tool is designed for DOE's Office of Building Technologies' (OBT) analysts, who are often called upon to answer questions from congressional staff, to defend budget re- quests, and to design new initiatives to meet congressional and executive mandates.

The collaboration with PNL on this project has been fruitful because it builds upon each laboratory's traditional strengths. LBL has a wealth of data on residential energy use and equipment. PNL's DC office directly supports the programmatic responsibilities of OBT analysts and PNL's DC staff is particularly well-attuned to the needs of these analysts. Together, the staffs of these two laboratories are ideally suited to this task.

In FY94, we put LBL data on residential appliance equipment shipments, saturations, efficiencies, and lifetimes into ROADMAP for easy access by OBT staff. We also created an electronic version of DOE's Energy Information Administration's (EIA's) Residential En- ergy Consumption Survey (RECS) data that is vastly more useful than the paper report. Users can now easily query ROADMAP to find out, for example, "How many households in the Northeast with income above $\$ 25,000 / y$ r have gas water heating?" The Figure shows a screen from the electronic version of the RECS database. The data associated with each of the roughly 5000 households in the RECS sample are available for analysis, making the ROADMAP data-analysis tool far more useful than the RECS printed documentation. Users can point and click on various options to choose which data they want to analyze.

We have also created a prototype module for water heating that contains the latest LBL data on water use by end use (hot and cold), water heating energy, cost vs. efficiency, and detergent cost. We continue to improve that module

\footnotetext{
* Pacific Northwest Laboratories, Washington, D.C.
} 
and to create a series of policy-relevant "stories" about water heating that can add context to the numbers shown in the module.

FY95 work will shift to the commercial sector. The first task will be to create a user-friendly electronic version of EIA's Commercial Building Energy Consumption Survey (CBECS). The second task will be to compile existing OBT, LBL, and PNL data in the commercial sector in a form suitable for input to ROADMAP and to work with PNL on the interface design so that OBT can easily access the wealth of data that has been developed over the past few years.

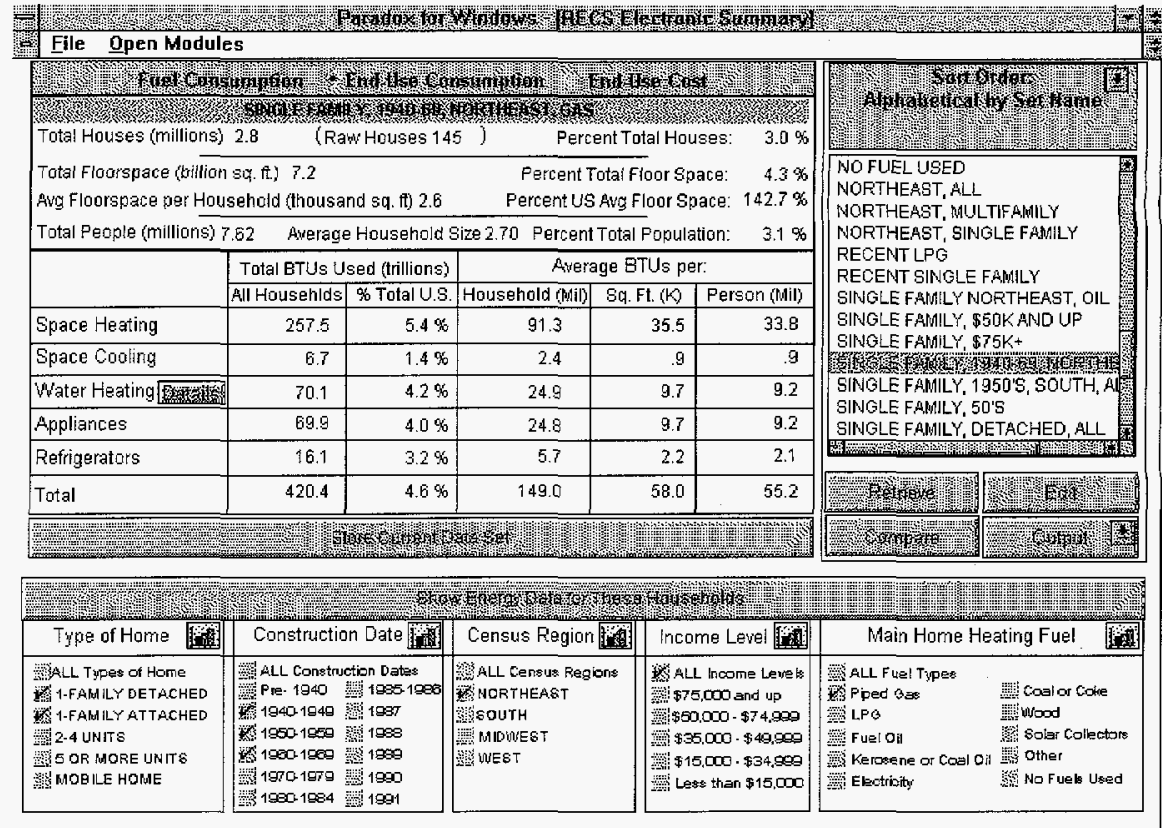

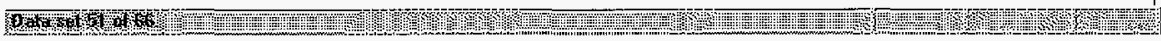

Figure. Sample screen from the ROADMAP software tool.

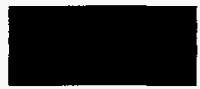

\section{Assessment of Markets for Energy-Efficient Residential Products}

R.E. Brown, J.G. Koomey, C.S. Atkinson, S.E. Bretz
The purpose of this project is to assist the U.S. Environmental Protection Agency (EPA) and the U.S. Department of Energy (DOE) in conducting effective programs that achieve the residentialsector greenhouse-gas stabilization goals of the national Climate Change Action Plan. The project concentrates on voluntary, "market-pull" programs that reduce air pollutant emissions by accelerating the penetration of new or underutilized energy-efficient technologies. These technologies include nearly all residential end uses and four LBLdeveloped technologies: advanced lighting, windows, ducts, and high-albedo surfaces.

This year, we developed a residential market assessment methodology, centered around a geographic information system-based (GIS) analysis tool, and initiated market assessments of ground-source heat pumps, gas furnaces, and gas heat pumps. The analysis methodology employs both energy analysis and marketing research techniques to analyze the market potential for efficient technologies and evaluate alternative program designs to promote these technologies. As shown in the Figure, the market assessment is based on research

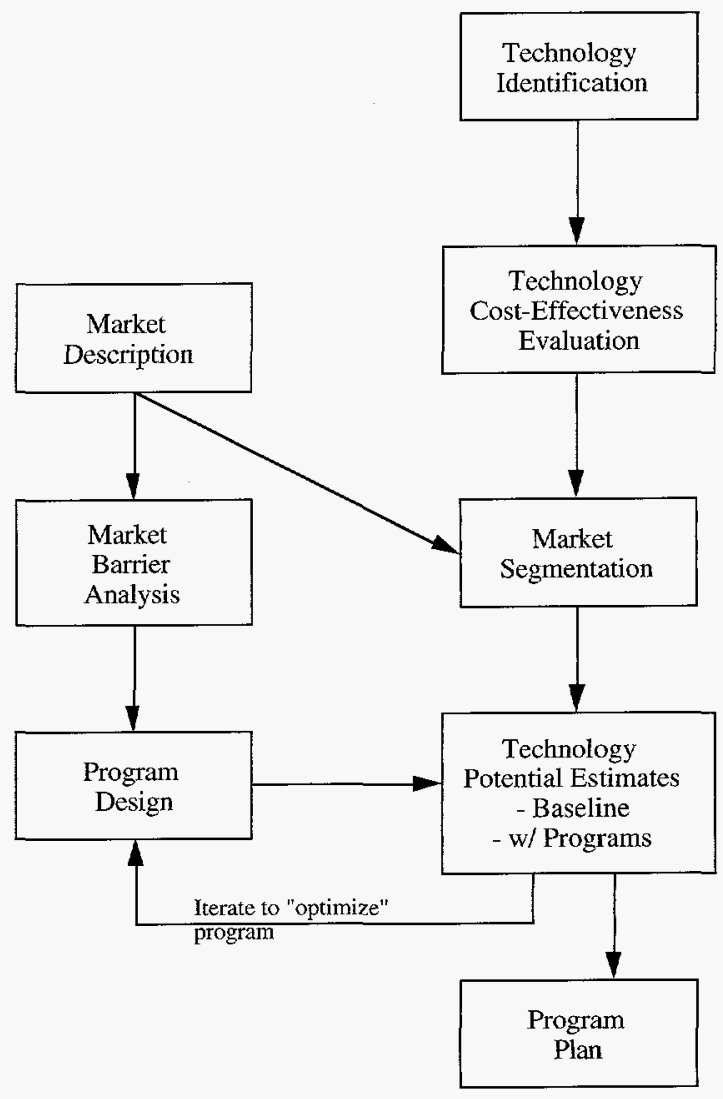

Figure. Market assessment methodology. 
into the ways that residential products are purchased and used, the existing market infrastructure for efficient products, and the market barriers to increased market penetration of these products. We then use the GIS model to identify regions and market segments in which energy-efficient technologies are technically feasible, cost-effective, and acceptable to consumers. The key feature of this model is its use of a detailed disaggregation to distinguish the market potential among regions, house types, demographic groups, and other analysis parameters. Within each market segment, we estimate the potential of efficient technologies to save energy and reduce pollution, both in a business-as-usual scenario and with the implementation of various programs to promote these technologies. Using the GIS, we can present the results in map format or perform further statistical analysis for display in graphs or tabular output. The policy-makers actually implementing the programs (such as EPA or DOE) then use this information to design programs targeted at the most attractive market segments. Candidate programs include coordinated utility incentive and loan programs, product labeling, building market infrastructure, better communications and marketing, home builder initiatives, home energy rating systems and energy-efficiency mortgages outreach, and partnerships with realtors and financiers.

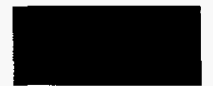

\section{Commercial Data and Forecasting}

\section{O. Sezgen, E. Franconi, Y.J. Huang, J.G. Koomey, M.D. Levine}

In FY94, we finalized our on-going work characterizing the current U.S. commercial floor stock in terms of space-conditioning technologies and cost-efficiency data for these technologies. We also characterized the annual and peak space-conditioning requirements for the building stock. The results will be published together with a companion report on the lighting end use in commercial buildings. This report represents, for the first time, a full compilation of all policy-relevant data for the most important end uses in the commercial buildings sector.

A by-product of the commercial sector space-conditioning study was the characterization of the interactions between lighting and space-conditioning end uses.

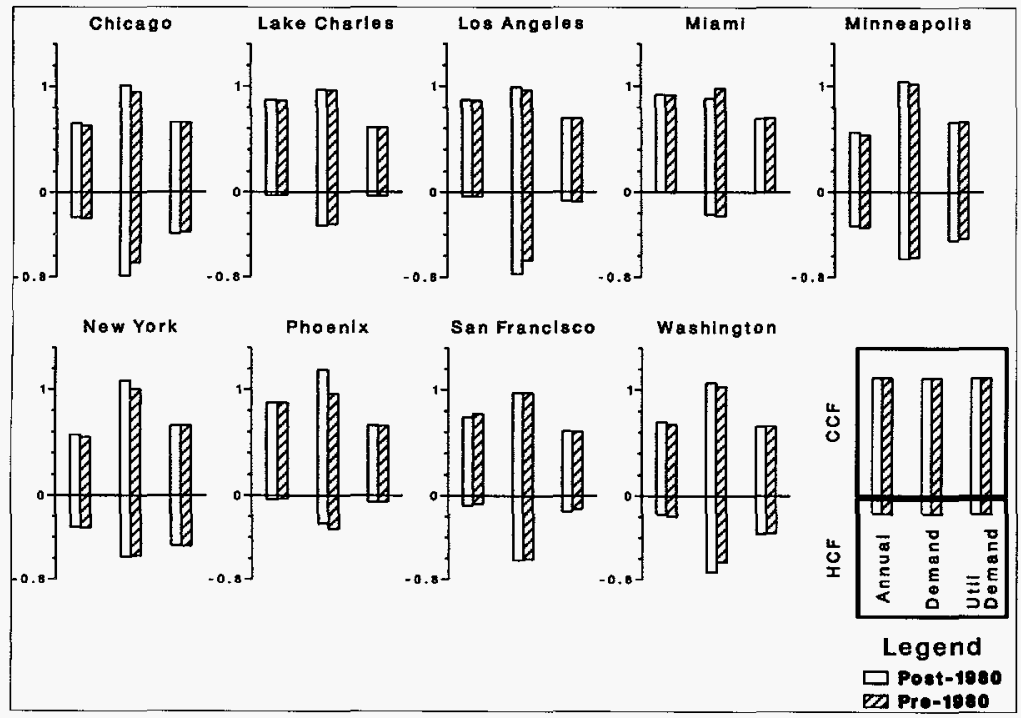

Figure. Heating and cooling coincidence factors (HCF and CCF, respectively) for large office buildings. The annual coincidence factors depict the ratio of the decrease (increase) in annual cooling (heating) loads to the decrease in annual lighting energy. The demand coincidence factors depict the ratio of the change in peak cooling/heating requirements to the change in lighting power density (LPD). The utility-demand coincidence factors depict the ratio of the change in peak heating/cooling requirements during the utility peak hours to $L P D$.
An improvement in lighting equipment efficiency reduces the annual and peak cooling requirements, but also increases the heating requirements. Data relating the reduction in lighting energy to heating/cooling annual and peak requirements for the different building types and climate zones were developed. The Figure characterizes such interactions for large office buildings. The results facilitate the extension of the cost-benefit analysis of lighting measures to include secondary effects of these measures for all of the commercial building types in the different regions of the U.S.

Data development is continuing for the commercial sector office equipment, refrigeration, and water-heating end uses. These data will be incorporated into future versions of the commercial sector forecasting model, COMMEND, developed by the Electric Power Research Institute. The results of these studies will be published in early 1995.

\section{Reference}

Sezgen AO, Huang YJ. Lighting/HVAC interactions and their effects on annual and peak HVAC requirements in commercial buildings. In: Proceedings of the ACEEE 1994 Summer Study on Energy Efficiency in Buildings, August 28-September 3, 1994. Vol. 3. Washington, DC: American Council for an Energy-Efficient Economy, 1994, pp. 3.229-239. Also published as Lawrence Berkeley Laboratory Report No. LBL36524, 1994. 


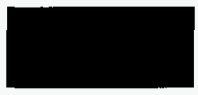

\title{
The AUTO Model
}

\author{
W.B. Davis, K.E. Train ${ }^{*}$,M.D. Levine, K.G. Duleep ${ }^{\dagger}$
}

The Automobile Use, Technologies, and Ownership (AUTO) model is a forecasting tool to analyze the effects of market-based policies toreduce fuel consumption and carbon dioxide emissions of the U.S. private, light-duty vehicle fleet. AUTO was developed under contract withseveral governmentagencies, including the U.S. Department of Energy, the U.S. Environmental Protection Agency, the Energy Information Administration, and the California Energy Commission. These agencies have based substantial policy analysis efforts on the application of AUTO.

AUTO simulates the market for vehicle production, ownership, and use, paying special attention to aspects that determine fuel consumption and carbon dioxide emissions. AUTO is an integrated-market model, with two main components, MPGS (Manufacturer Production of Gasoline Savings) and CARS (Consumer Automotive Response System), which are manufacturer and consumer submodels representing the supply and demand sides of the vehicle market (see Figure). AUTO is a disaggregated model, providing forecasts by year, vehicle subclass and vintage, and household. AUTO provides, in addition to changes in fuel consumption and emissions, a calculation of the effects on production costs, prices, and consumer welfare (in terms of consumer surplus). It is therefore useful for cost-benefit and distributional analysis of vehicle fueleconomy policies.

MPGS (also known as FEM) was developed by K. G. Duleep at Energy and Environmental Analysis, Inc. MPGS is an engineering/economic model that uses a modified cost-effectiveness decision rule to determine if a manufacturer introduces a fuel-economy technology in a particular vehicle subclass. The model starts with 95 actual 1990 vehicle subclasses. Each subclass is specified in detail, with special attention to the vehicle characteristics that determine fuel economy, including horsepower, weight, and installed fuel-economy technologies. MPGS then examines a menu of fuel-economy technology options, their cost, fuel savings, availability, and interactive effects with other technologies, to determine their cost effectiveness. Market penetration of these technologies is then calculated subclass-by-subclass as a function of this cost effectiveness, subject to availability constraints. The output of the MPGS submodel is vehicle characteristics in every forecast year for each of these 95 subclasses, including Corporate Auto Fuel Economy (CAFE) ratings, horsepower, weight, and price.

This output of MPGS is utilized in turn as input by CARS, which is a multinomial logit model of private demand for vehicles and vehicle travel, and thus indirectly for gasoline (and other fuels). CARS predicts these quantities first for an actual household sample that accurately represents the demographics of U.S. households in the base year and then for a household forecast based on projected trends in income, household size, geographic distribution, and other demographic characteristics. For each household, CARS predicts the numbers of vehicles that the household chooses to own $(0,1$, or 2 or more). For each of these options, CARS then calculates the ownership probabilities of all vehicle types input into the model (95 subclasses and 10 vintages). Then CARS predicts the vehicle-miles traveled for each household,

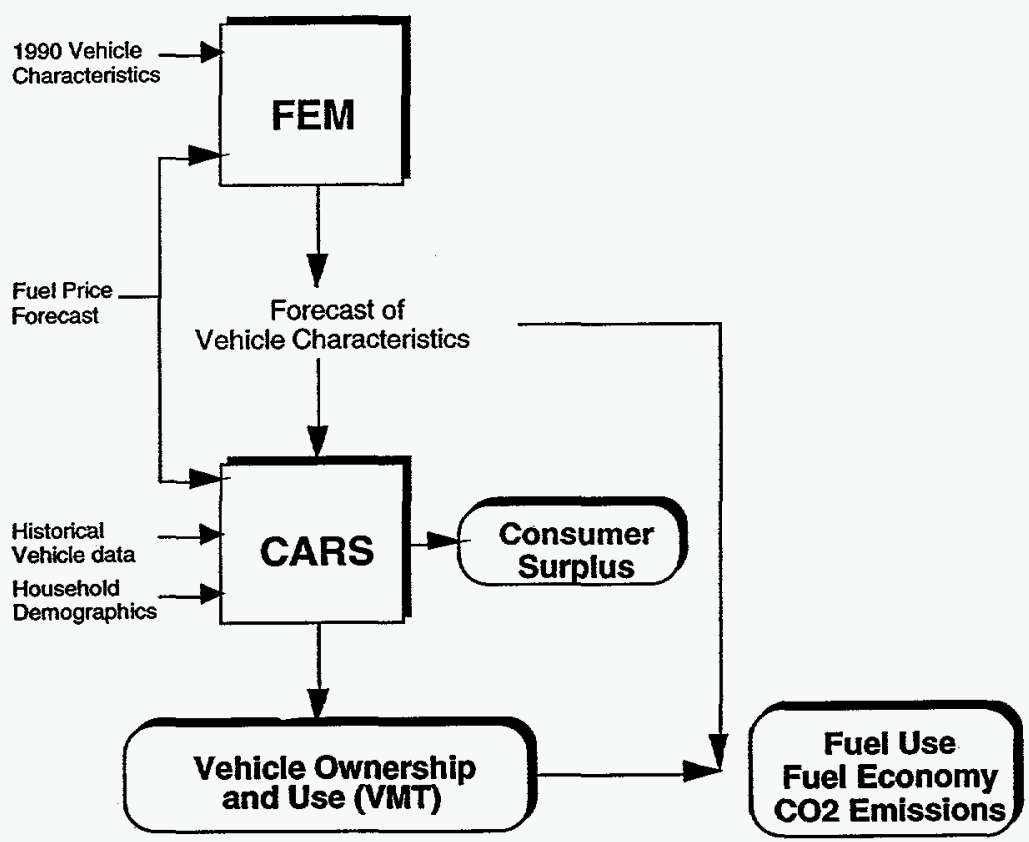

Figure. AUTO overview. given their vehicle ownership choices, and calculates annual fuel use. For this entire choice set, CARS also calculates the consumer surplus of each household. Finally,CARSaggregates theseindividual choices, using the sample weights in the household forecast, to forecast aggregate levels of ownership and use for the entire U.S. vehicle stock.

AUTO can be applied to forecast the impacts of any policy that changes the cost of owning or operating private vehicles. Such policies include feebates, gas taxes, pollution fees, road tolls, CAFE fines, gas-guzzler taxes, pay-at-the-pump auto insurance, or any combination of these. Recently, AUTO has been utilized in an extensive empirical analysis of feebates for the U.S. Department of Energy's Office of Policy.

\section{References}

Duleep KG. NEMS Transportation Sector Model Fuel Economy Model. Arlington, VA:Energy and Environmental Analysis, Inc., 1992.

Train KE. Qualitative Choice Analysis: Theory, Econometrics, and an Application to Automobile Demand. Cambridge, MA: MIT Press, 1986.

\footnotetext{
* Center for Regulatory Policy, University of California at Berkeley.

${ }^{\dagger}$ Energy and Environmental Analysis, Inc., Arlington, VA.
} 


\title{
Analysis of Revenue-Neutral Feebates as a Policy Tool for Increasing Auto Fuel Economy
}

\author{
W.B. Davis, M.D. Levine, K. Train*
}

Fuel economy feebates, a system of fees and rebates structured to encourage the manufacture and purchase of more fuel-efficient vehicles, have been receiving increasing legislative attention as a politically viable alternative to a gasoline tax. This study provides empirical estimates of the impacts of a variety of federal feebates programs. This study serves both as a guide for designing such programs and as an assessment of the impact of feebates relative to other fuel-economy policies for U.S. vehicles.

For this analysis, an econometric model of Automobile Use, Technologies, and Ownership (AUTO) is used to forecast the impacts of six feebate programs on fleet fuel economy and carbon dioxide emissions, as well as on consumer welfare, manufacturer market share, and profit. The impacts are calculated as the difference between each of the six feebate scenarios and a baseline with no feebates.

The analysis finds that low feebates (on the order of 1-2\% of vehicle price) will induce a significant reduction in fuel consumption and carbon dioxide emissions. Feebates are found to result in about a $10 \%$ improvement in on-road fuel economy within 10 years. Improvement in new vehicle fuel economy reaches 13 $18 \%$ for cars and $11-12 \%$ for trucks by the end of the forecast period (2010).

Most of these fuel-economy improvements are the response of manufacturers to feebates. Because feebates make fueleconomy technologies more cost-effective, manufacturers are projected to install more of them in their vehicles. The consumers' response is estimated to be much less important.

While about $25 \%$ of fuel-economy improvements are taken backin increased driving, these fuel-economy improvements result in large reductions in carbon. dioxide emissions. All scenarios are found to result in reductions of 7-8 billion gallons of gasoline per year, which translates into 70-80 million tons of avoided carbon dioxide emissions by 2005.

The fuel-economy improvements that result in these savings bring with them operating cost reductions, which are found to provide net benefit to consumers (see Figure). It is estimated that the peak benefits in several scenarios total over $\$ 10$ billion annually when summed over all households. The consumer surplus benefits accrue more to higher income households, since such households consume more vehicles and travel. Poor households, however, receive a larger proportional increase-the benefit they receive is a larger share of their incomes.

The impacts of feebates on manufacturers are small but negative for domestic manufacturers. Because foreign manufacturers have more fuel-efficient fleets, they initially capture higher feebates. Feebates cause domestic manufacturers to lose a small amount of market share initially. This share-shift is in the neighborhood of $1 \%$ and decreases later in the forecast period. Because feebates areforecast to stimulate sales initially, the in- crease in sales makes up for most of these losses in market share, and the discounted percent change in average annual sales of domestic manufacturers decreases only slightly. Total sales increase, and foreign manufacturers capture a larger share of this increase.

\section{References}

U.S. Department of Energy, Office of Policy. Effect of Feebates on Vehicle Fuel Economy, Carbon Dioxide Emissions, and Consumer Surplus, Technical Report 2. Energy Efficiency in the U.S. Economy Series, Report No. DOE/PO-0031. Washington, D.C.:U.S. Department of Energy, 1995.

Train KE, Davis WB, Levine MD. The design and impact of feebates. Submitted to Economic Inquiry, September 1994.

\begin{tabular}{|l|l|ll|}
\hline $\begin{array}{l}\text { Feebate Price Incentives } \\
\text { Rebates reduce the } \\
\text { price consumers pay } \\
\text { for fuel-efficient } \\
\text { vehicles. }\end{array}$ \\
$\begin{array}{l}\text { Fees increase the price } \\
\text { consumers pay for } \\
\text { inefficient vehicles. }\end{array}$
\end{tabular}$\quad$\begin{tabular}{ll}
\multicolumn{2}{|c|}{$\begin{array}{l}\text { Improved Fuel Economy of Vehicle Fleet } \\
\text { Short-Run Change }\end{array}$} \\
in Sales Mix & $\begin{array}{l}\text { Long-Run Change } \\
\text { in Product Mix }\end{array}$ \\
Available selection of & The selection of new \\
vehicles (including the & vehicles being marketed \\
fuel economy of individual & changes: Manufacturers \\
models) is unchanged, & make vehicles that are \\
but price incentives & more fuel-efficient \\
encourage consumers to & because the resulting \\
purchase the cheaper, & increase in the feebates \\
more fuel-efficient & helps pay for additional \\
vehicles. & fuel-economy technology. \\
\hline
\end{tabular}

Figure. How feebates result in a more fuel-efficient fleet of vehicles.

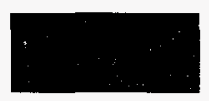

\section{Pay-As-You-Drive Auto Insurance as a Means of Reducing Greenhouse Gas Emissions}

\section{T. Wenzel}

As part of the U.S. Climate Change ActionPlan, a special federal advisory committee has been meeting to discuss various mechanisms to reduce greenhouse gas emissions from the transportation sector. One such mechanism, Pay-As-You-Drive automobile insurance (PAYD), would transfer a portion of fixed automobile insurance premiums to variable charges. We conducted a qualitative analysis of various PAYD systems proposed in California in support of insurance reform and analyzed the issues involved in adopting PAYD at a national level.

PAYD charges can be collected either forevery gallon of gasoline purchased (payat-the-pump insurance) or for every vehicle-mile driven (odometer-based annual registration fees). By transferring a portion of insurance costs from fixed to variable costs, PAYD policies would give an economic disincentive to consumers to drive (seeFigure). To the extent that PAYD reduces gasoline consumption or vehicle

* Center for Regulatory Policy, University of California at Berkeley. 


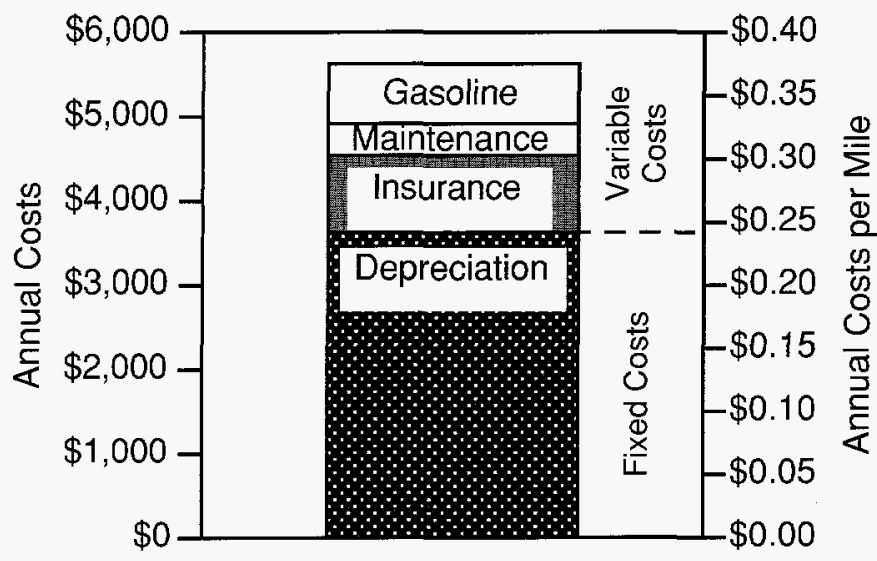

Figure. PAYD would nearly double the variable cost of driving.

miles traveled (VMT) directly, it may also address a host of problems such as emissions of greenhouse gases and air pollutants, as well as traffic congestion. In addition, PAYD would reallocate insurance premiums more equitably by requiring uninsured drivers to purchase insurance and by basing premiums on a better measure of accident frequency: gallons purchased or miles driven. The primary goal of several PAYD systems recently proposed in California has been to reduce average insurance premiums, rather than reduce VMT, fuel consumption, or vehicle emissions. However, interest groups, most notably the insurance industry and trial lawyers, havesuccessfully prevented adoption of PAYD in California.

We conducted an extensive review of the literature and summarized analyses of the impact of PAYD on national VMT, fuel consumption, and insurance provision. Research by the insurance industry indicates that location of vehicle registration, driving history, and annual miles driven are the three variables that best explain exposure to accidents. A PAYD system incorporating these three variables would consist of a per gallon surcharge of about $\$ 0.50$ coupled with annual registration fees that would vary based on driving history and location of registration. Such a system would introduce a better measure of accident exposure, while retaining more traditional insurance-rating variables. By requiring uninsured motorists to purchase insurance, PAYD would result in a small reduction in average premiums. However, otherinsurance reforms, such asadoption of strong restrictions on the ability to pursue "pain and suffering" lawsuits (nofault insurance), could be included to further reduce average premiums.

Insurance regulation is the jurisdiction of state governments. Therefore, implementing PAYD nationally involves developing incentives to encourage states to adopt a PAYD system that meets federal objectives. Such incentives might include allowing states to claim resulting reductions in pollutant emissions toward meeting their obligations under the Clean Air Act, restructuring Highway Trust Fund allocation formulas to benefit states that adopt PAYD, and instituting a revenue-neutral national gas tax rebated back to states that adopt PAYD. Future research will involve more detailed analysis of alternative incentives to promote PAYD.

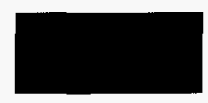

Research to Improve the Modeling of In-Use Vehicle Emissions
During the past 30 years, U.S. vehicle emission standards have reduced tailpipe volatile organic compounds and carbon monoxide emissions by $96 \%$ and oxide of nitrogen emissions by $75 \%$. Nevertheless, motor vehicles continue to account for a large share of pollutant emissions in most urban areas of the U.S. Ambient pollutant-concentration monitoring in roadway tunnels indicates that the computer models used to estimate emissions from motor vehicles underpredict in-use emissions. Without a better understanding of the size and sources of the motor vehicle emission inventory, regulators cannot craft cost-effective policies to reduce emissions and improve air quality.

We assembled the series of models used to develop regional emission inventories in the Southern California Air Ba$\sin$. On the basis of our experience with these models as well as a review of the literature and attendance at several conferences and workshops on the limitations of the models, we have identified several new areas of research needed to improve the accuracy of air-quality and emission-factor modeling.

The current emissions models are based on the driving cycles of the Federal Test Procedure (FTP), which do not account for such operating conditions as high engine loads due to high speeds, hard accelerations, climbing grades, warm starts (i.e., between 10 and 60 minutes since the engine was last run), and accessory use (see Figure). In addition, the models do a poor job of estimating vehicle activity (speed and acceleration profiles) and of estimating the effectiveness of vehicle inspection and maintenance

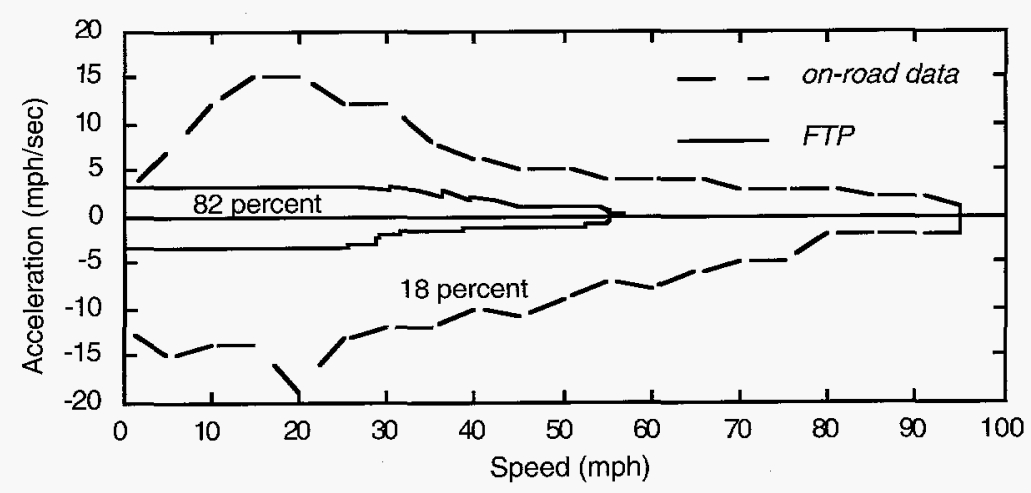

Figure. Area plot showing that $18 \%$ of on-road driving behavior is outside the envelope of the FTP. 
programs to enforce in-use emission standards.

Several agencies and researchers have recently collected real-time data on in-use emission rates using improved vehicle dynamometers, infrared remote sensing devices, and on-board emission monitors. Using these data, we are investigating several ways to improve vehicle- emission models, including an in-depth analysis of vehicles with malfunctioning or tampered emission-control systems, an analysis of separate emission factors for individual modes of vehicle operation (acceleration, deceleration, cruise, and idle), estimations of emissions based on vehicle fuel consumption rather than vehicle speed, and the development and use of a durable, inexpensive sensor to measure in-use emissions from a large sample of vehicles. Improved vehicleemission models will allow more rational decisions on the cost-effectiveness of alternative strategies to improve air quality, as well as better quantification of emissions from new vehicle technologies such as hybrid electric vehicles.

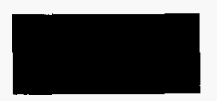

\section{Analysis of the Performance of Markets for Energy Efficiency}

A.H. Sanstad, W.H. Golove, E. Hirst, * R.B.Howarth, K.B. Janda, J.G. Koomey, M.D. Levine, J.E. McMahon, L.J. Schipper, R.S. Sonnenblick

Integrated policy analysis is a priority in the Energy Analysis Program. EAP researchers work on several fronts to meet the complex challenge of linking engineering and economic approaches to analyzing energy efficiency. A very important-and imperfectly understoodlinkage concerns the performance of markets for energy efficiency, including consumer decision-making, the role of various intermediariesin the decision-making process, and manufacturers' decisions. Our efforts in 1994 included both empirical and theoretical studies and spanned a range of topics. One accomplishment was the October 1994 special issue of the journal Energy Policy, "Markets for Energy Efficiency" co-edited by EAP staff. This important issue contains state-ofthe-art contributions by technologists, economists, and behavioral scientists on contrasting views of markets for energy efficiency.

\section{Quantitative Assessment of Markets and Policies}

The policy debate over energy efficiency frequently focuses on the existence and extent of the "efficiency gap": the degree to which cost-effectiveenergyefficiency opportunities are overlooked, or even ignored, in the absence of policy intervention. This debate is often conducted in theoretical or ideological terms, obscuring the empirical underpinnings on which an effective policy analysis must be based. Several of our recent efforts have sought to re-emphasize the empirical evidence of the energy-efficiency gap in the United States and the success of policies to overcome it.

We developed a framework to quantify the effects of market failures associ- ated with energy efficiency. This framework uses market data and applies engineering-economic methods to demonstrate the existence of market failures and sub-optimal adoption of specific energyefficient technologies. Using this framework, we showed empirically how market failures have impeded the diffusion of energy efficiency in several technologies, including refrigerators and fluorescent light ballasts (Koomey and Sanstad 1994).

Two of the key policy approaches to correcting market failures related to energy efficiency-demand-side management (DSM) and appliance efficiency standards-have had a significant impact on promoting the cost-effective adoption of efficient equipment. We reviewed the rationale for these policies and the evidence documenting their costs and benefits. Appliance standards, for example, have yielded a benefit-cost ratio of nearly 2.5 exclusive of their positive environmental impacts and without reducing energy services or consumer choices (Levine et al. 1994).

Following applications of the willingness-to-pay theory to the realm of DSM, we investigated customer decisions to participate in DSM programs and cus- tomer costs associated with program participation. Survey data collected by a Northeastern utility provided empirical evidence that consumers systematically underestimate the value of energy-efficient equipment, suggesting an important role for DSM as a means of alleviating market imperfections. We also found little evidence that additional costs are incurred by program participants. Customers who participate claim to be more likely to install additional efficient equipment after learning about the technology through the program (see Figure 1). These results suggest that the industry give additional consideration to the potential for DSM programs to transform markets. Ignoring DSM's ability to transform markets can result in the underestimating of the benefits of the utility DSM program, possibly by a considerablemargin (Levine and Sonnenblick 1994).

\section{"Discount Rates" and the Welfare Economics of Energy Efficiency}

Energy researchers have often documented that investments in energy-efficient technologies yielding rates of return well above those available on standard financial instruments are routinely passed up by households and firms. In other
Would you have installed the equipment in 1992 without a rebate?

Now that you have had experience with measure, would you choose to purchase this equipment without a rebate?

Figure 1. Participants' willingness to install energy-efficiency measures.

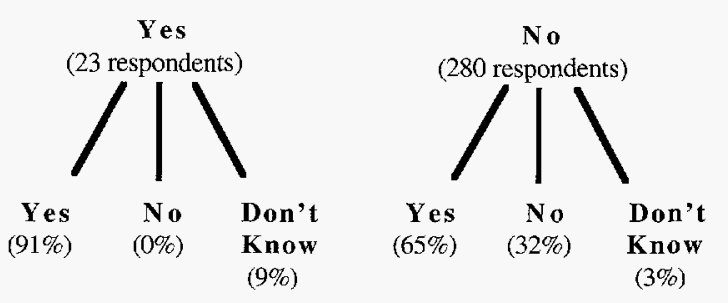

$(3 \%)$

* Oak Ridge National Laboratory, Oak Ridge, TN. 
studies, consumers reveal high "implicit discount rates" in their market decisions on the costs and benefits of energy efficiency. We reviewed this literature and concluded that attempts to explain this empirical pattern in terms of rational behavior and efficient markets are not convincing. In addition, we developed a simple model showing how, in the presence of imperfect information regarding the characteristics of energy-efficient technology, government intervention to promote energy-efficient technology could yield clear improvements in consumer welfare (Howarth and Sanstad 1994) (see Figure 2).

Another challenge to energy-efficiency policies has been the claim that the market barriers cited as justification for such policies are merely "normal" features of a competitive market and do not warrant intervention. We examined and refuted this critique, showing that engineering and economic approaches to energy analysis can to a great extent be reconciled with standard economic concepts and the basic framework of welfare economics. From this perspective, a number of market "barriers" cited by technol-

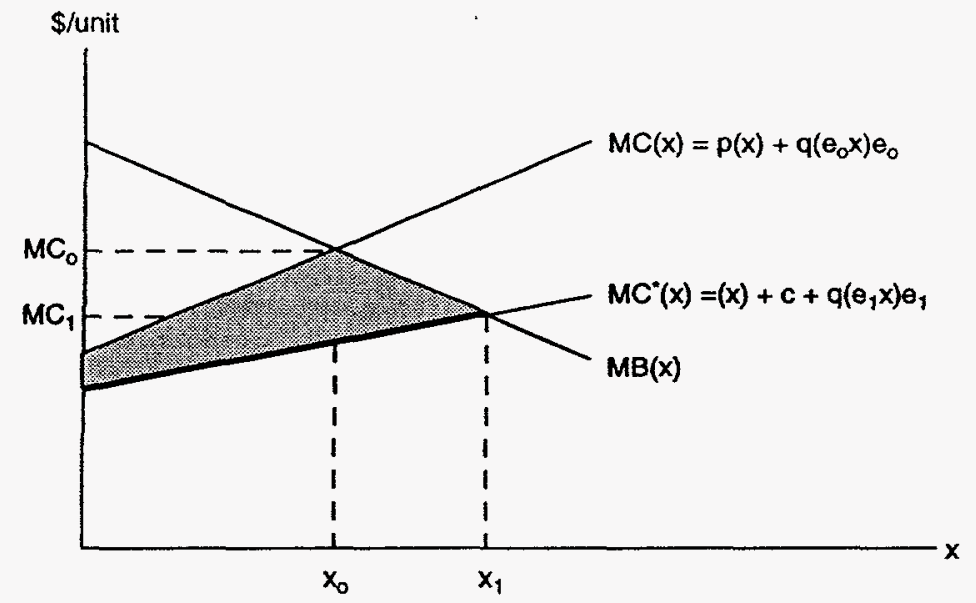

$$
\begin{aligned}
& M B=\text { marginal benefit } \\
& M C=\text { marginal cost } \\
& x=\text { units of equipment } \\
& e_{0}=\text { efficiency level before standard } \\
& e_{1}=\text { efficiency level after standard } \\
& p(\bullet)=\text { price of equipment } \\
& q(\bullet)=\text { price of energy } \\
& c=\text { cost due to standard }
\end{aligned}
$$

ogy analysts can be seen as market "imperfections" as defined by economists. In particular, problems associated with limited or imperfect information, transaction costs, and bounded rationality can have a substantial effect on the market mechanism's efficacy in promoting adoption of cost-effective energy-efficient technologies (Sanstad and Howarth 1994a).

Further work in this vein addressed the following problem: If the primary failure in the market for energy efficiency is an information failure, economic theory tells us that we might expect either overor under-investment in energy efficiency. Do we have evidence to support claims that total investment in energy efficiency is below the economically efficient level? On a sector-by-sector basis, characteristics of investor behavior and of the energy-efficiency markets were examined to determine the direction of their effect on investment levels with respect to the economically efficient level. Although certain effects were identified that would tend to promote over-investment, the substantial majority of features were found to lead unambiguously to underinvestment (Golove 1994).

\section{$\mathbf{x}$}

Figure 2. Welfare analysis of an energy-efficiency standard.

\section{Rationality and Decision-Making}

The nature of consumer decisionmaking regarding energy has long been one of the most controversial topics in energy analysis. We studied several key methodological issues underlying the long-standing debate over whether consumers make energy-related decisions in a manner consistent with standard economic models. Behavioral energy researchers and technology analysts have often argued that the economic paradigm of consumer behavior fails to capture, or even distorts, consumers' decisions to invest in energy-consuming equipment. Energy economists, by contrast, have suggested that energy decisions are indeed economically rational if analyzed correctly. The broader implications of this debate are relevant when considering a variety of policies and programs, including DSM and appliance efficiency standards.

We detail the distinctions between rational choice theory and alternative approaches, using examples drawn from the literature on energy-related decisionmaking. Particular attention was given to the concept of bounded rationality and its use as an organizing principle for a range of findings on consumer behavior and energy. We found that the evidence does support the case for skepticism regarding standard economic models of behavior and reviewed efforts to extend this paradigm to account for various deviations from perfect rationality. We also assessed implications of bounded rationality in energy decisions for policies and programs (Sanstad and Howarth 1994b).

Another study examined two electric utility research projects designed to demonstrate the "real world" feasibility of energy-efficiency measures (EEMs) for buildings. Although EEMdecisions were treated in these projects as if they were based exclusively on engineering-economic criteria, additional analysis pointed to the presence of other institutional and cultural factors that influence the EEM selection process. Factors such as aesthetics, the inertial effects of common practice, and professional liability forced the rejection of cost-effective measures and supported the selection of more conventional (but less efficient) alternatives. Because the engineering-economic criteria used to estimate EEM costs and savings do not incorporate cultural or institutional factors, any non-economic, non-technical influence can complicate 
the capture of predicted benefits. To address the question of how these "other" factors affect EEM decisions and therefore conservation potential, we investigated the EEMs not installed and developed a typology of rejected EEMs. Figure 3 shows the distribution of accepted and rejected measures for two houses. Of the approximately 100 measures considered for each building, more than half were rejected. Most of the rejected measures were discarded for technical or economic reasons, but a handful of feasible, costeffective measures were eliminated for "other" reasons. The purpose of this research is not to identify more savings than the engineering-economic calculations suggest, but to promote a path that will help planners achieve the most from their predictions (Janda 1994).

\section{References}

Golove WH. Are investments in energy efficiency over or under?: An analysis of the literature. In: Proceedings of the ACEEE 1994 Summer Study on Energy Efficiency in Buildings, August 28-September 3, 1994. Vol. 1. Washington, DC: American Council for an EnergyEfficient Economy, 1994, pp. 1.37-1.44.

Howarth RB, Sanstad AH. 'Discount Rates and Energy Efficiency. Paper pre-
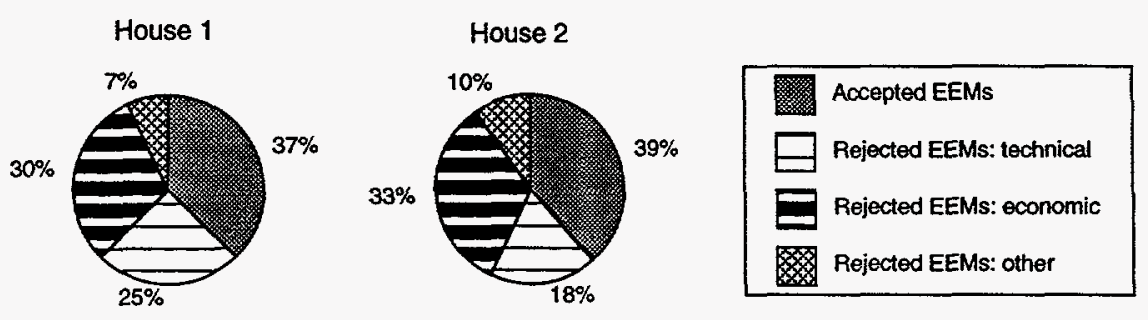

Figure 3. Distribution of EEM decisions in two houses.

sented to the Western Economics Association International Conference, Vancouver, British Columbia, Canada, July 3, 1994.

Janda KB. Bounded decision-making and analytical biases in demand-side management. In: Proceedings of the ACEEE 1994 Summer Study on Energy Efficiency in Buildings, August 28-September 3, 1994. Vol. 1. Washington, DC: American Council for an Energy-Efficient Economy, 1994, pp. 1.75-1.84.

Koomey JG, Sanstad AH. Technical evidence for assessing the performance of markets affecting energy efficiency. Energy Policy: Special Issue on Markets for Energy Efficiency 1994;22(10):826-832.

Levine MD, Hirst E, Koomey JG, McMahon JE, Sanstad AH. Energy Efficiency, Market Failures, and Government Policy, Lawrence Berkeley Labo- ratory LBL Report No. LBL-35376 and Oak Ridge National Laboratory Report No. ORNL/CON-383, 1994.

Levine MD, Sonnenblick RS. On the assessment of utility demand-side management programs. Energy Policy: Special Issue on Markets for Energy Efficiency 1994;22(10):848-856.

Sanstad AH, Howarth RB. "Normal" markets, market imperfections, and energy efficiency. Energy Policy: Special Issue on Markets for Energy Efficiency 1994a;22(10):811-818.

Sanstad AH, Howarth RB. Consumer rationality and energy efficiency. In: Proceedings of the ACEEE 1994 Summer Study on Energy Efficiency in Buildings, August 28-September 3, 1994. Vol. 1. Washington, DC: American Council for an Energy-Efficient Economy, 1994b, pp. 1.175-1.184.

\section{International Energy and Environmental Issues}

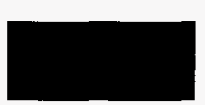

\section{Long-Term Trends in Manufacturing Energy Consumption}

W. Golove, L.J. Schipper, R. Howarth

This work extends and develops efforts made in previous years to decompose total U.S. manufacturing energy consumption into structural, activity, and, intensity components. Two important contributions of the current effort will be to extend the analysis both by gathering and using more current data and including calculations of carbon emissions. In addition, alternative indicators of manufacturing output-other than the traditional Gross Domestic Product-will be evaluated as activity measures.

This method of analysis is valuable because it enables us to separate the effects of economic shifts from changes in technical energy efficiency. Preliminary results suggest that total manufacturing energy consumption, given 1973 base year levels of manufacturing activity and industry structure, but 1991 intensities, would have been approximately $30 \%$ less than observed consumption in 1973 and $10 \%$ lower than actual consumption in 1991 (see Figure). Holding activity and intensity constant at base year levels with 1991 industry structure would have produced a consumption level $20 \%$ below 1973 actual and approximately equal to 1991 actual levels. However, holding structure and intensity at 1973 levels and allowing activity to increase to 1991 levels would have increased total manufacturing energy consumption 50\% over 1991 actual levels of consumption.
These changes translate into changes in $\mathrm{CO}_{2}$ emissions as well. Although there are additional factors contributing to $\mathrm{CO}_{2}$ emission levels, manufacturing activity at 1991 levels with 1973 structure and intensity would have yielded almost $50 \%$ more $\mathrm{CO}_{2}$ emissions than what was actually observed.

We have recently acquired data that will enable a comparison to be made between manufacturing energy consumption patterns in periods of relatively stable energy prices and those during periods of rising prices. This analysis will aid our understanding of the manufacturing sector's response to changes in energy prices, a key variable in the development of effective energy policy. 


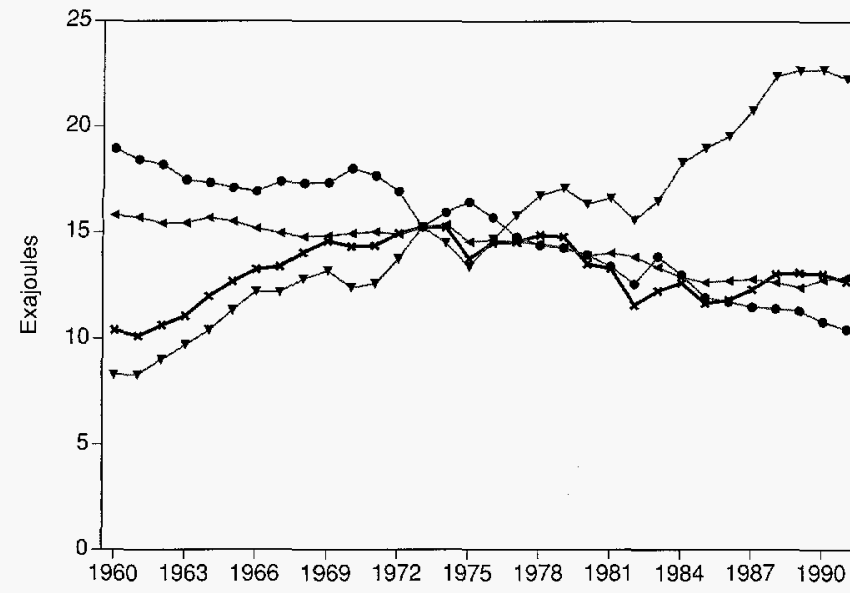

$$
\begin{aligned}
& \rightarrow-\text { Actual } \\
& \leftarrow \text { Activity Effect } \\
& \rightarrow \text { Structure Effect } \\
& \rightarrow \text { Intensity Effect }
\end{aligned}
$$

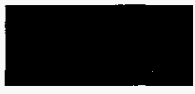

\section{Land Use, Urban Design, and Urban Travel}

E. Deakin, N. Kiang, R. Steiner, L.J. Schipper

The mix of land uses, the pattern and grain of their arrangement, and the density of employment and population are well-known correlates of urban travel patterns. Household and personal characteristics including size, income level, occupation, age, and sex of individual members are also key determinants of travel. The qualities of the transportation supply - the availability and level of transit service and auto transport, the presence or lack of facilities for walking and cycling-also are important. A group of faculty researchers and students at UC Berkeley and LBL have been sorting out the contributions of these factors during the past year.

Three research approaches are being used. One investigates travel patterns at the neighborhood scale as a function of urban design characteristics and population/user characteristics. A second research direction uses household travel diaries and transportation network data to explore travel patterns on a larger, regional scale. The third research thrust is to compare land-use and transportation characteristics across regions of the U.S. and Western Europe.

At the neighborhood scale, research to date has focused on travel characteristics in districts with pedestrian and transit amenities. Over the past year, we have surveyed shoppers and merchants in a sample of community and neighborhood shopping centers in the San Francisco Bay Area, to identify the market area served by these centers and to assess the extent to which bus or rail transit and pedestrian amenities affected travel choices. Preliminary findings suggest that the presence of transit plays only a modest role in shoppers' travel. Surveys will be conducted in additional shopping areas and will be extended to area residents in 1994-95.

At the regional scale, we have assembled data from a number of U.S. and Canadian metropolitan areas and in 199495 will perform detailed analyses of travel patterns as a function of socioeconomic and land-use characteristics. Both socioeconomic and geographic characteristics will be used to identify market segments and to explore the relative contribution of personal and household characteristics and place characteristics in the ob- served travel patterns. For example, the Figure shows the amount of car travel per household as a function of household income and the density of the neighborhood where the household is situated. Note that for a given income, those grouped in "high-density" areas use cars less than those in "low-density"; at the same time, note that the entire income range is associated with a wide variation in travel, just as would be the case if we plotted the range of residential densities. Both income and residential density are important determinants of household travel.

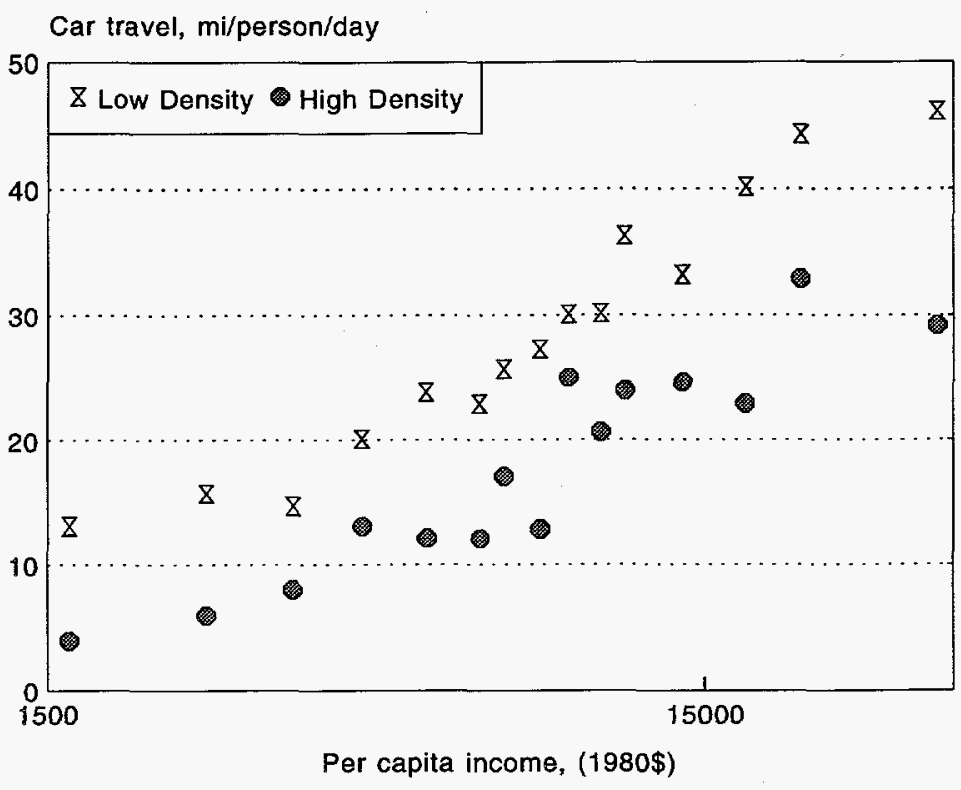

Figure. Income and daily car travel per person, San Francisco Bay Area, 1991. 


\title{
People on the Move: A Comparison of Travel Patterns in OECD Countries
}

\author{
L.J. Schipper, M.J. Figueroa
}

We analyzed national surveys of individual travel in the U.S. and six other industrialized countries--theU.K., theNetherlands, the former West Germany, Sweden, Norway, and Denmark. All surveys had been taken between 1989 and 1993; while that for Sweden was carried out in 1984.

Results show that per capita travel in the U.S., measured in passenger-kilometers, is $75 \%$ higher than travel in Europe. However in all countries, approximately $30 \%$ of trips and $25 \%$ of travel are to and from work; travel for family business takes between $25 \%$ and $35 \%$ of total travel, while the remaining share is devoted to travel during free time and vacation. The Figure shows that U.S. travel to and from work is close to average for the countries studied, but U.S. travel for other purposes is considerably greater than in Europe.

By car Americans travel almost twice as much as Europeans. Europeans travel more than Americans by rail or bus, while Americans travel up to ten times farther by domestic airplane. In comparing modal choice, trip frequency, and trip length by purpose, we found that the U.S. stands out in many ways. Automobiles have the largest share of all trips and all travel, most strikingly for trips to work-around $90 \%$

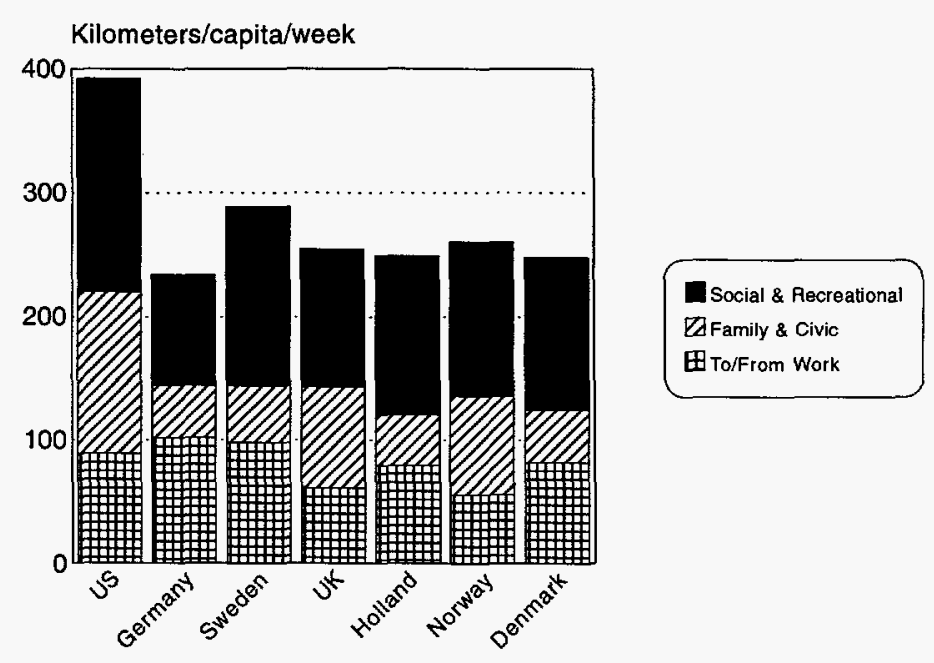

Figure. Travel by purpose.

vs. typically $60 \%$ in Europe. However, we found that the dominance of the automobile is not becausetriplengths arelonger in the U.S., but rather because trip frequency is higher in the U.S. Indeed, the average length of a trip by car was relatively uniform, around $13-15 \mathrm{~km} /$ trip, across the countries studied.
In future work, we will analyze changes in travel patterns in each country over time and then focus more closely on surveys of travel in cities or regions. We will then be better able to measure the impact of land use, the provision of alternatives to automobile use, and other factors on total travel and modal mix.

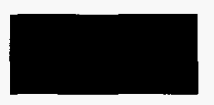

\section{$\mathrm{CO}_{2}$ Emissions from Passenger and Freight Transportation: A Historical Decomposition of Trends from 1973 to 1992}

\section{L.J. Schipper, L. Scholl}

Using a database that we have assembled and standardized from a very large variety of sources, we estimated $\mathrm{CO}_{2}$ emissions from travel and freight activity in the U.S., Japan, and seven European countries between the early 1970 s and 1992. We found that automobiles and freight trucks were the dominant source of emissions in every country. Surprisingly, only in the U.S. were 1992 total emissions close to their 1973 level. In other countries, total emissions rose $10 \%$ to $50 \%$ over 1973 values (see Figure).

We performed a decomposition of these changes for both travel and freight. This decomposition permits us to examine how a change in any one factor can affect total emissions. Emissions in any one year can be decomposed into the product of (total travel or freight activ- ity) $\times$ (share of activity by mode) $\times(e n-$ ergy intensity of each mode in energy/ passenger- $\mathrm{km}$ or tonne- $\mathrm{km}) \times\left(\mathrm{CO}_{2}\right.$ intensity of the energy used in each mode). $\mathrm{CO}_{2}$ intensity reflects the mixes of both oil products and fuels to generate electricity. These mixes have small but observable impacts on total emissions, since the $\mathrm{CO}_{2}$ intensity (in $\mathrm{CO}_{2}$ per unit of energy) varies only slightly among oil products, while the overall share of electricity in transportation fuels and its contribution to $\mathrm{CO}_{2}$ emissions are small.

When we perform this decomposition on travel, we find that the overall level of travel alone boosted emissions by $36 \%$ in the U.S. and by $98 \%$ in Italy. Shifts in modal mix decreased emissions by $4 \%$ in Denmark, but raised them by $20 \%$ in Japan. Changes in fuel mix had a small upward impact on emissions.
Changes in modal energy intensities had a small upward impact on emissions in most countries except the U.S., where a dramatic decline in the energy intensity of automobile travel ( $20 \%$ decrease in energy/ passenger-km between 1973 and 1992) reduced overall energy use and subsequent $\mathrm{CO}_{2}$ emissions significantly.

For freight, both overall activity and shifts from rail to trucks boosted $\mathrm{CO}_{2}$ emissions in every country. The energy intensity of trucking fell in Japan, Norway, and the former West Germany only. Intensities of rail and shipping fell in some countries, resulting in a net decrease in overall energy intensity and $\mathrm{CO}_{2}$ emissions in the U.S., the U.K., Norway, Japan, and Germany. The shift from gasoline to diesel trucks in most countries boosted $\mathrm{CO}_{2}$ emissions slightly, but in the U.S., the Nordic countries, and 


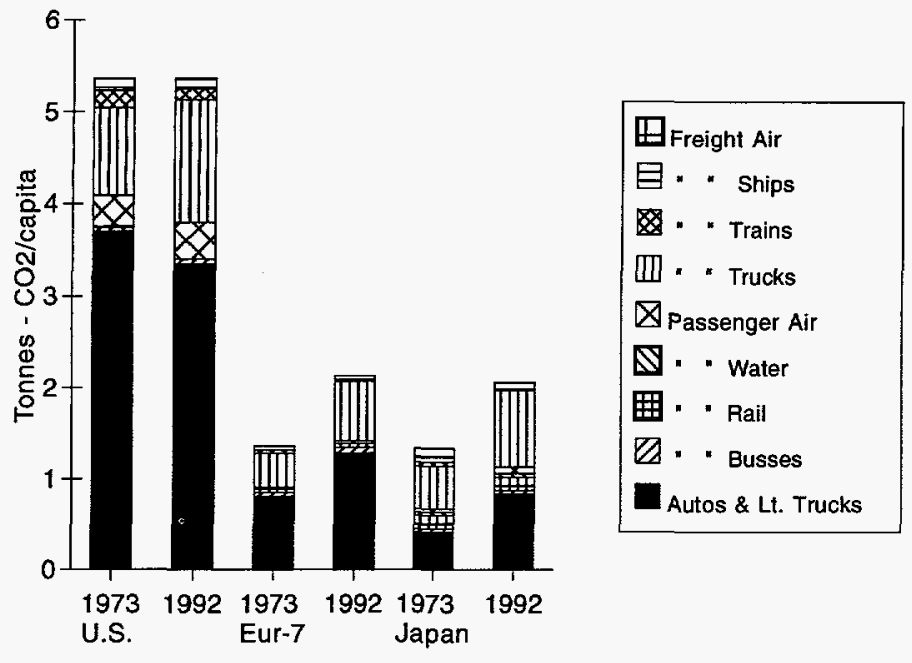

Figure. $\mathrm{CO}_{2}$ emissions from OECD transportation in 1973 and 1992. the U.K., small gasoline trucks remained important, raising the energy intensity of freight.

Our findings present a challenge to policymakers concerned with $\mathrm{CO}_{2}$. In general, rising activity and shifts to autos, trucks, and air traffic boosted $\mathrm{CO}_{2}$ emissions from transportation. Fuel mix per se had little effect on emissions; while energy intensities had only a small impact outside the U.S. The factors that lower energy intensities-higher fuel prices, and, in the U.S., the Corporate Automobile Fuel Economy standardshave lost much of their effectiveness, and consequently, 1992 energy intensities are relatively flat or only decreasing slowly. Hence $\mathrm{CO}_{2}$ emissions from transportation can be expected to increase. In future work, we will explore ways in which these trends might be altered.

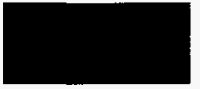

\section{Energy Use and $\mathrm{CO}_{2}$ Emissions from Transportation in Japan}

\author{
N. Kiang, L.I. Schipper
}

Because of its relatively low per capita energy use or low ratio of energy use to gross domestic product (GDP), Japan is often characterized as an "energy-efficient" country. To ascertain the validity of this, we analyzed the structure of transportation activity, energy use, and consequent $\mathrm{CO}_{2}$ emissions in Japan between 1965 and 1992. What we found tends to contradict the popular image of Japan as highly energy-efficient.

Driven by rapid economic growth, travel and freight activity grew dramatically over the entire period. The number of cars per person increased by $130 \%$ (i.e., by a factor of $230 \%$ ) between 1973 to 1991 . At thesametime, thestructure of travel shifted markedly; whereas in 1973, fully $62 \%$ of travel in Japan was on bus, rail, or ferry, by 1992 fully $50 \%$ of all travel was by car and $5 \%$ by air. This shift alone raised per capita energy use for travel by more than $25 \%$. Except for air travel, energy intensities of travel modes increased slightly, while the overall volume of travel increased $62 \%$. Despite growth in the number of very small mini-cars, the average car in Japan in 1991 consumed barely $5 \%$ less energy $/ \mathrm{km}$ than it did in 1973, since the sizeand power of automobiles have increased markedly. These changes led to a doubling of energy use between 1973 and 1992, a slower pace than the tripling that took place between 1965 and 1973, but still an impressive change.
For freight the trends were somewhat different. Energy use increased 2.5 times between 1965 and 1973, thence only 63\% more by 1992 , largely as a result of the slow growth in the volume of domestic freight, which lagged far behind growth in GDP.

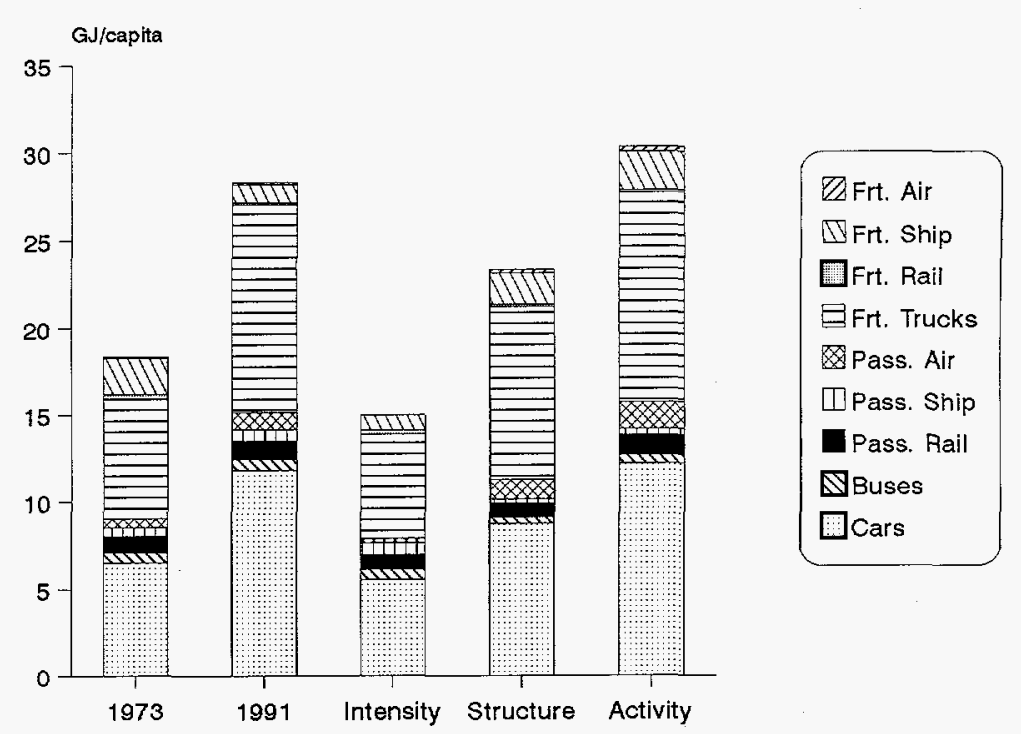

Figure. Energy use for transport in Japan, 1973 and 1991; effects of changes in intensity, structure, and activity. The changes in energy use by mode between 1973 and 1991 are decomposed into three factors; "Intensity", defined as MJ energy per passenger-kilometer; "Structure", defined as the modal shares of total travel; and "Activity", defined as total passenger-kilometers traveled. The first two bars represent actual energy use for transport in 1973 and 1991, while the latter three depict hypothetical energy use in 1991 if only one factor, e.g., energy intensity, had changed, holding the other two factors constant. 
between 1973 and 1992. These developments mean that energy use for transportation in Japan increased some $14 \%$ per year between 1965 and 1973 and then by 3\% between 1973 and 1992. Energy for travel increased almost twice as rapidly as that for freight before 1973. Not surprisingly, $\mathrm{CO}_{2}$ emissions followed suit. When we compare our findings with those from Europe or theU.S., we find that the level of transportation - the low mobility of Japanese people and the high share of travel on rail or bus-accounts for the low ratio of transportation energy use to population or GDP. Automobile travel per se in Japan requires more energy per passenger-km than in any other country except the U.S., while truck freight has one of the highest energy intensities of $O E C D$ countries, due in part to the large number of small trucks carrying light loads and, of course, congestion in the cities and on highways. While the share of bus and rail travel in Japan is far higher than in Europe, the share of trucks in freight is also very high, both attributes arising from Japan's high population density. Thus, while transportation in Japan is not dramatically more "energyefficient" than in Europe, the patterns we found make sense given the geography and density. The trends we have observed appear to bedriven primarily by motorization for travel and for competition of the "just-in-time" distribution of goods, lead- ing towards more trucks and, more recently, a radical restructuring of the railroads. Since recent tax policies in Japan reduce taxation on larger cars, it is not clear whether an "energy policy" that restrains energy use for travel exists. Since $\mathrm{CO}_{2}$ emissions for both travel and freight are still rising, Japan's reluctance to make bold commitments to $\mathrm{CO}_{2}$ reduction is understandable.

In future work we will explore the spatial structure of Japan and its impact on transportation. We will also study how Japanese households use energy. Finally we hope to learn more about how Japan will confront $\mathrm{CO}_{2}$ restraint.

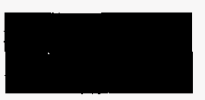

The Residential Space Heating Problem in Eastern Europe

S. Meyers, L.J. Schipper, Z. Voracova, J. Salay, M. Khrusch, E. Martinot, M. L'Heureux
Several important problems are associated with heating of housing in Central and Eastern Europe. Residential heating in many countries is heavily dependent on coal whose combustion is a major contributor to air pollution in urban areas. Subsidies from the State budgets to maintain the residential heat price at a below-cost level have declined considerably in recent years, but are still a burden. Yet eliminating subsidies is politically difficult, as many households face difficulty in paying their rising heating bills. In addition to the above problems, use of fossil fuels in general and coal in particular for residential heating contributes to the atmospheric build-up of carbon dioxide.

The magnitude of the above problems is heightened by the inefficient manner in which energy is used to heat residential buildings. There are inefficiencies in the heat supply to buildings (large losses in transmission and distribution of district heat), in heat distribution within apartment buildings (lack of proper control and balancing of systems), and high levels of thermal losses through the building envelopes. The situation is made worse by the lack of control and metering of district heat at either the building or dwelling level and by the tradition of charging for heat according to floor area rather than actual consumption. Even as the price of heat has risen, households served by district heat have had neither the incentive nor the means to modify the amount of heat they use.
Improving the energy efficiency of heating is recognized as an important goal for addressing these problems, but achieving gains faces strong barriers. Further, efforts to assist energy efficiency improvement must take into account the changes in ownership and other factors that are taking place in the housing sector. This study was initiated to provide a context for the design of effective strategies for addressing the residential heating problem in Central and Eastern Europe. Focusing on three countries-the Czech Republic, Poland, and Estonia-

we sought to investigate:

- what progress has been made so far in establishing conditions for improving the efficiency of heating;

- the effect of privatization and other changes taking place in the housing sector on efforts to improve heating efficiency; and

- existing and planned policies and programs designed to improve heating efficiency.

For each of the three countries, we have collected data on the housing sector, the manner of heating (see Figure),
Dwellings (Mn.)

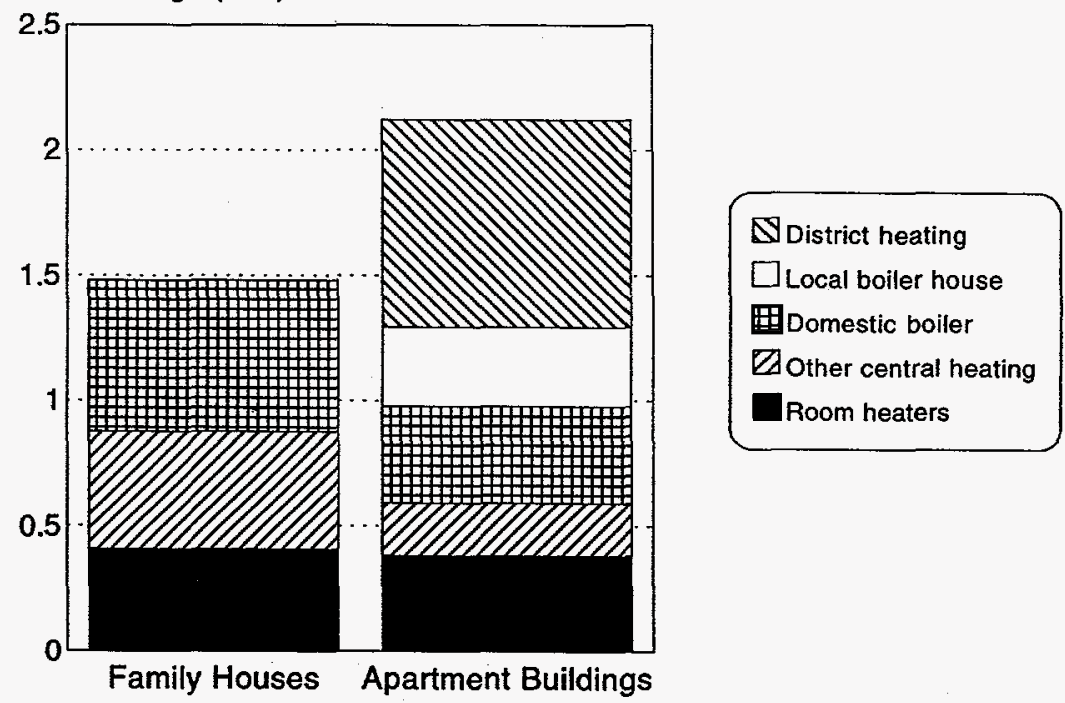

Figure. Type of heating in family houses and apartment buildings in the Czech Republic, 1991. 
energy consumption for heating, and energy prices, and interviewed a large number of people in government, institutes, and the private sector. We have found that privatization of formerly public housing is proceeding slowly, but this change alone is unlikely to result in very much improvement in the energy efficiency of heating. Higher energy prices have increased interest in metering and measures to reduce energy use, however the high cost of financing and uncertainly about building ownership are barriers to action. Government programs to encourage thermo-renovation of existing housing are in place in Poland and the Czech Republic but have had a relatively limited impact to date. Final results of the project will be published in 1995.

\section{Comparison of Service Sector Electricity Use in OECD Countries}

\section{A.O. Sezgen, L.J. Schipper}

Studies of service sector electricity use in nine OECD countries-Denmark, France, Germany, Italy, Japan, Norway, Sweden, United Kingdom, and the United States-indicate that electricity intensity and the share of electricity in final energy use are increasing. Our study sought to understand what drives electricity growth and to quantify and compare the electricity efficiency by activity (building type) and end use. The project consisted of two sections: 1) we looked at time-series data from 1972 to 1991 on aggregate energy consumption and basic aggregate drivers-namely GDP, number of employees, population, and floor area, and 2) we examined the energy consumption in some of the countries by service activity and end use in a single year.

The time-series data between the years 1972 and 1990 reveal many developments and differences among all the countries. GDP per capita for services increased at a steady rate in all countries. This in turn generated a steady increase in the number of service sector employees. However, the rate of growth in the number of employees was slower than the rate of growth in the services GDP due to increased employee productivity. Even though productivity levels were increasing at similar rates in all countries, the productivity levels differed considerably. In a similar manner, the floor area per employee is more or less constant over time in any given country but quite different among countries. Primary energy intensity, although showing fluctuations, is not changing much in most countries. Electricity's share of final energy is increasing and that of fuels is decreasing in all countries.
Examination of the 1990 data for Denmark, France, Japan, Sweden, and the U.S. reveals the differing composition of the service sector building stocks in terms of floor area used for services: 1) in the U.S., the largest percentage of area is used for retail and wholesale; 2) in Japan the largest percentage of area is used for education and offices, the smallest for health care; 3) France has the largest area percentage for hotels and restaurants; and 4) in Denmark the smallest percentage of area is for retail and wholesale and hotels and restaurants. Given that the energy requirements for the buildings from which services are provided are very different, it is clear that energy intensity comparisons will only be meaningful at a disaggregated level-by service activity and end use.

We compared energy intensities for the five countries by service activity and end use. The differences in the end-use electricity intensities highlight the potential for energy efficiency in the different activity types and end uses, as shown in the Figure. In addition, large savings potentials for the electricity consumption of the lighting, cooling, refrigeration, and also office equipment end uses have also been noted.

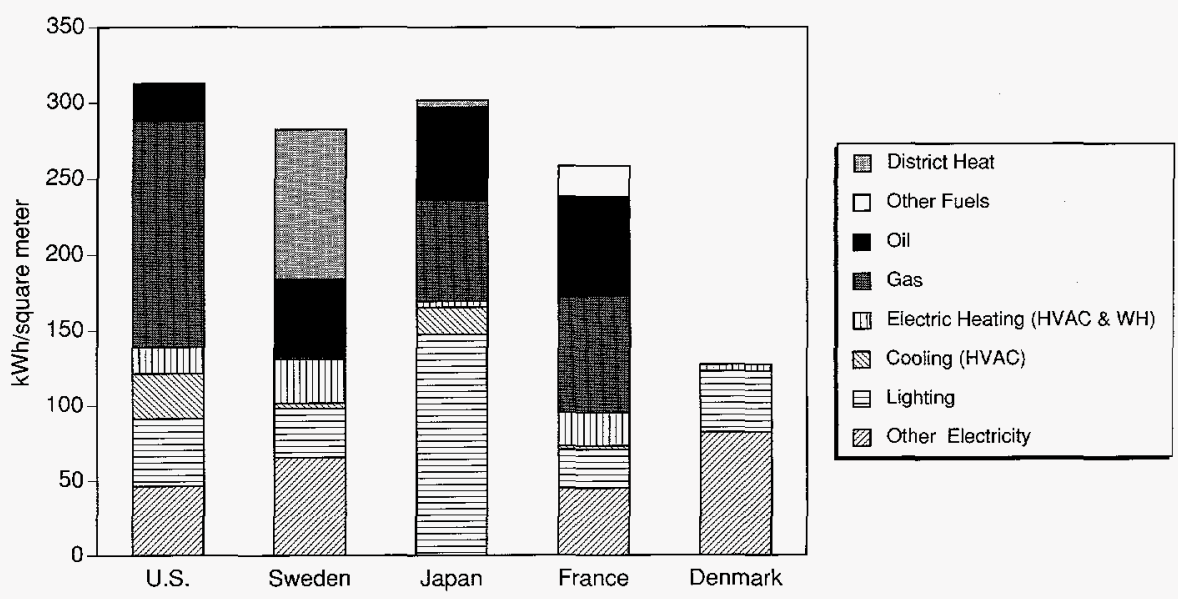

Figure. Fuel and electricity intensities by end use in the OECD service sector. For Japan, lighting includes other electric end uses; for Denmark, fuel data are available. We are in the process of matching categories. Notes: HVAC = heating, ventilation and air conditioning; $W H=$ water heaters . 


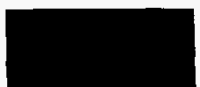

Continuing our analysis of energy use in Nordic countries, we have analyzed the structure of energy use in Finland from 1970 to 1992 . We studied the contribution of changing population and economic activity, changes in the mix of activities (goods produced, modes used for freight and travel, energy-using activities in households) that drove upward total energy use in Finland. We also analyzed the trends that reduced the energy intensities of approximately 25 end uses or activities during this period.

Wecompared the results of our analysis of Finland with those from other Nordic countries, the former West Germany, the U.S., and Japan. We found that Finland's industrial structure and climate contribute to the increase in energy use, relative to the other countries, but lower levels of mobility and smaller homes reduce energy use. High levels of thermal insulation in homes and low energy intensities in industry reduce energy use further, while energy intensities for travel and freight are close to European averages. The important role of the relatively energy-intensive paper and pulp industry makes manufacturing energy use high relative to many other countries. But living standards have been somewhat lower than those of otherNordic countries. Until the recent recession there, however, Finland was closing the gap in living standards as auto ownership and mobility and home size and appliance ownership grew rapidly in the 1970s and early 1980s.

The Figure shows how different forces affected primary energy in Finland since 1973 . The actual energy consumption that has occurred since 1970 is labeled, appropriately, "Actual". Two other curves show the limited ability of aggregated parameters, gross domestic product (GDP) and energy use per unit GDP (energy/GDP), to explain the changes in energy consumption. The remaining four curves show the much better ability of six sector-specific parameters and 25 subsector-specific parameters to explain these changes.

At the aggregated level, the curve labeled "GDP Effect" shows how energy use would have grown had energy/GDP remained at the 1973 level and only the growth in GDP caused energy use to change. Likewise, the curve labeled " $\mathrm{E} /$ GDPEffect" shows how energy use would have grown had GDP remained at the 1973 level and only the change in energy/ GDP had caused energy use to change.

At the level of sectors (households, services, travel, freight, manufacturing, and an aggregate of agriculture, mining, and construction) and sub-sectors (e.g., manufacturers of chemical products), three parameters interact: sector or subsector activity level, structure of the economy (relative mix of sub-sector activities within each sector), and energy intensity (energy use per unit of activity). The curve labeled "Activity" shows how energy use would have evolved had the structure and energy intensities in each sub-sector remained unchanged from the 1973 level and only the fluctuations in activity within each sub-sector had caused energy use to change. Likewise, the curve labeled "Structure" shows how energy use would have evolved had the activities and energy intensities in each sub-

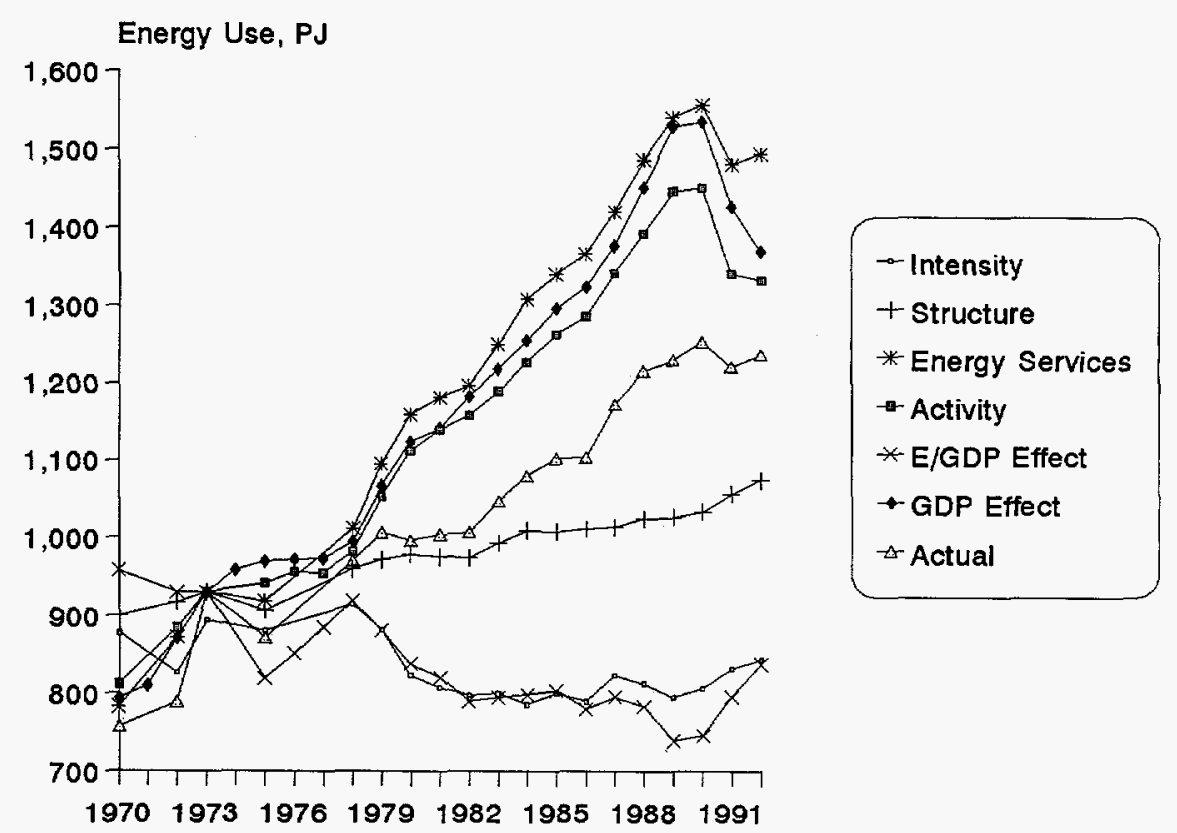

Figure. Primary energy use in Finland, 1970-1992. sector remained unchanged from the 1973 level and only the structural shift caused energy use to change. The curve labeled "Energy Services" combines the above two analyses, allowing both activity and structure to change, but at the energy intensity that existed in each sub-sector in 1973. This curve provides the closest estimate we have on how much energy would have been used in any year had there been no improvements in energy efficiency. Finally, the curve labeled "Intensity" shows the energy use since 1973 had the economy (sectoral structure and activity levels) remained at the 1973 level. This curve shows the real change in energy intensity, which is the nearest we have come to judging changes in the efficiency with which energy is used. Notable is the huge drop in "Activity" after 1990 caused by a very deep recession, which also led to an increase in some of the energy intensities in the economy as factories ran at low capacity. In the current year, we will complete this analysis and then compare all four Nordic countries.

\footnotetext{
${ }^{*}$ University of Helsinki, Helsinki, Finland

${ }^{\dagger}$ Institute for Energy Technology, Kjeller, Norway
} 


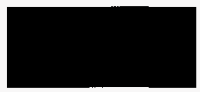

\section{Building Standards for Mexico}

Y.J. Huang, O. de Buen, N. Martin, M.D. Levine

Like other developing countries, Mexico has not yet implemented building energy standards but is now addressing that need. Under the guidelines of a Standardization and Normalization Program of the Mexican government and under the sponsorship of the Comision Nacional de Ahorro de Energía (National Commission for Energy Savings) (CONAE), a set of standards for energy conservation in equipment and buildings has been developed for Mexico. Of all the standards, the Integral Energy-Efficiency Standard for Non-Residential Buildings is the most complex and, therefore, CONAE has requested the technical assistance of LBL to provide guidance and to analyze energy conservation alternatives to be included in that standard, under the sponsorship of the U.S. Agency for International Development.

We provided technical assistance in developing this standard in three ways: 1) organizing meetings between U.S. experts and Mexican officials to define a general course of action from the drafting of the standard to its implementation, 2) performing building energy simulations in support of the standard, and 3) reviewing the proposed standard and proposing modifications to improve its accuracy and validity.

DOE-2.1E was used as the primary tool to evaluate cooling energy use in non-residential buildings in Mexico and the cost-benefit of various conservation strategies. For this analysis, we obtained and processed detailed weather data for three locations (Mexico City, Monterrey, and Mérida), defined a prototypical office building in collaboration with CONAE and Pacific Northwest Laboratories (PNL), and subcontracted PNL to do the initial DOE-2 simulations and costbenefit analysis.

In August 1994, CONAE completed a draft of the proposed energy standard. After review, we proposed changes in the calculational procedure of the standard to highlight the importance of solar heat gain through windows and to de-emphasize insulation measures in typical Mexi-

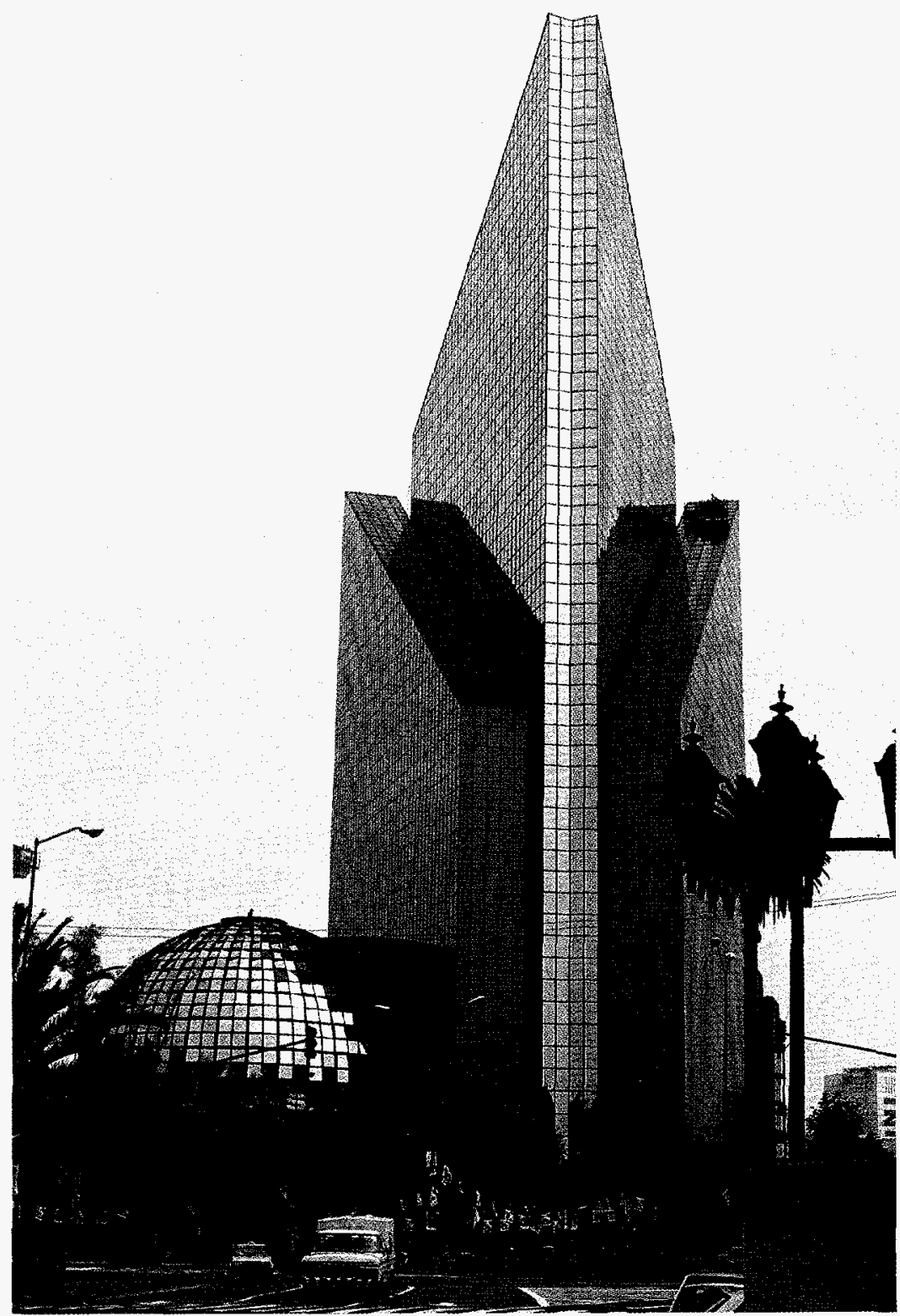

Figure. Typical new office building in Mexico with a curtain wall system.

can buildings and climates (see Figure). LBL and CONAE have been working together to incorporate these suggestions into the final draft of the Integral EnergyEfficiency Standard for Non-Residential
Buildings, scheduled for release in February 1995. After the standard has been finalized, we will continue to provide technical assistance in its implementation. 


\section{Electricity End Use in Mexico: International Comparisons for Three Industries}

\author{
S. Meyers, O. de Buen, J. Sathaye
}

One serious limitation to the development of energy-conservation measures and programs in Mexico is the lack of disaggregated and reference data on energy intensities by end use. This lack reduces the quality of estimates of savings from energy-conservation programs and standards.

The Fideicomiso de Apoyo al Programa de Ahorro de Energía del Sector Eléctrico (FIDE) is a private fund that sponsors electricity-conservation projects in Mexico. To define benchmarks of energy intensities to be used as reference for their activities, FIDE requested LBL's technical assistance under the sponsorship of the U.S. Agency for International Development.

Researchers from LBL collected data on energy intensities for three industrial processes-steel, cement, and paper and pulp-for a number of countries, among them Mexico, and used these data to analyze the cross-country energy intensities of these industries. In the analysis, the energy intensities were disaggregated by stages of production and examined for the impact of such factors as technology and raw materials. The study also included a short overview of technological trends that reduce power consumption.

An analysis shows that, in general, in Mexico electricity intensities for steel and cement production are high because of the types of processes that predominate in those industries. For the steel industry, the contribution of electric arc furnaces (see Figure) is responsible. In the cement industry, the dominant use of dry kilns (which reduce the use of

energy overall) is reflected in $\mathrm{kWh} /$ tonne values that are the highest in Latin America. Yet high levels of recycled materials make the $\mathrm{kWh} /$ tonne values of the Mexican paper and pulp industry lower than those of the U.S., Japan, and France.

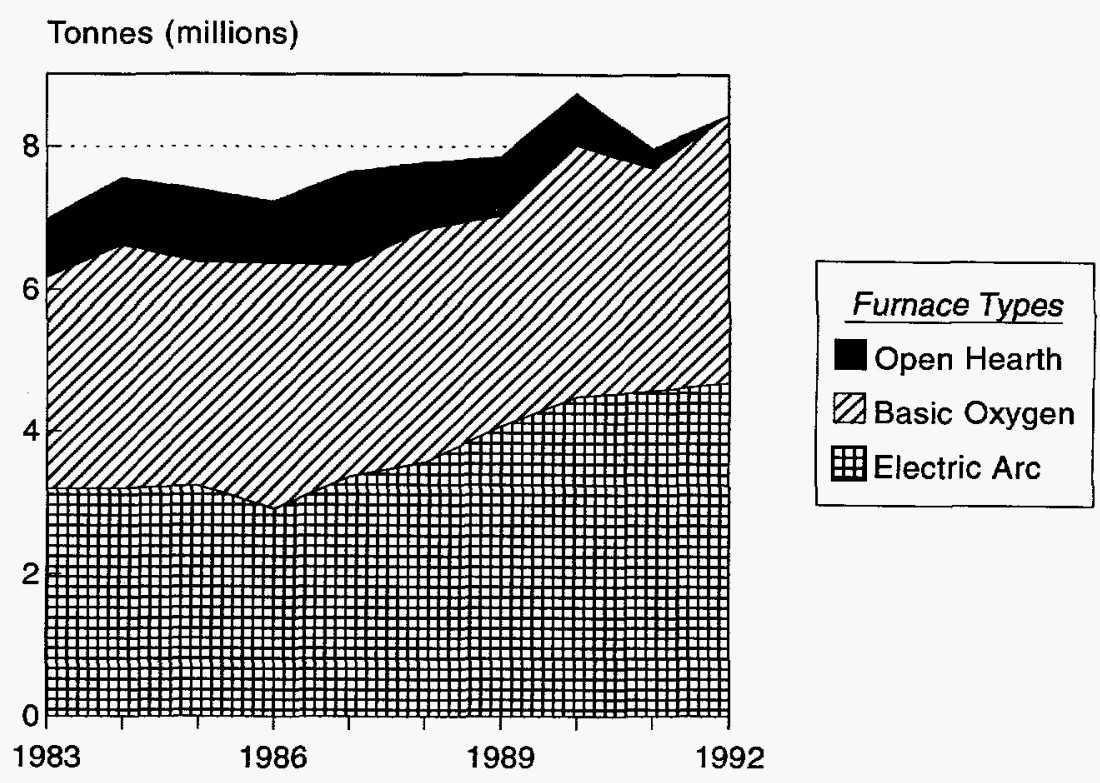

Figure. Mexican steel production by process.

\section{The Role of Cogeneration in China's Energy System}

\section{F. Yang, D. Xin, * M.D. Levine}

China's reliance on coal to fuel its large energy system - coal supplies threequarters of China's energy needs-raises concern over the large amount of greenhouse gas emissions. China already ranks third globally in $\mathrm{CO}_{2}$ emissions, and rapid economic expansion will raise emission levels further. The attitude of the Chinese government toward energy-conservation measures, including cogeneration programs, is increasingly important to the worldwide promotion of energy efficiency and the reduction of greenhouse gas emissions.

In many situations, cogeneration presents a cost-effective way of reducing the burden on primary energy supplies and alleviating the environmental pollution resulting from energy use. Starting with emulation of the Soviet model of development in the 1950s, cogeneration already has a 40-year history in China. In the late 1970 s and early 1980s, reforms of the economic system stimulated rapid economic growth and caused an overall shortage of energy, especially electricity. This shortage, combined with mounting pollution problems, prompted the Chinese government to place new emphasis on cogeneration development. By the end of 1993 nearly $12 \%$ of China's installed generation capacity, i.e., 14.65 gigawatts of electricity, was produced at cogeneration facilities (see Figure). The patterns of governmental policy and regulation, investment sources, management, ownership, technologies, scale, and incorporation of environmental concerns have changed significantly over the decades, and greater change is expected (see Table).

A forthcoming report will provide a comprehensive understanding of cogeneration development and its potential market in China, including institutional, legislative, economic, technological, environmental and marketing aspects. The paper will review historical development in cogeneration and its patterns over regions, sectors, and sizes, but emphasize analysis of government policy and bureaucratic functions in fund allocation

* Beijing Energy Conservation Center, Beijing, Peoples' Republic of China. 


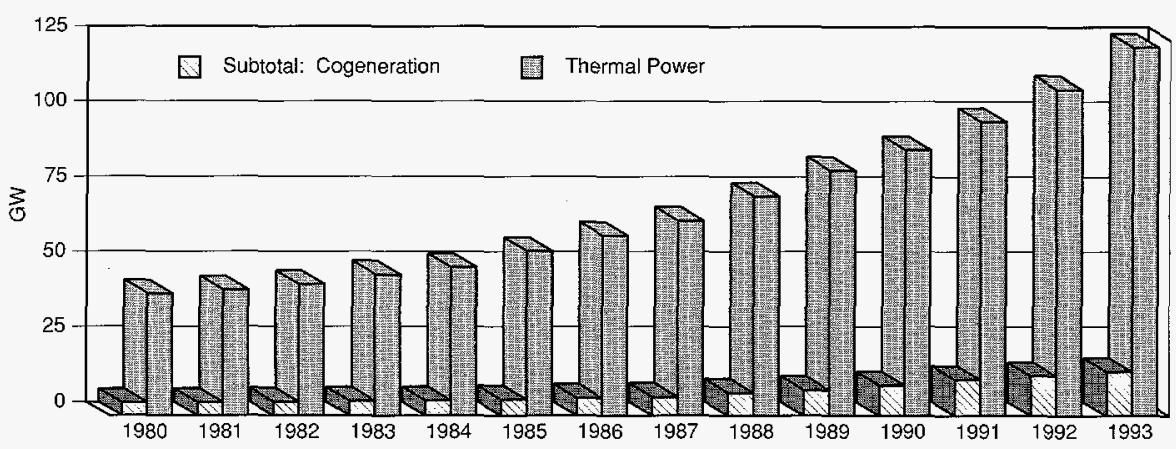

Figure. Total installed thermal power generation capacity and cogeneration subtotal. and program implementations. The feasibility of specific cogeneration projects will be discussed in terms of economic evaluation, cost allocation, and technological aspects. Market barriers to implementing cogeneration programs and other related problems will also be examined. The great potential for further cost-effective expansion of cogeneration capacity raises the possibility of commercial involvement by foreign firms. The report recommends specific changes in Chinese legislation and policy to encourage cogeneration development. Sections will also describe American investors' involvement in the Chinese cogeneration market and the potential role of cogeneration projects in joint implementation efforts for reducing greenhouse gas emissions.

Table. Cogeneration development: past, present and planned.

\begin{tabular}{|c|c|c|c|c|}
\hline & 1953-1965 & $1966-1980$ & 1981-Present & Present-2000 \\
\hline Ownership & State and enterprise. & State and enterprise. & $\begin{array}{l}\text { State, local government, } \\
\text { government, enterprise, } \\
\text { collective, and joint } \\
\text { venture. }\end{array}$ & $\begin{array}{l}\text { Stockholder, collective, } \\
\text { local government, } \\
\text { enterprise, state, } \\
\text { and joint venture. }\end{array}$ \\
\hline Financing & State investment. & State investment. & $\begin{array}{l}\text { State investment and } \\
\text { loans, local, collective, } \\
\text { and internal funds, } \\
\text { foreign capital. }\end{array}$ & $\begin{array}{l}\text { Stock issues, local and } \\
\text { collective funds, state } \\
\text { loans, internal funds } \\
\text { and foreign capital. }\end{array}$ \\
\hline Technology & $\begin{array}{l}\text { Large- and small-scale } \\
\text { equipment imported } \\
\text { from the Soviet Union. } \\
\text { Trend toward larger } \\
\text { systems. }\end{array}$ & $\begin{array}{l}\text { Small-scale equipment } \\
\text { made in China, large- } \\
\text { scale equipment } \\
\text { imported from the } \\
\text { Soviet Union. } \\
\text { Maintain larger systems. }\end{array}$ & $\begin{array}{l}>100 \mathrm{MW} \text { turbines and } \\
>24 \mathrm{t} \text { steam } / \mathrm{hr} \text { boilers } \\
\text { still imported. Trend } \\
\text { toward smaller systems. }\end{array}$ & $\begin{array}{l}\text { All equipment } \\
\text { domestically } \\
\text { manufactured. }\end{array}$ \\
\hline Operation & $\begin{array}{l}\text { Utility-run, state- } \\
\text { owned cogen serves } \\
\text { both public electricity } \\
\text { and steam needs. } \\
\text { Enterprise-owned } \\
\text { cogen serves own } \\
\text { thermal needs. }\end{array}$ & $\begin{array}{l}\text { Same as in previous } \\
\text { period. }\end{array}$ & $\begin{array}{l}\text { Independent } \\
\text { cogeneration plants } \\
\text { increase. }\end{array}$ & $\begin{array}{l}\text { Independent } \\
\text { cogeneration plants } \\
\text { play major role. }\end{array}$ \\
\hline Costs & $\begin{array}{l}\text { Stable, controlled by } \\
\text { planning system. }\end{array}$ & $\begin{array}{l}\text { Stable, controlled by } \\
\text { planning system. }\end{array}$ & $\begin{array}{l}\text { Move toward markets. } \\
\text { Cost increases rapidly. }\end{array}$ & $\begin{array}{l}\text { Market-driven and } \\
\text { marginal costs. }\end{array}$ \\
\hline Policies & Encourage cogen & No attention paid to & Give incentives for & Formulate \\
\hline Regulation & $\begin{array}{l}\text { development. } \\
\text { Both electricity and } \\
\text { heat prices regulated. }\end{array}$ & $\begin{array}{l}\text { cogen projects. } \\
\text { Both electricity and } \\
\text { heat prices regulated. }\end{array}$ & $\begin{array}{l}\text { cogen development. } \\
\text { Flexible electricity } \\
\text { pricing, regulated } \\
\text { for heat pricing. }\end{array}$ & $\begin{array}{l}\text { comprehensive policy. } \\
\text { Deregulation of both } \\
\text { electricity and heat } \\
\text { prices. }\end{array}$ \\
\hline Competition & Monopolies. & Monopolies. & $\begin{array}{l}\text { Introducing } \\
\text { competition. }\end{array}$ & $\begin{array}{l}\text { Increasing } \\
\text { competition. }\end{array}$ \\
\hline $\begin{array}{l}\text { Environmental } \\
\text { concern }\end{array}$ & None. & None. & Increasing concern. & $\begin{array}{l}\text { Incorporation of } \\
\text { environmental } \\
\text { constraints. }\end{array}$ \\
\hline
\end{tabular}




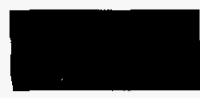

\section{The Building Materials Industry in China: An Overview}

F. Liu, S. Wang

Unprecedented construction in China since the late 1970s has brought about a rapid expansion of the building materials industries. Output of major construction materials tripled within a decade. By the late 1980s, China led the world in the production of cement, lime, bricks, and flat glass. This rapid growth brought its own particular set of problems: inadequate investment capital, primitive technologies, and the proliferation of small factories burdened an industry already clogged with inefficient and polluting small enterprises that produced low-quality goods. Such a rapid build-up of capacity, without much technological advancement, produced costly long-term problems in energy efficiency and environmental protection. In the coming years a tremendous amount of work will be required to raise the industry's technological sophistication, improve its energy efficiency, and bring it into compliance with environmental regulations.

This study was a collaborative work between the Energy Research Institute of the State Planning Commission of China and LBL. The main objectives of this study were:

- to investigate and evaluate energy consumption and efficiency of energy end uses in the major branches of the building materials industry;

- to estimate potential energy savings of various technical measures and to evaluate economic costs of such measures; and

- to identify barriers to energy conservation and propose policies that would both facilitate research and development and enable the industry to achieve higher energy efficiency.

Thousands of vertical kilns, now rarely used in industrialized countries, dominate production by the Chinese cement industry (see Figure). Vertical kiln energy intensities vary widely, but the average is believed to be $165 \mathrm{kgce} /$ ton of clinker, ${ }^{*}$ with intensities slightly lower than that for the much larger key plants in China. The most efficient vertical kilns have intensities as low as $110 \mathrm{kgce} /$ ton of clinker, close to that of advanced Japanese plants. These plants, however, producelower-quality cement and higher pollution emissions than modern plants with rotary kilns.

During the 1980s the cement industry, with government assistance, introduced vertical kiln renovations, demonstrated improvements for other cement-making technologies, built some large modern precalciner kilns, and helped manufacturers produce modern cement equipment. Based on this experience we analyzed the prospects for renovating existing facilities and building new ones during the 1990s. The technical potential is good for renovating most vertical kiln plants to improve their energy intensity by $10-30 \%$ while substantially increasing their capacity and reducing pollution, all at low cost. Renovating large wet-process rotary kilns appears less attractive, but the experience with demonstrations may beskewed by the high cost of imported equipment. Electricity conservation has become as
Figure. Structure of cement production technologies in China. important as fuel conservation in terms of costs and primary energy. Renovations of electrical equipment adopted in industrialized countries are promising. Cost data for China are sparse.

We performed economic evaluations of energy-conservation measures in the cement industry and found that available data do not justify more serious analyses of the cost effectiveness of energy-conservation investments. Problems arise from how the data were collected and the multiple objectives of such an investment. Energy-conservation investments in the cement industry have rarely focused on energy savings exclusively. Many renovation projects aim at increasing both production capacity and energy conservation. When energy is relatively cheap, additional cement production capacity is considered a quick way of paying back the investment because of the highly profitable sales. To

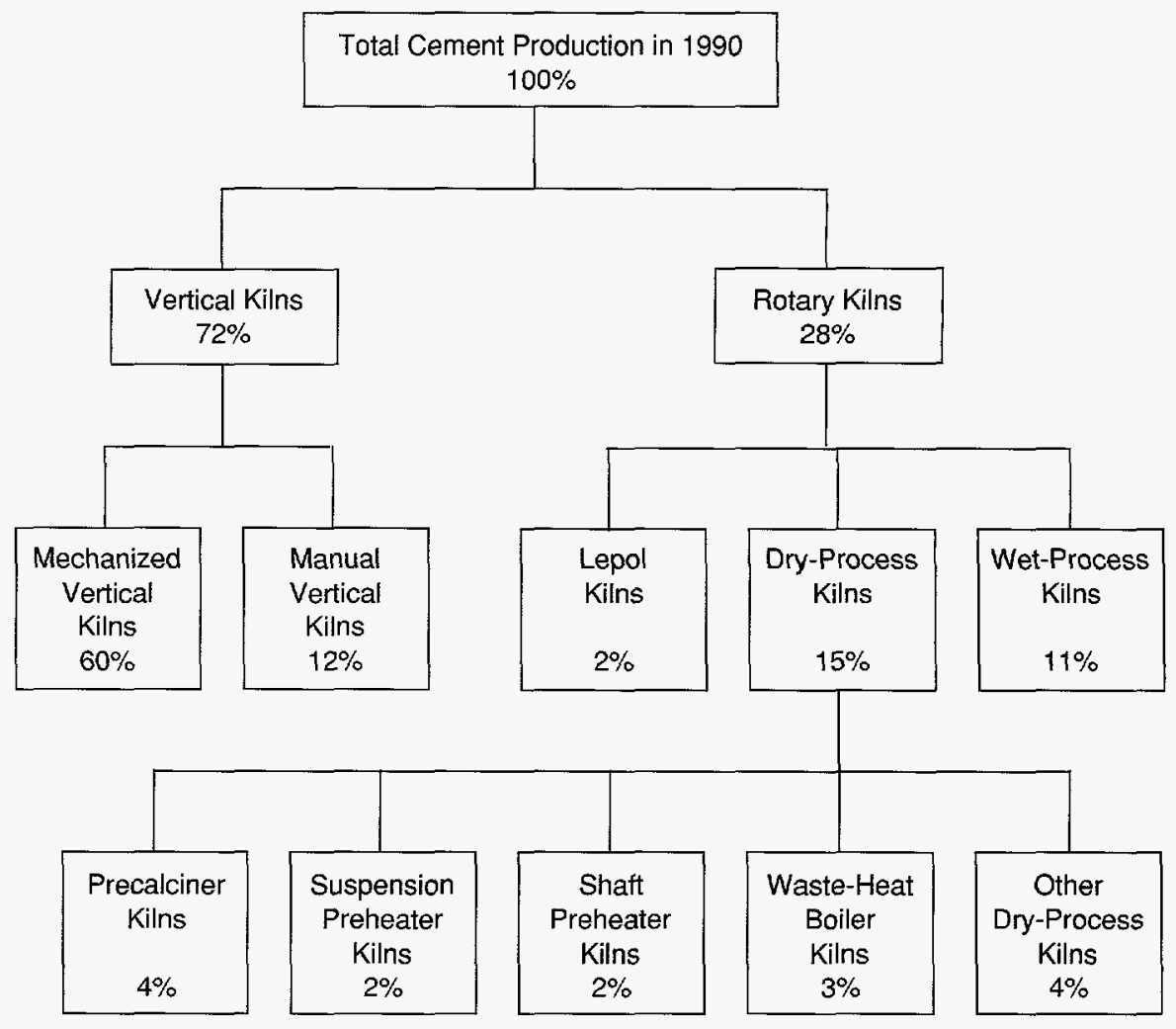

* Clinker is a precursor of cement; $\mathrm{kgce}=$ kilogram of coal equivalent. 
assess the cost of saved energy, we need to obtain data that indicate net investments in energy conservation. Such data usually cannot be derived without ambiguity.

We project cement production in the 1990 s to continue to keep pace with economic growth. Three scenarios, dif- fering in the technology of new plants and associated capital costs, are developed, emphasizing: 1) high capital-cost, state-of-the-art, precalciner kilns, 2) moderate capital-cost ad vanced vertical kilns, and 3) low-cost small vertical kilns without advanced technology (as characterized most of the growth in the 1980s).

\section{Reference}

Liu F, Wang S. Energy Use and Conservation in China's Building Materials Industry. Lawrence Berkeley Laboratory Report LBL-34549, 1993.

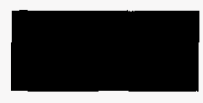

\section{Energy Efficiency of Cement Plants in China: Results of Case Studies Involving Site Visits}

\section{J.E. Sinton}

With approximately 6000 plants distributed across all parts of the country, China's cement industry accounts for $4 \%$ of the total commercial energy consumption and $8 \%$ of its anthropogenic $\mathrm{CO}_{2}$ emissions. Between 1990 and 1993 annual cement output jumped by $70 \%$ to $356 \mathrm{Mt}$, and demand for cement continues to grow faster than the rate of GNP growth. Despite more than a decade of investments from the central government and policies to promote efficiency, most equipment at large state-owned cement enterprises fails to perform as well as similar equipment abroad. The average fuel intensity of cement clinker production at state-owned plants, for instance, is nearly $180 \mathrm{~kg}$ of coal equivalent ${ }^{1}$ per metric ton. Typical average intensities in U.S. cement plants range from 125 to $145 \mathrm{kgce} / \mathrm{t}$ clinker. Intensity is also high at China's thousands of small cement plants, which account for over half of cement output and lie outside the central government's influence.

In this ongoing investigation, we examine energy efficiency and, more broadly, decision-making as it affects energy use at ten medium- and large-scale cement plants in Jiangsu Province, bordering Shanghai. Jiangsu was chosen becauseeconomicsystem reforms are relatively advanced, and also because it provides a model of development to other areas in China. We use multiple sources of information-including interviews, enterprise data, and documentary sources- to trace energy intensity changes between 1985 and 1993. The ten cement plants ranged in scale from under $200 \mathrm{kt}$ to $700 \mathrm{kt}$ cement per year and spanned most of the range of production technologies to be found in the Chinese cement industry, including mechanized vertical kilns, wet process rotary kilns, and dry process rotary kilns, with and without preheaters and precalciners. The sample excluded very inefficient nonmechanized vertical kilns, which continue to operate in many rural areas. All plants used coal as their major fuel, except one, which burned fuel oil to manufacture white cement. Most plants used ball mills for both raw and finish grinding, though several had installed a number of roller

Fuel Intensity of Cement Clinker Production (kg of coal equivalent/metric ton clinker)

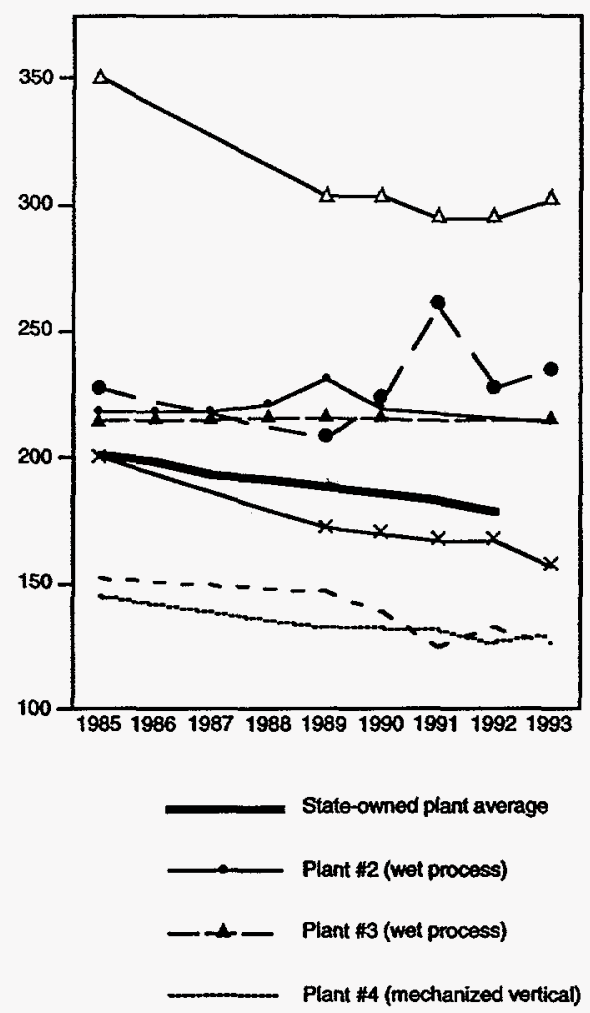

Electricity Intensity of Cement Production (kg of coal equivalent/metric ton cement)
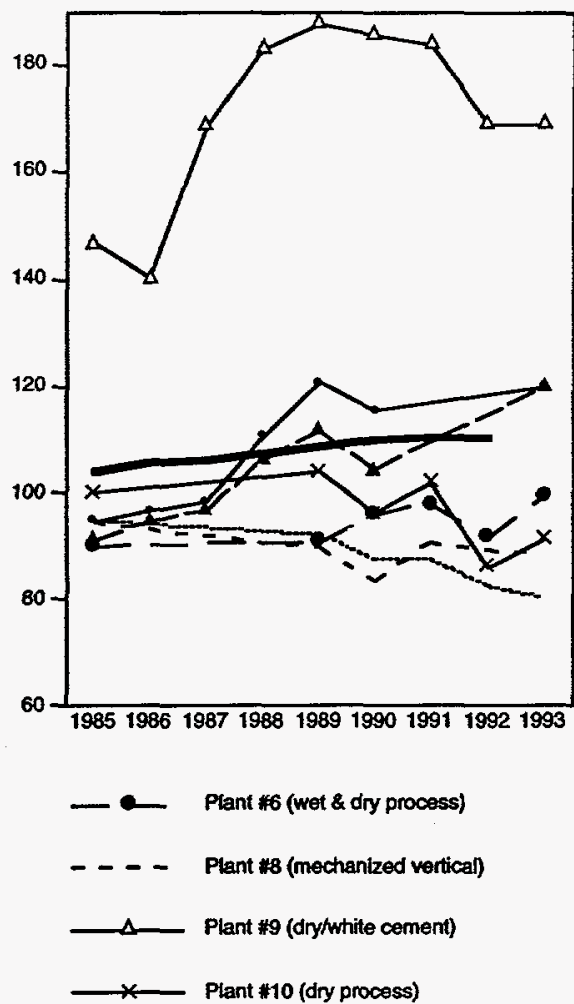

Figure. Fuel and electricity intensities of cement-production processes. 
by far the most important explanation for energy intensity changes appears to have been installation of new equipment. While new equipment was generally associated with significant fuel intensity declines (e.g., Plant\#10), poor performance of new facilities led to temporary and longerterm increases in some cases (e.g., Plant \#6). Operator performance is a factor in intensity trends mainly at plants using mechanized vertical kilns. Deterioration in efficiency was clear at several plants utilizing very old equipment. The desire to maximize output, and the rationalization that such equipment is still somewhat more efficient than that used in some rural plants, keeps old equipment in service long after it is obsolete. In some cases product quality and energy intensity were closely linked, e.g., lack of proper skills in operating labor-intensive mechanized vertical kilns results in a low quality and energy-intensive products. Some plants may have reduced energy intensity in responding to market pressures to improve quality.

Strong growth in demand for both high-and low-quality cements foreshadows continued expansion of two types of cement plants: large-scale, fuel-efficient, and electricity-intensive plants that produce expensive high-quality cement for regional markets, and small-scale, fuelintensive, non-electricity-intensive plants that produce low-quality cement for local markets. This planned expansion of production, along with the poor energy performance of many existing facilities that will continue to operate, suggests significant opportunity for efficiency improvements. Among the technology alternatives most attractive to plant managers and local officials are waste heat cogeneration, improved raw material and cement clinker-grinding circuits, improved coal mills and burners, and process automation. Some alternatives that offer large fuel savings and have been heavily backed by central authorities, such as the construction of advanced precalciner kilns and conversion of wet process plants to dry process, are unattractive to most local decision-makers for financial, technical, and other reasons. Vertical kilns, many with operating efficiencies better than nominally more advanced rotary kilns, will continue to be the technology of choice for smaller cement producers because of smaller unit size, rapid construction times, ease of use, and low electricity intensity. The lack of adequate emissions controls at most cement plants (especially in rural areas) offers a large reservoir of costeffective opportunities to improve plant efficiency and environmental quality, if mechanisms to encourage adoption can be implemented.

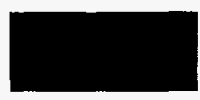

\section{Energy Efficiency and Decision-Making in the Chinese Cement Industry} J.E. Sinton

This study, although linked to the work on the cement industry in Jiangsu Province, China, described in the accompanying article "Energy Efficiency of Cement Plants in China: Results of Case Studies Involving Site Visits," focuses on decision-makers and decision-making structures and processes as they affect energy use, rather than on the technical causes of efficiency and the potential for improvements. An understanding of both dimensions is important to the design of effective measures to improve energy efficiency in China. This is especially true now, as the economic reforms of recent years have given greater powers of self-determination to plant managers and local officials and rendered the top-down approach to efficiency work taken to date less effective.

Actors at many levels may influence energy use and efficiency at a particular plant. Operators who run cement kilns exert their influence directly in the performance of their duties, while plant managers have a number of impacts, i.e., through modifying operator performance, by selecting, retrofitting and repairing process equipment, and by their choice of different outputs. Actors outside the plant also have roles. Some are relatively direct, for instance, officials who have a hand in planning produc- tion, providing energy, or choosing technologies; others, like bureaus that set (or free up) prices, and investors that require different kinds of outcomes, are less direct. Actors may be more or less aware of the energy impacts of the decisions they take individually and collectively, spanning the range from decisions taken primarily with a view toward affecting energy use, to those that involve no awareness at all of energy impacts. A major aim of this study is to determine which categories of actors and decisions have most influenced energy use

State-owned plants and some larger non-state plants are subject to a variety of formal structures for energy management and conservation. Perhaps most striking is the system of energy-management offices that extends from the highest levels of the state government, through ministerial systems and local branches of planning bureaus, to the management of larger enterprises. This is the main system for coordinating the implementation of energy-intensity standards, energy-conservation bonuses, the discontinued system of energy-performance certification, and other measures. Local governments, ministries, and enterprises themselves may also undertake other measures just as energy-conserva- tion competitions and internal standards overseen by "three-level (e.g., plant, workshop, and shift) energy-savings networks." Another important means of promoting efficiency has been the state's program of subsidized energy-conservation loans. While fewer than previously, there remain bureaus that control enterprise energy use. The most powerful of these are the provincial, municipal, and county "Three Electricities" Offices. Responsible for electricity safety and conservation, they have emerged as the most powerful allocators of electricity in most localities.

These formal structures undoubtedly have influenced the way energy is used in most industrial enterprises and have raised awareness of energy impacts. (At the very least, they have given decision-makers a new vocabulary to use in justifying their choices.) In the case of the cement and perhaps other industries, however, it seems likely that decisions based primarily on considerations of energy have had less of an impact on energy use and efficiency than investment and operation decisions based on other motivations. These investments in new equipment and decisions to keep older plants running have more of an energy impact than most efficiency retrofits or changes in production practices. 
Facing seemingly limitless expansion in demand for cement, plant managers and local officials have been mainly concerned with growth and thus the need for capital. From the plants that are struggling to stay afloat and need major overhauls in order to begin to make a profit, to profitable ones that seek to expand, decision-makers spend a large portion of their time pursuing investment capital. Investments tend to reflect the priorities of the most influential players in the process, i.e., the plant manag- ers, who value increases in production and improvements in quality above most other outcomes, with full employment and steady increases in wages ranking high as well. As funding shifts to nonstate sources, economic performance has become more of a concern as well.

Except in certain circumstances, energy issues tend to be quite secondary in investment decisions, even in areas with steadily rising energy costs. Even in cases where energy is a major issue in investment choices, improving efficiency and reducing overall energy costs may be less critical than ensuring energy supply. This seems to be the case in the Suzhou area, for instance, where power generation using waste heat from cement kilns is seen as a more attractive option than the more efficient precalciner kilns because of the security in electricity supply offered by the former.

Interim reports on this continuing project will be available until the final report is issued in calendar year 1995.

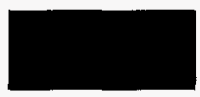

\section{Recent Trends in China's Energy Supply and Demand}

While the pattern of primary energy production in China remained constant in 1992 and 1993, consumption trends held some surprises. Total primary production in 1993 was 1102 Mtce, comprising $1141 \mathrm{Mt}$ raw coal, $145 \mathrm{Mt}$ crude oil, 16.6 billion $\mathrm{m}^{3}$ natural gas, and 154 TWh primary electricity (including 2.5 TWh from nuclear power plants). ${ }^{\dagger}$ The relative shares of the various energy sources were similar to those of the past decade, except primary electricity contributed more than $5 \%$ of the total, an amount higher than in any previous year. The energy source breakdown of 1993's 1118 Mtce of primary consumption changed substantially from 1992. Driven by the demand for diesel and gasoline for transportation and power generation, oil consumption rose from $17 \%$ of primary consumption in 1992 to over $19 \%$ in 1993. Moreover, coal consumption dropped for the first time in 12 years, from 1158 to $1151 \mathrm{Mt}$.

Perhaps the most surprising change in 1993 was the continued drop of energydemand elasticity of economic output (see Figure). Primary energy consumption. rose only $3 \%$, while gross domestic product (GDP) was up more than $13 \%$ in real terms, leading to an elasticity of slightly more than 0.2 . Whether such change reflects the rising importance of the service sector or the shutting down of inefficient plants and equipment with little change in sectoral structure remains to be seen. Massive structural change seems an unlikely explanation, unlessit is within the industrial sector, sinceindustry's share in GDP has been rising in recent years. Misreporting of statistics, including hidden inflation in economic indicators, is a likely factor as well, but probably would not affect the overall trend.

In 1993 coal output at state-owned mines dropped for the first time since 1981. State-owned coal mines now account for just under $40 \%$ of coal output, while small collective and private mines account for $42 \%$. Preliminary figures show a decline in residential coal use, which is thought to be driven by more efficient use of coal (switching from raw coal to briquettes) and an increasing substitution of gas fuels and electricity for cooking and space heating in more affluent areas.
Oil imports rose to unprecedented levels during 1993. Between 1992 and 1993 gasoline imports rose from $0.33 \mathrm{Mt}$ to $2.14 \mathrm{Mt}$, and diesel imports from 5.01 Mt to $9.41 \mathrm{Mt}$. China was still a net exporter of crude oil in 1993 (3.78 Mt), while net imports of refined products grew from $1.8 \mathrm{Mt}$ in 1992 to $12.98 \mathrm{Mt}$ in 1993. Overall consumption of oil products jumped by $14 \%$, a figure considerably higher than the $2.9 \%$ growth in primary energy consumption.

Gross electricity generation in 1993 grew by more than $11 \%$ (as in the previous year) to nearly 840 TWh. China's generation capacity is heavily dominated by thermà power plants, which account

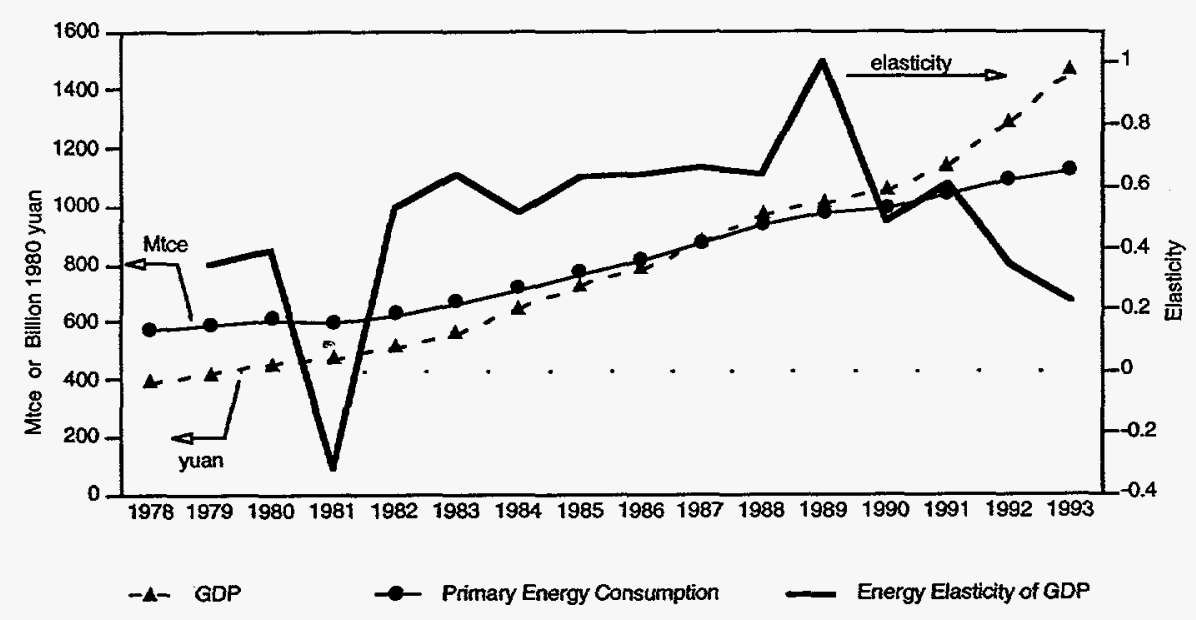

Figure. Energy consumption, GDP, and energy demand elasticity of GDP.

\footnotetext{
* Million metric tons of coal equivalent. One tce $=29.3 \mathrm{GJ}=27.8 \mathrm{MBtu}=7$ million kcal. One ton of raw coal $=0.7143$ tce; one ton of raw oil $=1.4286$ tce; $1000 \mathrm{~m}^{3}$ of natural gas $=1.33$ tce; 1000 $\mathrm{kWh}$ of electricity $=0.1229$ tce.

+ Primary electricity includes hydropower, nuclear power, and other renewable electric energy.
} 
for $75 \%$ of the total 1993 installed capacity of $182.9 \mathrm{GW}$; the rest is mainly hydropower. The structure of electricity end use has begun to swing back toward industry. The 1980's general downward trend of industry's share of total end use reversed in 1991 or 1992, and in 1993 it stood at $74 \%$. Agriculture's share continued its long, slow decline, while the share of residential and commercial consumption continued to grow, to reach $7 \%$ and 17\% respectively in 1993.
Plans for further work in data collection and analysis include updates, revisions, and a reissuing of the China Energy Databook, and preparation of reports on trends in energy end use in various sectors.

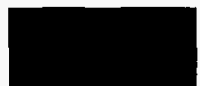

\section{Macroeconomic
P. Mongia, J. Sathaye}

In recent years, concerns about $\mathrm{CO}_{2}$ emissions has focused attention on the crucial link between economic growth, energy utilization, and the environment. Sharing this concern, we propose a conceptual framework and outline a model for analyzing macroeconomic effects of energy and environmental policies.

Demand for energy in developing countries is likely to increase manyfold in the near future. Provision of matching supplies will, on the one hand, tie up a significant amount of economic resources and, on the other hand, be a source of serious environmental pollution. Energyefficiency programs have an important role in reducing the seriousness of these problems, particularly since the present pattern of energy consumption in developing countries is highly inefficient. Therefore, policy-makers face a dilemma: where should the additional dollar be invested-in increasing the capacity of the energy sector or for improving energy efficiency?

Our work focuses on macroeconomic effects of such investment choices in the framework of a multi-sector computable general equilibrium (CGE) model. The model investigates the effect of increased overall investment in the energy sector on economic growth. It also analyzes the effects of increased prices of domestic energy-relative to world prices-on energy consumption and other macroeconomic variables such as sectoral production, imports, exports, and theaggregate pricelevel. The effects of energy price increases are contrasted with the effects of investments in improving energy efficiency in individual sectors. Linking bottom-up and top-down analyses, the model quantifies the effects of $\mathrm{CO}_{2}$ mitigation on gross domestic product and other macroeconomic variables.

Adistinctive feature of this CGEmodel is that energy inputs into the productive processes, as well as energy consumption in the household sector, are shown to be sensitive with respect to investments in

energy-efficiency programs. This is in contrast to the practice in conventional models in which energy use is assumed to be a fixed proportion of output or is assumed to be sensitive with respect to energy prices only.

While the model is quite general in its specifications, it is currently being used to analyze interactions between the energy sector and the economy in Venezuela where the present pattern of energy consumption is highly inefficient. With up to $25 \%$ of production being consumed in-country, the potential for exports is significantly

reduced. In the past, energy price increases to reduce consumption proved to be ineffective and politically unacceptable. The model shows that investments in energy efficiency could achieve the desired reductions in energy consumption much more effectively and that the price increases, if required at all, would be much smaller than they would be in the absence of these investments.

In 1995, this model will be used for analyzing macroeconomic consequences of energy and environmental policies in Nigeria.

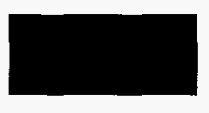

\section{Carbon Flows and Costs of Mitigation Options in the Forest Sector: Studies for Eight Developing Countries}

\section{J. Sathaye, W. Makundi}

In collaboration with researchers from Brazil, China, India, Malaysia, Mexico, Nigeria, Tanzania, and Thailand (known as F7), we have examined the costs and benefits of possible mitigation options to reduce carbon emissions from the forest sector. This work is important since, in order to prepare plans, policies, and measures to stabilize future greenhouse gas (GHG) emissions, national policymakers must weigh the costs, benefits, and impacts of climate change mitigation and adaptation options, in the face of competition for limited government funding. The policy goal for land-use-based climate change mitigation options is to identify the best mix of options that will most likely achieve the stated forestry goal at the least cost, while attempting to maximize economic and social benefits and minimize environmental and social impacts.

Improved national-level cost estimates of forest mitigation options were generated for the aforementioned eight countries by estimating and comparing the costs and benefits of different forestmanagement practices appropriate for specific country conditions. Land availability analyses were performed for forest land and for degraded lands potentially available for reforestation or other options, reflecting opportunity cost of land and local and national development priorities. These cost- and land-use estimates were combined to develop cost of carbon sequestration curves, which will assist policymakers in constructing policies and programs to implement forest mitigation options.

The F7 research group used a common methodology (COMAP) for estimating costs and benefits of mitigation options. The key findings of this work are that 1) the land available for reforestation falls in the upper range of estimates made by earlier researchers, 2) for many of the study countries, $75 \%$ of the technical potential for carbon storage may be tapped for an initial cost of less than $\$ 10 /$ tonne of carbon (tC) (see Figure), and 3 ) the monetizable benefits of tree plantations outweigh the corresponding costs.

Our analysis shows that the direct costs for reducing net carbon emissions 
Initlal Cost (S/tC)

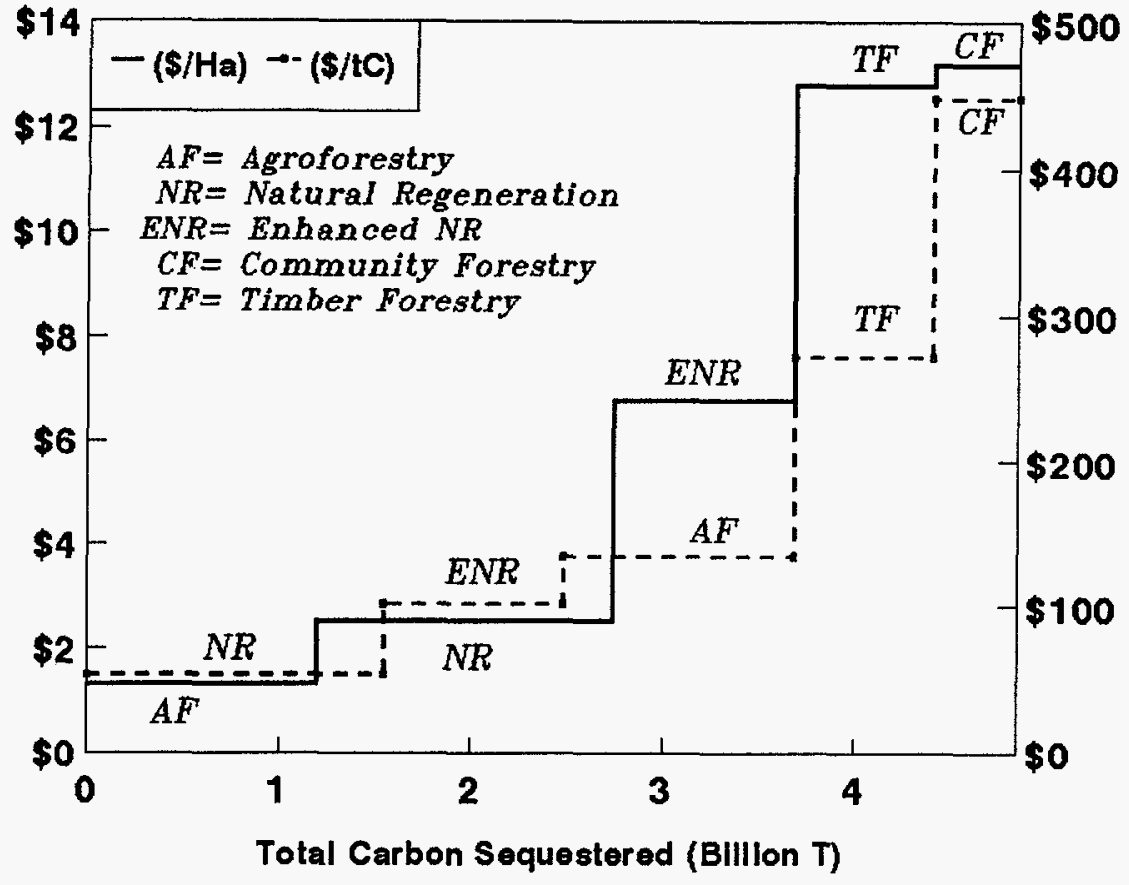

Figure. Initial cost of carbon sequestration for India, 1993 (Ha= hectare).

are lower for decreasing deforestation and protecting forests (up to $\$ 3 / \mathrm{tC}$ ) than for expanding tree cover (up to $\$ 10 / \mathrm{tC}$ ). However, these cost estimates may increase by $200 \%$ when the opportunity cost of land is included. On the other hand, inclusion of carbon stored in wood products and the indirect benefits of forests and their stock value will reduce, and may offset, this increase. However, even if the cost estimates for carbon mitigation by forestry were doubled or tripled, they would still be considerably lower than the reported U.S. tax on fossil-fuel of $\$ 100$ to $\$ 350 / \mathrm{tC}$

These favorable cost estimates should be weighed against the institutional and legal barriers faced by carbon sequestration or saving strategies, which will ultimately determine their success.

Several topics related to the economic analysis of forest sector mitigation options deserve further research. These topics include 1) consideration of full costs and benefits, 2) exploration of alternative indicators, such as the benefits of reducing atmospheric carbon, and 3) better and more detailed national and sub-national data on mitigation options.

\section{References}

Sathaye J, Makundi W. (Guest Eds.). Biomass and Bioenergy Journal: Special Issue on Forestry and Climate Change Issues of Major Tropical Countries 1995 (March, in press)

Sathaye J, Norgaard R, Makundi W. A Conceptual Framework for the Evaluation of Cost-Effectiventess of Projects to Reduce GHG Emissions and Sequester Carbon. Lawrence Berkeley Laboratory Report No. LBL-33859, 1993.

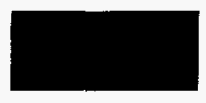

\title{
An Assessment of Energy Efficiency in Buildings and Industry: A Study for the World Energy Council
}

\author{
M.D. Levine, M. Hirose, ${ }^{*}$ N. Martin, L. Price, E. Worrell ${ }^{t}$
}

The World Energy Council (WEC) is a non-governmental international organization dedicated to providing a realistic framework for the solution of global and regional energy issues, while being sensitive to environment, energy efficiency, and sustainable energy supply. The WEC, with over 100 member countries, supports research, debate, and discussion in the global energy community, particularly centered around the triennial congresses hosted by various member countries.

Our research for this effort focuses on an historical global assessment of energy efficiency in the buildings and industry sectors, which together account for nearly two-thirds of global energy consumption. The study quantifies existing knowledge related to understanding the patterns of energy consumption in these two sectors and analyzes both the structural and intensity trends that lie behind energy efficiency changes. The report will serve as the major WEC project on advanced technology for energy efficiency in industry and buildings. As such, it will be featured at the 1995 Triennial World Energy Congress in Tokyo, Japan.

Preliminary results indicate a large decline in manufacturing energy intensities in industrialized countries (see Figure) brought about primarily by increas- ing efficiency as well as by a structural shift toward less energy-intensive industries. Overall manufacturing intensity trends in the developing countries, in Eastern Europe, and in the former Soviet Union are more difficult to quantify, but have generally increased in the former (with the exception of China), but fallen in the latter due to drops in economic output. Efforts are also being made to describe building intensity trends, for which data are less consistent, particularly in regard to the service sector.

An extensive appendix to the report will contain cases studies that have been produced by authors in seven or eight industrial countries for this analysis. The

\footnotetext{
* Tokyo University, Tokyo, Japan

t Utrecht University, Utrecht, The Netherlands
} 


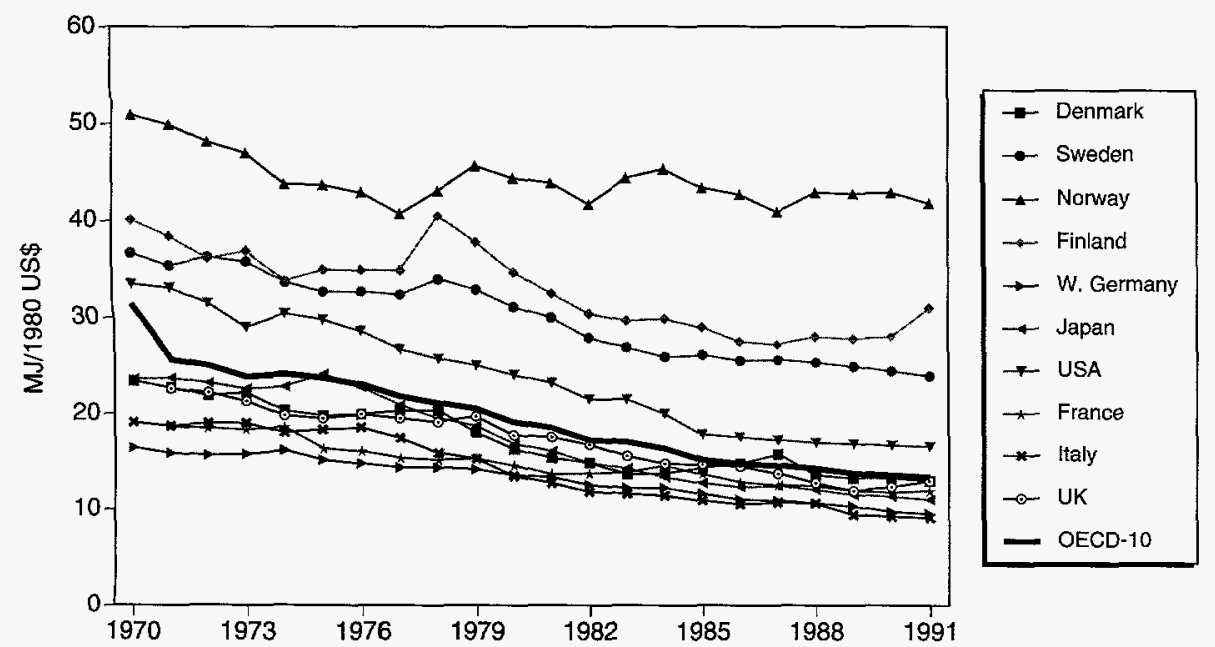

Figure. Manufacturing final energy intensities in selected industrialized countries. case studies identify advanced energyefficiency technologies in key energy-intensive industries such as iron and steel and pulp and paper manufacturing.

The results of the historical analyses, which focus on energy intensity at the industrial sectoral level, and the case studies will be used to estimate the potential for achieving more sustainable levels of energy development and use in the medium term, i.e., the year 2020 .

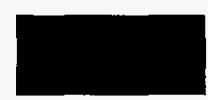

\section{International Comparisons of Energy Efficiency Workshop}

N. Martin, E. Worrell ${ }^{*}$, L. Schipper, K. Blok ${ }^{*}$

In March of 1994, Lawrence Berkeley Laboratory, together with Utrecht University, organized an intensive four-day workshop on international comparisons of energy efficiency. The purpose of the workshop was to work toward reaching a broader international consensus on the type and use of indicators for measuring and comparing energy efficiency among countries, particularly industrialized countries.

The LBL workshop is part of a broader movement in Europe and North America to improve energy-efficiency policy-making and thereby improve the quality of our environment. Energy-efficiency indicators help relate levels of carbon dioxide emissions to energy enduses in the home, in transport, and at the office and factory. Only through the development of appropriate indicators and careful measurement can we tell if we are using more or less energy. The development of a better methodology for the comparison of energy efficiency will also help increase our understanding of such important topics as what lies behind changes in the patterns of our energy use, and how effective are programs which promote increased energy efficiency.

The meeting brought together expert analysts from Europe, North America, Japan, and developing countries. Discussions were oriented toward the development of indicators - ways to identify changes in energy use that ac-

\footnotetext{
* Utrecht University, Utrecht, The Netherlands.
}

count for structural changes and other lifestyle and behavioral effects - with particular emphasis at the sectoral level (residential, commercial, transportation, industry, energy transformation). The Figure shows an example of an energyefficiency indicator pyramid that was used as a discussion tool for the workshop sessions on the various sectoral efficiency indicators.

Based on the workshop, the group concluded that many energy analysts and forecasters today routinely aggregate countries and regions in their energy forecasts and often do not account for lifestyle and structure effects. A great responsibility therefore falls on the researcher to point out the underlying differences in energy consumption patterns among countries. Only continued strong cooperation and involvement by policymakers and research analysts in individual countries and international organizations can result in greater consensus on the best choice and use of indicators. Specific recommendations included:

- Develop an informal network of research analysts involved in the development and use of indicators,

- Pursue follow-up workshops in individual sectors, and

- Develop a handbook on the measurement and comparison of energy efficiency and on the analysis of potentials to improve energy efficiency.

\section{Reference}

Martin N, Worrell E, Schipper L, Blok K. Workshop Proceedings: International Comparisons of Energy Efficiency, March 6-9, 1994. Utrecht, The Netherlands: Utrecht University, 1995.

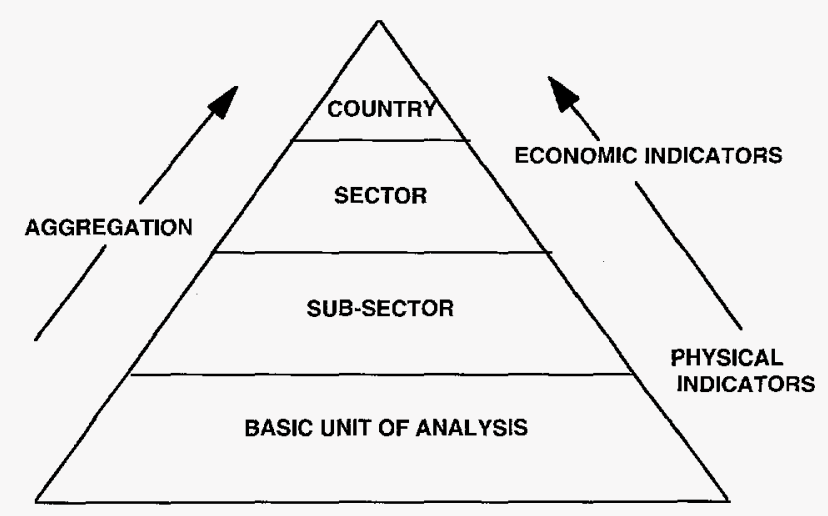

Figure. Energy-efficiency indicator pyramid. 


\title{
Mitigation Options for Human Settlements: A Report for the Intergovernmental Panel on Climate Change
}

\author{
M.D. Levine, G. Dutt* , P. Komor ${ }^{\dagger}$, S. Meyers, K. Hogan ${ }^{\ddagger}$, H. Akbari, J. Busch, H. Tsuchiya ${ }^{\S}$
}

The Intergovernmental Panel on Climate Change (IPCC) is the scientific body established by the International Negotiating Committee and tasked with the responsibility for assessing the current state of knowledge related to global climate change. This report has been prepared as a state-of-the-art description and assessment of our ability to reduce or mitigate the level of greenhouse gas emissions due to activities in human settlements (i.e., all locations where people live).

The research focuses on four areas: understanding historical trends of greenhouse gas emissions from human settlements, analyzing the potential for emissions reductions, identifying various policy options, and comparing the results of the building sector analysis to existing emissions scenarios for human settlements.

The analysis of existing data indicates that nearly one-third of man-made carbon dioxide emissions are a result of activities in human settlements and that much of the growth in emissions from human settlementshasoccurred in the developing world (see Figure). The most significant factors affecting emissions from human settlements include the efficiency of energy use, population growth, the carbon intensity of the fuels used, the nature of economic development in the developing world, global economic growth, and political commitment to emissions reductions.

There exists significant potential to improve the efficiency of energy use in buildings through the incorporation of more efficient technologies for space-conditioning, lighting, refrigeration, and cooking. In addition to technological improvement, the report describes policy options for reducing greenhouse gas emissions. The options include energy-pricing strategies, regulatory programs, utility demandside management programs, demonstration programs, and research and development.

Finally, a review of energy scenarios developed by many different groups sug-

\footnotetext{
* Independent consultant, Buenos Aries, Argentina.

${ }^{+}$U.S. Congress, Office of Technology Assessment, Washington, D.C.

$\ddagger$ U.S. Environmental Protection Agency, Washington, D.C.

$\$$ Research Institute for Systems Technology, Tokyo, Japan.
}
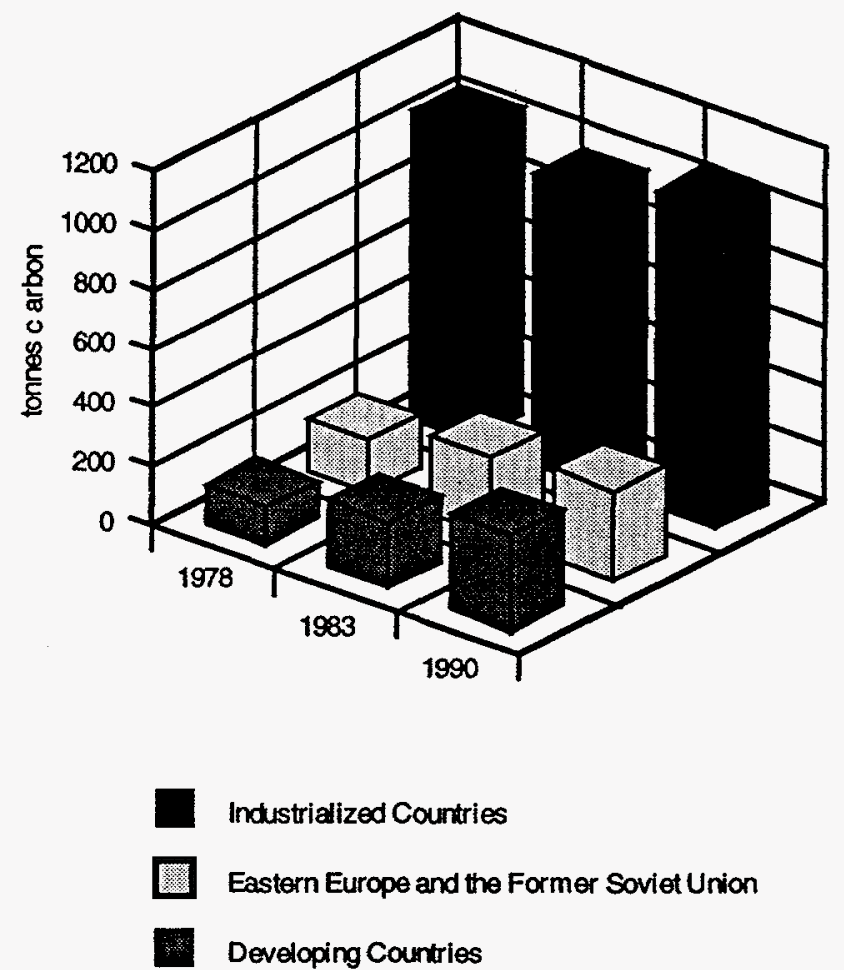

Figure. Global carbon emissions from buildings. gests that much greater attention to a wide variety of policy approaches than has occurred in the past will be needed to meet the most rigorous efficiency scenarios in which energy efficiency contributes about half of the carbon reductions needed to maintain carbon emissions at current levels over the next two to three decades.

\section{Reference}

Levine MD et al. Mitigation Options for Human Settlements:IPCC Working Group II, Chapter III-D, First Order Draft, August 23, 1994. Geneva, Switzerland: Intergovernmental Panel On Climate Change, 1994.

\section{Conducting Greenhouse Gas Mitigation Assessment in Developing Countries \\ J. Sathaye, S. Wiel*, S. Meyers, W. Makundi, M. della Cava*, N. Martin, B. Goldberg}

The Framework Convention on $\mathrm{Cl}$ mate Change, signed by more than 150 governments worldwide, calls on parties to the Convention to undertake inventories of national sources and sinks of greenhouse gases (GHGs) and to develop plans for responding to climate change. To assist developing countries and countries with economies in transi- tion to meet this obligation, the U.S. government has committed \$25 million to support climate change country studies. Fifty-five countries are participating in the program.

Technical and financial assistance is being provided through the newly created U.S. Country Studies Program, which is composed of personnel from
* Energy and Environment Division Washington, D.C. Project Office. 
the U.S. Environmental Protection Agency, U.S. Department of Energy, National Oceanic and Atmospheric Administration, U.S. Agency for International Development, U.S. Department of Agriculture, and the Department of State.

Studies to be supported under this program may address various climate change issues of concern to the recipient country, including an inventory of sources and sinks of GHGs, an assessment of vulnerabilities to the impacts of climate change, an evaluation of options to adapt to these potential impacts, an evaluation of options to mitigate net emissions of GHGs, and development of national measures and strategies and public outreach activities.

LBL has been conducting research on country GHG mitigation studies for the last six years. In light of that, LBL was selected to lead the technical assistance in the field of mitigation assessment to be provided by a team of experts drawn from various universities, laboratories, and consulting firms.

We organized an international workshop in June 1994, that brought together more than 60 scientists from 16 developing and transition countries. They came to LBL for hands-on training in techniques and models used for GHG mitigation analysis (see Figure). Weprepared a guidance document used by workshop participants to learn about techniques for mitigation assessment in the energy, forestry, agriculture, and other sectors. Workshop participants received two full weeks of analytical training composed of lectures and computer demonstrations.

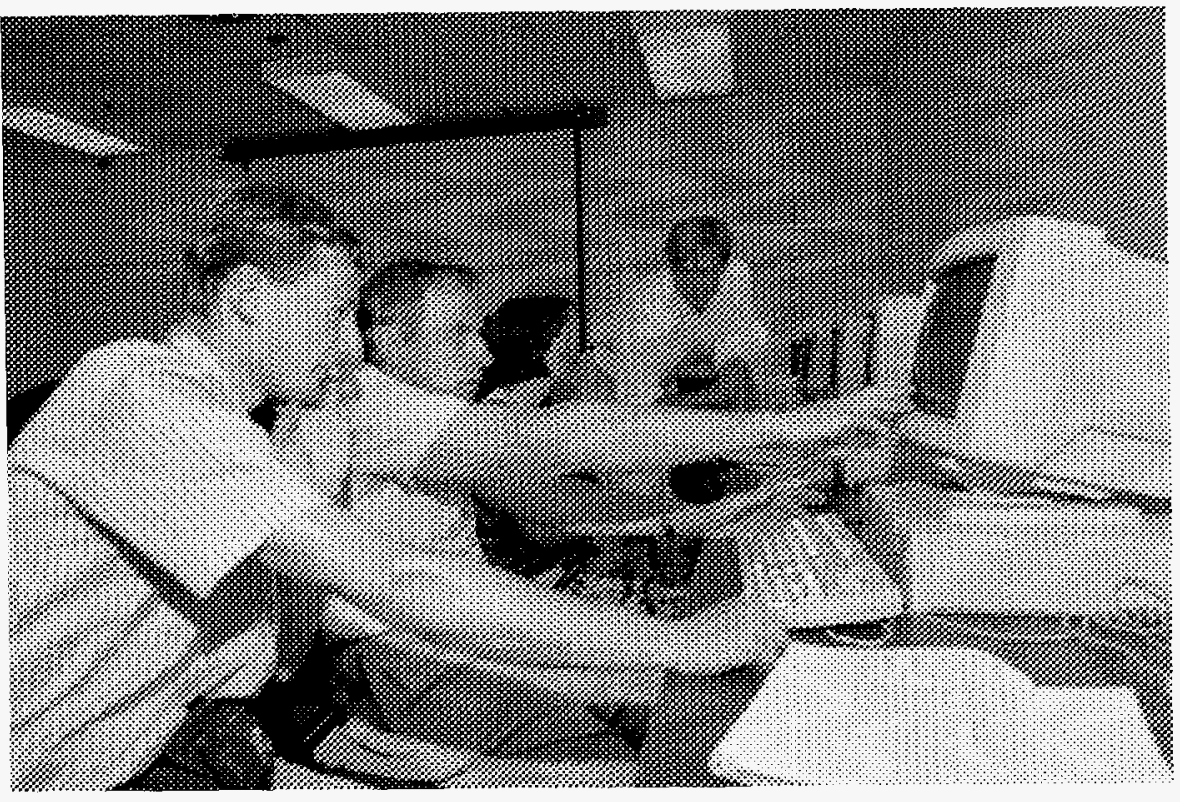

Figure. Researchers from the Czech Republic study the details of an energy model during a hands-on training session.

They were divided according to their area of expertise-energy, non-energy, or macro-economic analysis. More than 20 experts provided the detailed analytical instruction.

At the end of the workshop, participating countries prepared workplans for their mitigation assessments. To providecontinuing support to these nations' GHG reduction efforts, we are tailoring specific technical assistance to each country. Our support is in the form of further training in the use of specific models, site visits to countries, and regional workshops where national representatives will discuss the results of their studies.

\section{References}

Energy Analysis Program and Countries Studies Management Team (Washington, D.C.). Guidance for Mitigation Assessments: Version 2.0. U.S. Support for Country Studies to Address Climate Change. Lawrence Berkeley Laboratory Report No. LBL-36367, 1995.

Sathaye J (Guest Ed). Energy Policy: Special Issue on Climate Change - Country Case Studies 1991;19(10).

Sathaye J, Christensen J. (Guest Eds). Energy Policy: Special Issue on Methods for the Economic Evaluation of Greenhouse Gas Mitigation Options 1994;22(11). 


\section{Sponsors}

Support from the following sources was provided through the U.S. Department of Energy under Contract No. DE-AC0376SF00098:

- Assistant Secretary for Energy Efficiency and Renewable Energy, U.S. Department of Energy

Deputy Assistant Secretary for Building Technologies, Office of Building Energy Research

Deputy Assistant Secretary for Utilities Technologies, Office of Energy Management

Office of Codes and Standards

Office of Planning and Assessment

- Assistant Secretary for Fossil Energy, U.S. Department of Energy

Deputy Assistant Secretary for Coal Technology

- Assistant Secretary for Domestic and International Energy Policy, U.S. Department of Energy

Associate Deputy Under Secretary for Policy Analysis, Office of Electricity/Coal/Nuclear, and Renewable Policy

Associate Deputy Under Secretary for Policy Analysis, Office of Environmental Analysis

- Office of the Administrator, Energy Information Administration, U.S. Department of Energy

- U.S. Department of Commerce, National Oceanic and Atmospheric Administration

- U.S. Department of Defense, U.S. Army Corps of Engineers, Construction Engineering Research Laboratory

- U.S. Environmental Protection Agency

Office of Policy, Planning, and Evaluation

Office of Policy Analysis, Division of Climate Change

Office of Air and Radiation, Global Change Division

Office of Air and Radiation, Acid Rain Division

- U.S. Agency for International Development, Office of Energy and Infrastructure

- AB Volvo

- Bonneville Power Administration

- California Energy Commission

- California Institute for Energy Efficiency

- Chevron

- Conoco

- Consumers Power Company

- Danish Energy Agency

- Dutch Ministry of Housing, Physical Planning, and the Environment (VROM)

- Electric Power Research Institute

- Energy Foundation

- Exxon Company International

- Finnish Ministry of Trade and Industry

- International Energy Agency

- LBL Laboratory-Directed R\&D Program

- National Aeronautics and Space Administration, Office of Mission to Planet Earth

- New York State Energy Research and Development Authority

- Oak Ridge National Laboratory

- Pacific Gas \& Electric Company

- Pacific Northwest Laboratory

- Public Service Electric and Gas Company

- Rockefeller Family and Associates

- Shell International Petroleum Company

- Shell Oil Company (Houston)

- Swedish Transport Research Board

- United Nations Environmental Program, Collaborating Centre on Energy and Environment

- University of California, Transportation Center 